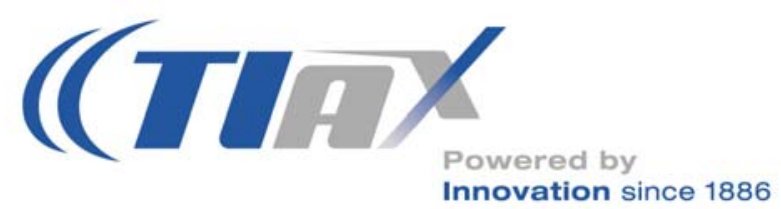

Innovation since 1886

\section{Application of Hydrogen Assisted Lean Operation to Natural Gas-Fueled Reciprocating Engines (HALO)}

\author{
Final Scientific/Technical Report
}

Reporting Period Start Date:

October 10, 2004

Reporting Period End Date:

October 31, 2005

Principal Author:

Chad Smutzer

Report Issued:

January 2006

Cooperative Agreement No.

DE-FC26-04NT42235

TIAX LLC

15 Acorn Park

Cambridge, Massachusetts

02140-2390 U.S.A.

Copyright (C) 2006 TIAX LLC. This paper was written with support of the U.S. 


\section{DISCLAIMER:}

This report was prepared as an account of work sponsored by an agency of the United States Government. Neither the United States Government nor any agency thereof, nor any of their employees, makes any warranty, express or implied, or assumes any legal liability or responsibility for the accuracy, completeness, or usefulness of any information, apparatus, product, or process disclosed, or represents that its use would not infringe privately owned rights. Reference herein to any specific commercial product, process, or service by trade name, trademark, manufacturer, or otherwise does not necessarily constitute or imply its endorsement, recommendation, or favoring by the United States Government or any agency thereof. The views and opinions of authors expressed herein do not necessarily state or reflect those of United States Government or any agency thereof.

Any use which a third party makes of this report, or any reliance on it, or decisions to be made based on it, are the responsibility of said third party. TIAX accepts no duty or care or liability of any kind whatsoever to any such third party, and no responsibility for damages, if any, suffered by any third party as a result of decisions made, or not made, or action taken, or not taken, based on this report. This report may be produced only in its entirety, and only with the prior written consent of TIAX LLC. 


\begin{abstract}
Two key challenges facing Natural Gas Engines used for cogeneration purposes are spark plug life and high NOx emissions. Using Hydrogen Assisted Lean Operation (HALO), these two keys issues are simultaneously addressed. HALO operation, as demonstrated in this project, allows stable engine operation to be achieved at ultra-lean (relative air/fuel ratios of 2) conditions, which virtually eliminates NOx production. NOx values of $10 \mathrm{ppm}(0.07 \mathrm{~g} / \mathrm{bhp}-\mathrm{hr}$ NO) for $8 \%\left(\mathrm{LHV} \mathrm{H}_{2} / \mathrm{LHV} \mathrm{CH}_{4}\right.$ ) supplementation at an exhaust $\mathrm{O}_{2}$ level of $10 \%$ were demonstrated, which is a $98 \%$ NOx emissions reduction compared to the leanest unsupplemented operating condition. Spark ignition energy reduction (which will increase ignition system life) was carried out at an oxygen level of $9 \%$, leading to a NOx emission level of 28 $\mathrm{ppm}(0.13 \mathrm{~g} / \mathrm{bhp}-\mathrm{hr} \mathrm{NO})$. The spark ignition energy reduction testing found that spark energy could be reduced 22\% (from $151 \mathrm{~mJ}$ supplied to the coil) with 13\% ( $\mathrm{LHV} \mathrm{H}_{2} / \mathrm{LHV} \mathrm{CH}_{4}$ ) hydrogen supplementation, and even further reduced $27 \%$ with $17 \%$ hydrogen supplementation, with no reportable effect on $\mathrm{NO}_{\mathrm{x}}$ emissions for these conditions and with stable engine torque output. Another important result is that the combustion duration was shown to be only a function of hydrogen supplementation, not a function of ignition energy (until the ignitability limit was reached). The next logical step leading from these promising results is to see how much the spark energy reduction translates into increase in spark plug life, which may be accomplished by durability testing.
\end{abstract}




\section{Table of Contents}

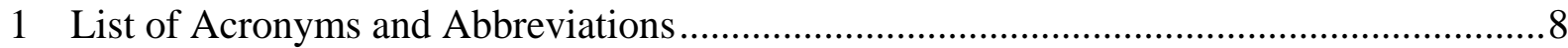

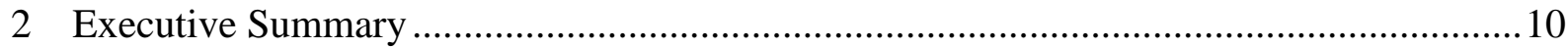

$2.1 \quad$ Project Objectives .............................................................................12

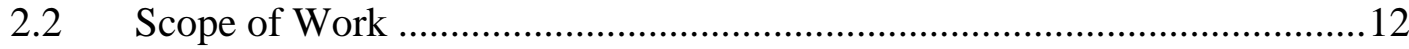

$2.3 \quad$ Tasks to be Performed.............................................................................12

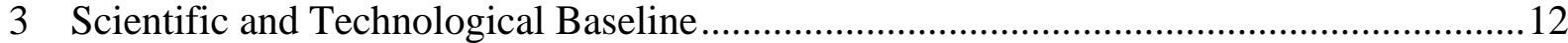

3.1 Introduction .........................................................................................13

3.1.1 Lean-Burn Can Provide Ultra-low Engine-out $\mathrm{NO}_{\mathrm{x}}$ and High Efficiency...13

3.1.2 Lean Burn Technical Challenges ................................................................14

3.1.3 Hydrogen Assisted Operation Addresses the Central Challenges of Lean-burn .........................................................................................17

3.2 Problem Statement ..........................................................................19

3.3 Project Goals and Objectives ......................................................................19

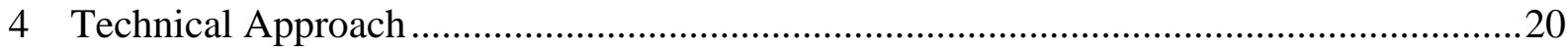

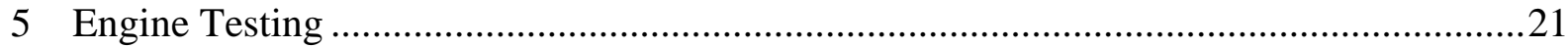

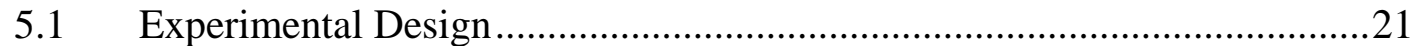

5.2 Engine Description................................................................................22

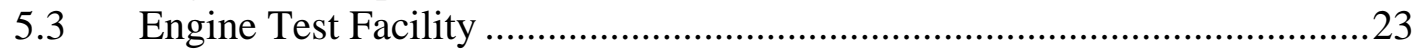

$5.4 \quad$ General Test Procedures …………………….........................................24

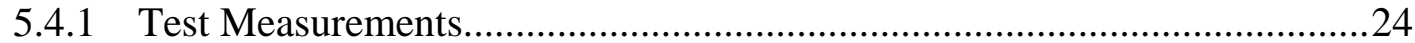

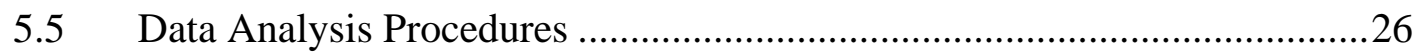

5.6 Quality Assurance Procedures ...............................................................26

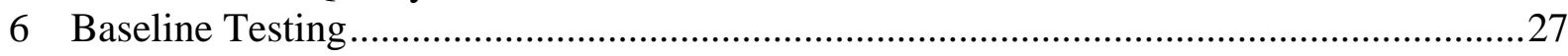

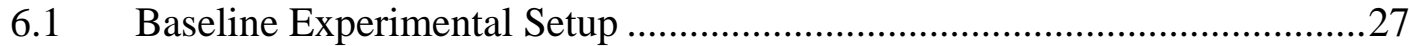

6.2 Baseline Test Results and Conclusions............................................................30

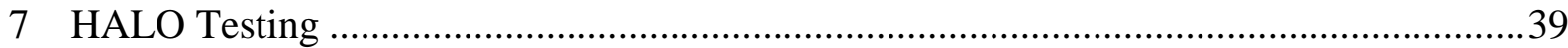

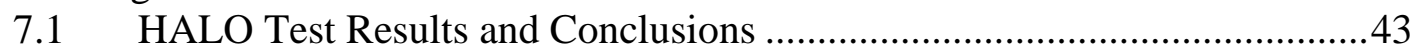

8 HALO/Spark Energy Reduction Testing ............................................................................45

8.1 HALO/Spark Energy Reduction Results and Conclusions.............................47

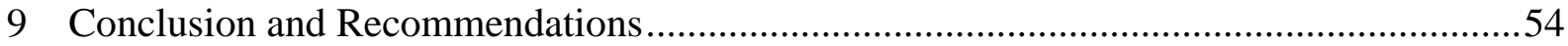

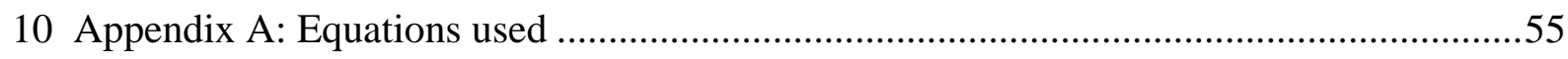

11 Appendix B: Smartfire Ion Current Traces.....................................................................57

12 Appendix C: Comparison of Energy Fraction, Volume Fraction, and Mass Fraction of

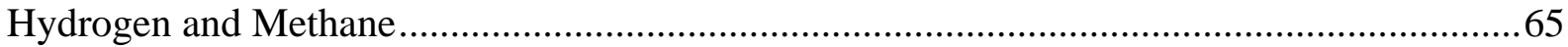
13 Appendix D: Comparison of Inclusion of Cylinder 6 on the COV Average Versus Exclusion

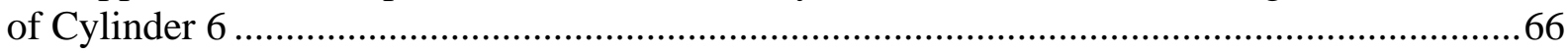




\section{Table of Figures}

Figure 1. Emissions from IC Engines Vary with Air/Fuel Ratio 19

Figure 2. Technical Tasks Flow Chart 21

Figure 3. Overview of Experimental Test Program 22

Figure 4. Photographs of TIAX's Engine Test Facility 23

Figure 5. Baseline Engine Setup with Close-up of Fueling and Spark Ignition System 28

Figure 6. Engine Control Schematic 29

Figure 7. MBT Timing Sweep $\quad 31$

Figure 8. Representative Pressure Traces from Ten Consecutive Cycles 32

Figure 9. Baseline Engine Lean Operation Capability 33

Figure 10. Baseline Engine NOx Emissions 34

Figure 11. Typical Mass Fraction Burn Curve with 10-90 Highlighted 35

Figure 12. Baseline Engine Results for LPP and 10-90 Burn Times 35

Figure 13. Baseline Burn Times 36

Figure 14. Baseline Emissions as a Function of Relative Air/Fuel Ratio 37

Figure 15. Baseline Ion Current Results from Cylinder \#4 38

Figure 16. Top View Engine Schematic (Note: intake runners not shown for visual clarity) $\quad 40$

Figure 17. Cylinder-to-Cylinder Distribution of Torque Fluctuation 40

Figure 18. Cylinder-to-Cylinder Variation for 13\% $\mathrm{H}_{2}$ Supplementation 41

Figure 19. Experimental Setup 42

Figure 21. Baseline and HALO Engine Lean Operation Capability 43

Figure 22. Baseline and HALO Engine Lean Operation Capability 44

Figure 23. High Exhaust $\mathrm{O}_{2}$ Points Showing Extremely Low NOx 45

Figure 24. Simplified Smartfire Schematic 46

Figure 25. Spark Energy Reduction Potential as a Function of Hydrogen
Supplementation

Figure 26. HALO Engine Operation with Reduced Ignition Energy 49

Figure 27. Peak Pressure Location throughout Testing Program 50

Figure 28. Maximum Pressure Rise Rate as a Function of Hydrogen Supplementation 50

Figure 29. 10-90 Burn Time as Function of Hydrogen Supplementation 51 
Figure 30. Start of Combustion Times as a Function of Hydrogen Supplementation

Figure 31. Ion-current Results Comparison for HALO Tests With Spark Energy Reduction 


\section{List of Tables}

Table 1. Optional Emission Controls Approaches for Low $\mathrm{NO}_{\mathrm{x}}$ IC Engines............................... 14

Table 2. Comparison of Engine Test Facility vs. Generator.......................................................... 22

Table 3. Relevance of Selected Engine to Cogeneration Unit...................................................... 23

Table 4. TIAX LLC Engine Test Facility Capabilities...................................................................... 24

Table 5. Measured Engine Operating Parameters......................................................................... 25

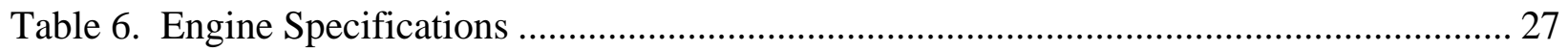

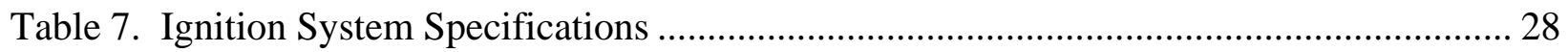

Table 8. Natural Gas Composition Used in all Tests................................................................... 29

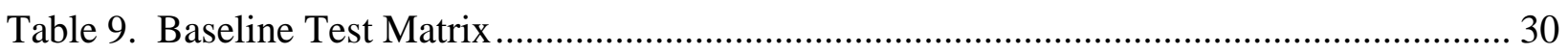

Table 10. Baseline Test Results ........................................................................................... 32

Table 11. Property Comparison of Natural Gas and Hydrogen ................................................... 36

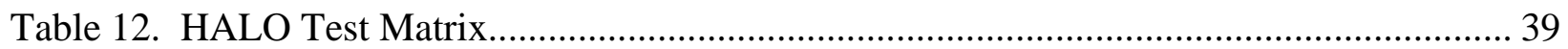

Table 13. General Summary of Hydrogen Supplementation Results ........................................... 43

Table 14. HALO Testing with Spark Energy Reduction............................................................... 46

Table 15. Hydrogen Supplementation and Ignition Energy Reduction......................................... 47

Table 16. Comparison of Standard and Reduced Spark Energies ............................................. 48

Table 17. Comparison of LHV, Volume, and Mass Fractions ..................................................... 65

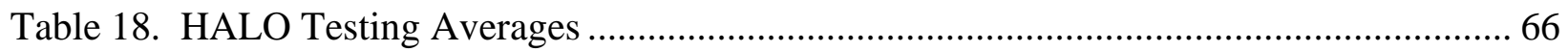

Table 19. Spark Energy Reduction Testing Averages .................................................................. 66 


\section{List of Acronyms and Abbreviations}

\begin{tabular}{|c|c|}
\hline A & Humidity coefficient \\
\hline B & Temperature coefficient \\
\hline $\mathrm{C}$ & Carbon \\
\hline CEM & Continuous Emissions Monitoring \\
\hline CID & Cubic Inches of Displacement \\
\hline $\mathrm{CO}$ & Carbon Monoxide \\
\hline $\mathrm{CO}_{2}$ & Carbon Dioxide \\
\hline $\mathrm{COV}$ & Coefficient of Variation \\
\hline ECU & Engine Control Unit \\
\hline $\mathrm{Fb}$ & Spindt constant \\
\hline Fc & Spindt fuel constant \\
\hline $\mathrm{H}$ & Specific humidity \\
\hline $\mathrm{H}(2)$ & Hydrogen \\
\hline HALO & Hydrogen Assisted Lean Operation \\
\hline $\mathrm{IC}(\mathrm{E})$ & Internal Combustion (Engine) \\
\hline IMEP & Indicated Mean Effective Pressure \\
\hline $\mathrm{K}$ & Dimensionless correction factor \\
\hline LHV & Lower Heating Value \\
\hline LNV & Least Normalized Value \\
\hline LPP & Location of Peak Pressure \\
\hline $\mathrm{O}_{2}$ & Oxygen \\
\hline $\mathrm{Pb}$ & Barometric Pressure \\
\hline $\mathrm{Pv}$ & Partial pressure of water \\
\hline $\mathrm{Q}$ & $\mathrm{O} 2 / \mathrm{CO} 2$ ratio \\
\hline $\mathrm{R}$ & $\mathrm{CO} / \mathrm{CO} 2$ ratio \\
\hline $\mathrm{RH}$ & Relative Humidity \\
\hline RPM & Revolutions Per Minute \\
\hline $\mathrm{T}$ & Temperature \\
\hline $\mathrm{Y}$ & $\mathrm{H} / \mathrm{C}$ mass fraction \\
\hline $\mathrm{NOx}$ & Oxides of Nitrogen \\
\hline
\end{tabular}


(this page intentionally left blank) 


\section{Executive Summary}

Because of their low cost and widespread availability, internal combustion engines have been the prime mover of choice for natural gas to electricity projects. Unfortunately, IC engines suffer from high engine-out $\mathrm{NO}_{\mathrm{x}}$ levels, and the two currently available emissions reduction technologies, Three-Way Catalyst (TWC) and Selective Catalytic Reduction (SCR), both carry operating cost penalties as well as added initial system costs.

A more attractive $\mathrm{NO}_{\mathrm{x}}$ reduction technique for NG IC engines is lean burn operation. At present, the lowest emitting lean-burn NG IC engines are equipped with pre-chambers resulting in $\mathrm{NO}_{\mathrm{x}}$ emissions ranging from 0.4 to $0.6 \mathrm{~g} / \mathrm{bhp}-\mathrm{hr}$. Looking forward, a $95 \%$ reduction in $\mathrm{NO}_{\mathrm{x}}$ is required to meet the new distributed generation target equivalent to central station power plant emissions.

One $\mathrm{NO}_{\mathrm{x}}$ reduction technique ideally suited to NG applications is Hydrogen Assisted Lean Operation (HALO). Because hydrogen has wide limits of flammability, it allows combustion at ultra-lean conditions, drastically reducing $\mathrm{NO}_{\mathrm{x}}$ emissions. HALO for natural gas fired engines is a well-documented idea that has been studied by numerous groups, including TIAX, over the past 25 years ${ }^{1,2,3,4}$. Modeling and engine testing performed by TIAX for two separate commercial clients has shown that, for natural gas engines, the lean limit can be extended from a relative air/fuel ratio, lambda of 1.6 to a lambda of over 2.5 by replacing a small percent of the natural gas with hydrogen. For lambda values greater than 2.2, the $\mathrm{NO}_{\mathrm{x}}$ is virtually zero.

While these previous studies have demonstrated that hydrogen assisted lean operation can enable ultra-lean operation, they have not explored whether HALO could simultaneously also address the other key issue for natural gas engines, namely spark plug life by reducing the ignition energy requirement.

For pre-mixed moderately lean spark ignition engines, in-field data show that spark plugs must be serviced frequently (spark gap adjustment every 1,000 to 4,000 hr, and spark plug replacement every 10,000 hr) which carries a significant maintenance cost and lowers the total availability of the system

Fractional hydrogen supplementation is particularly interesting with respect to minimizing the ignition or spark energy required to initiate combustion since hydrogen has a significantly lower ignition energy than natural gas. For quiescent stoichiometric mixtures the minimum ignition energy for hydrogen is $0.019 \mathrm{~mJ}$ compared to $0.34 \mathrm{~mJ}$ for methane which is the main constituent of natural gas (the minimum ignition energy for the other significant hydrocarbon components in natural gas are: $0.29 \mathrm{~mJ}$ for ethane, and $0.30 \mathrm{~mJ}$ for propane $)^{5}$. If the minimum ignition energy

1 "Stoichiometric Synthesis, Exhaust, and Natural-gas Combustion Engine," U.S. Patent No. 5,947,063, 1999.

${ }^{2}$ Andretta, D., and Dibble, R. W., "An Experimental Study of Air-Reformed Natural Gas in Spark-ignited Engines," SAE Meeting Proceedings, pp. 85-93, 1996.

${ }^{3}$ Watson, H.C., and Milkins, E. E., "Some Problems and Benefits from the Hydrogen Fueled Spark Ignition Engine," SAE Meeting Proceedings, pp. 1170-1177, 1978.

${ }^{4}$ Proprietary R\&D by TIAX, LLC, 1998-1999.

${ }^{5}$ Rose, J. W., and Cooper, J. R.: "Technical Data on Fuel”, Seventh Edition, 1977, Published by The British National Committee World Energy Conference. 
could be significantly reduced, the ignition system could be redesigned for minimal spark plug wear by reducing the electrode gap and shortening the spark duration, both of which would significantly reduce the electrode erosion rate.

The key area of focus for this proposed study was therefore to explore and resolve the trade-off between lean-operating limit and ignition energy for various levels of fractional hydrogen supplementation in a representative natural gas engine of less than $100 \mathrm{~kW}$. The first phase of the project was to establish the benefits of hydrogen supplementation. During this phase, it was found that hydrogen supplementation allowed emissions levels of $10 \mathrm{ppm}(0.07 \mathrm{~g} / \mathrm{bhp}-\mathrm{hr} \mathrm{NO})$ for $8 \%\left(\mathrm{LHV} \mathrm{H}_{2} / \mathrm{LHV} \mathrm{CH}_{4}\right)$ supplementation at an exhaust $\mathrm{O}_{2}$ level of $10 \%$. This condition supports stable combustion. Without the addition of hydrogen, engine stability was only acceptable to $7.5 \% \mathrm{O} 2$ in the exhaust, which correspond to NOx levels of $400 \mathrm{ppm}$, after which engine torque output fluctuations would be unacceptable.

The final phase of testing was to map the reduction of ignition energy as a function of hydrogen supplementation. This testing was carried out at an oxygen level of $9 \%$, leading to a NOx emission level of $28 \mathrm{ppm}(0.13 \mathrm{~g} / \mathrm{bhp}-\mathrm{hr} \mathrm{NO})$. The spark ignition energy reduction testing found that spark energy could be reduced 22\% (from $151 \mathrm{~mJ}$ supplied to the coil) with 13\% (LHV $\mathrm{H}_{2} / \mathrm{LHV} \mathrm{CH}_{4}$ ) hydrogen supplementation, and even further reduced $27 \%$ with $17 \%$ hydrogen supplementation, with no reportable effect on $\mathrm{NO}_{\mathrm{x}}$ emissions for these conditions and with stable engine torque output. Another important result is that the combustion duration was shown to be only a function of hydrogen supplementation, not a function of ignition energy (until the ignitability limit was reached).

These results are encouraging, because this spark energy reduction will play a key role in increasing the spark plug life, which was the overall goal of this project. The results could be further improved by using surface-gap spark plugs (J-type plugs were used in this test program as representative stock spark plugs) and using multi-point hydrogen injection (single-point prethrottle injection was used), but the results shown here still show excellent promise towards increasing spark plug life while simultaneously reducing NOx emissions.

Further exploration (i.e. Durability testing) is recommended to determine the amount of spark plug life to be gained from this proven energy reduction. 


\subsection{Project Objectives}

The overall objective of the proposed program is to explore and demonstrate the potential for fractional hydrogen supplementation as a key enabler for operating a natural gas engine at ultralean engine conditions $(\lambda>2)$, to produce ultra-low $\mathrm{NO}_{\mathrm{x}}$ emissions, while at the same time reducing the spark energy to increase the spark plug durability and reliability.

\subsection{Scope of Work}

The technical investigation of the HALO approach occurred at TIAX's facilities in Cambridge, MA. In TIAX's engine test facilities, a representative Natural Gas engine was modified and reconfigured for HALO testing. Specifically, hydrogen supplied from gas cylinders was bled into the intake system of the engine (in addition to the natural gas fuel), and the stock ignition system was replaced by a highly controllable and specially modified spark ignition system, SmartFire ${ }^{\mathrm{TM}}$, from Adrenaline Research. The SmartFire system features ionization feedback which provides real-time misfire and knock detection. The SmartFire system was modified so that the spark energy level can be varied in real-time. Next, a series of engine scoping tests with various hydrogen supplementation rates and ignition energy levels were performed. The test data was analyzed and synthesized so that the trade-off between lean-operating limit and ignition energy for various levels of fractional hydrogen supplementation in a representative natural gas engine could be resolved.

\subsection{Tasks to be Performed}

The four tasks that were performed are listed below:

Task 1: $\quad$ Baseline Engine Testing

Task 2: $\quad$ Reconfigure Engine for HALO Operation

Task 3: $\quad$ HALO Scoping and Performance Testing

Task 4: $\quad$ Management and Reporting

\section{Scientific and Technological Baseline}

This project addressed the key technical issues related to ultra-lean burn operation of natural gas engines. Ultra-lean engine operation is an attractive approach for achieving low $\mathrm{NO}_{\mathrm{x}}$ emissions and high engine efficiencies. However, even with high energy ignition systems, the low flame speed of methane limits the extent of lean operation to levels that are insufficient to meet the most stringent current emissions mandates without exhaust gas treatment. 
The project explored the operation of a modern natural gas IC engine cogeneration unit with fractional hydrogen supplementation. The engine was operated in a Hydrogen Assisted Lean Operation (HALO) configuration. This section describes the challenges associated with ultralean operation of natural gas IC engines. HALO is directed at the central challenge of ultra-lean burn - repeatable, controlled, and complete combustion at very lean mixture ratios.

\subsection{Introduction}

Reciprocating combustion engines are in use today in virtually every application requiring mechanical or electrical power. For all practical purposes, reciprocating engines represent the backbone of the entire transportation sector and a significant portion of the power generation segment. With over a century of technology development behind them, reciprocating engines now achieve fairly high indicated efficiencies ( $35 \%$ to $45 \%$ ) and low emissions.

The natural gas reciprocating engine has evolved during the past decade as a competitive prime mover in the power generation market. Looking ahead, the trend is expected to continue and accelerate as the Office of Power Technologies is encouraging greater focus on advanced distributed energy systems in the Distributed Energy Resources (DER) program. The DER program has set a goal to achieve $20 \%$ of new electric capacity additions by 2010 with a suite of distributed energy technologies that will have increased efficiency and reliability with reduced costs and emissions. Natural gas reciprocating engines are expected to play a critical role in meeting that demand.

However, in many significant market segments of the distributed generation industry, the efficiency, emissions signature, and cost (primarily maintenance cost) of producing power with the existing suite of natural gas engines is still not adequate for achieving the long term vision and goals of the Distributed Energy Resources program. In addition, increasingly stringent restrictions for emissions and world competition over the next twenty years are expected to drive industrial, commercial, institutional and residential energy consumers to seek increasingly higher energy efficiency and cleaner means of heat and power generation.

To increase efficiency, engine manufacturers are already striving to develop engines that can operate at very lean fuel conditions, combined with higher cylinder pressures to maintain the specific power of the engine.

\subsubsection{Lean-Burn Can Provide Ultra-low Engine-out $\mathrm{NO}_{\mathrm{x}}$ and High Efficiency}

The concept of lean-burn IC engines is one that engine manufacturers have been pursuing for a long time. It is well known and documented that lean burn operation offers several valuable advantages, such as increased ratio of specific heats over the expansion stroke, less dissociation, reduced cooling losses, and reduced throttling losses. Over the years it has been well documented that lean burn reduces $\mathrm{NO}_{\mathrm{x}}$ and $\mathrm{CO}$ emissions while increasing engine thermal efficiency. 


\subsubsection{Lean Burn Technical Challenges}

However, there are significant challenges associated with lean operation. The two key challenges are: (a) combustion limits to lean operation results in relatively high emissions of nitrogen oxides $\left(\mathrm{NO}_{\mathrm{x}}\right)$, and (b) spark plug durability/reliability.

\subsubsection{NO $\mathrm{NO}_{x}$ Emissions from Lean-Burn Engines - Ultra-lean Burn is the Most Attractive Approach}

The formation of $\mathrm{NO}_{\mathrm{x}}$ emissions in spark ignition engines is primarily controlled by two parameters: in-cylinder peak gas temperature and in-cylinder oxygen concentration. Both of these parameters are affected by the air-fuel (A/F) ratio. For any fixed engine power setting, the in-cylinder gas temperature peaks at a slightly rich $\mathrm{A} / \mathrm{F}$-ratio (fuel equivalence ratio, $\phi \approx 1.1$ ). However at rich conditions the oxygen concentration is low resulting in low $\mathrm{NO}_{\mathrm{x}}$ emissions. As the A/F-ratio is progressively made leaner, the oxygen concentration increases and the incylinder peak gas temperature falls off. Initially, the increasing oxygen concentration offsets the falling gas temperature resulting in maximum $\mathrm{NO}_{\mathrm{x}}$ emissions at an $\mathrm{A} / \mathrm{F}$-ratio slightly lean of stoichiometric $(\phi \approx 0.9)$. As the $\mathrm{A} / \mathrm{F}$ ratio becomes leaner $(\phi<0.9)$, the temperature effect dominates over the oxygen concentration effect and $\mathrm{NO}_{\mathrm{x}}$ emissions decrease to very low levels at ultra-lean mixtures $(\phi<0.5)$.

shows different configurations for IC engines and how the emissions are affected by emission controls. The concept proposed in this proposal, ultra-lean burn through hydrogen supplementation, is also included in the table for comparison.

Table 1. Optional Emission Controls Approaches for Low NO $\mathrm{N}_{\mathrm{x}}$ IC Engines

\begin{tabular}{|c|c|c|c|c|}
\hline $\begin{array}{l}\text { Engine } \\
\text { Operation }\end{array}$ & Emission Control & Impact on Emissions & $\begin{array}{c}\mathrm{NO}_{x} \\
\text { (g/bhp-hr) }\end{array}$ & $\begin{array}{l}\text { Other } \\
\text { Impacts }\end{array}$ \\
\hline Stoichiometric & None & Highest $\mathrm{NO}_{\mathrm{x}}$ emissions & 8 & - \\
\hline Stoichiometric & $\begin{array}{c}\text { Three-way } \\
\text { catalyst (TWC) }\end{array}$ & $\begin{array}{l}\mathrm{NO}_{x} \text { reacts with } \mathrm{CO} \text { and } \mathrm{HC} \text { on } \\
\text { catalyst }\end{array}$ & 0.15 & Cost Penalty \\
\hline $\begin{array}{l}\text { Lean burn, } \\
\text { prechamber }\end{array}$ & None & $\begin{array}{l}\text { Lower combustion temperatures, less } \\
\mathrm{NO}_{\mathrm{x}}\end{array}$ & 0.4 & - \\
\hline Lean burn & $\begin{array}{l}\text { Selective Catalytic } \\
\text { Reduction (SCR) }\end{array}$ & $\begin{array}{l}\mathrm{NO}_{x} \text { reacts on SCR catalyst in the } \\
\text { presence of injected ammonia }\end{array}$ & 0.05 to 0.15 & Cost Penalty \\
\hline $\begin{array}{l}\text { Ultra-lean burn } \\
\text { with hydrogen }\end{array}$ & None & $\begin{array}{l}\text { Hydrogen in fuel extends lean } \\
\text { operating limit }\end{array}$ & $\begin{array}{l}0.032 \text { to } \\
0.10\end{array}$ & $\begin{array}{l}\text { Hydrogen } \\
\text { Supply } \\
\text { needed }\end{array}$ \\
\hline
\end{tabular}

Both three-way catalyst (TWC) and selective catalytic reduction (SCR) can achieve very low $\mathrm{NO}_{\mathrm{x}}$ emissions. However, both of these concepts are less attractive than ultra-lean burn from an economical standpoint. With TWC exhaust aftertreatment, the engine has to be operated stoichiometrically, which means that the inherent fuel economy benefits associated with leanburn can not be realized. The TWC also represents a significant added cost to the total system. 
SCR exhaust aftertreatment is compatible with lean exhaust and therefore enables lean-burn. However, the SCR catalyst requires a reducing agent, typically ammonia or urea, which adds to the operational cost of the engine as well as the complexity of the overall system. The SCR system is also considerably more expensive compared to TWC.

The lean-burn prechamber approach has been pursued by many engine manufacturers. It uses two combustion chambers. One called a torch chamber, Jet Cell ${ }^{\mathrm{TM}}$, or pre-chamber, contains a near stoichiometric (or even rich) mixture that is ignited by conventional spark ignition. This pre-chamber is connected via a short passage to the other main chamber that contains the bulk, lean mixture. As a result of combustion generated pressure rise in the pre-chamber, a jet plume of hot burning gas is injected into the main chamber lean mixture. This hot jet serves as a powerful ignition source and turbulence generator, promoting fast burn of the lean bulk charge.

Prechamber systems can achieve very lean overall operation $(\phi \approx 0.5-0.6)$. However, the prechamber technology has inherently higher $\mathrm{NO}_{\mathrm{x}}$ than a homogeneous charge ultra-lean configuration. While the rich mixture in the prechamber enables overall lean combustion, it is a hot, near stoichiometric zone that promotes $\mathrm{NO}_{\mathrm{x}}$ formation. As a consequence, emissions from lean-burn engines with prechambers are typically no lower than $0.4 \mathrm{~g} / \mathrm{bhp}$-hr (because the prechamber results in $\mathrm{NO}_{\mathrm{x}}$ formation). In addition, prechamber configurations typically suffer from relatively high heat losses from the hot jet as it passes through the short and narrow passage to the main chamber. This additional heat loss mechanism has a negative impact on the overall fuel efficiency. On balance therefore, homogeneous charge ultra-lean burn is the optimal approach for achieving low emissions from natural gas engines.

However, even though homogenous charge ultra-lean engine operation is an attractive approach for simultaneously achieving high engine efficiencies and low $\mathrm{NO}_{\mathrm{x}}$ emissions, the low flame speed of methane limits the extent of lean operation to levels short of that required to meet stringent emissions mandates. A critical challenge, therefore, in realizing practical ultra-lean burn systems for natural gas engines is that as the $\mathrm{A} / \mathrm{F}$ ratio is increased, combustion becomes unstable before $\mathrm{NO}_{\mathrm{x}}$ and $\mathrm{CO}$ emissions are reduced sufficiently.

\subsubsection{Spark Plug Durability in Lean-Burn Engines}

Historically, homogeneous charge lean burn has been pursued by increasing the level of turbulence in the combustion chamber (typically by mechanical vortex generators in the intake port and/or piston). The idea is to accelerate the burn rate through turbulence (increased thermal and mass diffusion and increased flame area by flame wrinkling and stretch) and thereby extend the lean limit for stable combustion. A problem with the high turbulence approach, however, is that the initial flame kernel generated by the ignition spark can be quenched by the increased thermal diffusivity and flame stretch, resulting in misfires. Therefore, special high-energy ignition sources (e.g., high-energy break down and/or multi spark systems and plasma ignition systems) are typically required to generate a relatively large initial flame. Unfortunately, highenergy ignition systems tend to aggravate spark plug erosion , resulting in more frequent spark plug replacement and higher maintenance costs.

For pre-mixed moderately lean spark ignition engines, in-field data show that spark plugs must be serviced frequently (spark gap adjustment every 1,000 to 4,000 hr, and spark plug 
replacement every 10,000 hr) which carries a significant maintenance cost and lowers the total availability of the system.

Over time, the electrodes of a spark plug degrade through a mechanism known as electrode wear, whereby the energy associated with spark discharge causes the electrode material to heat up in local hot-spots during the spark ${ }^{6}$, and gradually evaporate. Electrodes also tend to wear as the surface continually oxidizes in the presence of high temperature and the oxide scales flake off. The electrode erosion rate is a function of the spark voltage, which in turn is a function of the product of in-cylinder pressure and electrode gap ${ }^{7}$. Higher in-cylinder pressures combined with larger electrode gaps result in higher spark voltages, which quickly lead to faster electrode erosion. Lean-burn engines need to be boosted or turbocharged to maintain high specific power, which results in high in-cylinder pressures. This explains why electrode erosion is a much more critical issue in lean-burn natural gas engines.

A seemingly simple solution would be to reduce the electrode gap to lower the spark voltage. However, this approach is limited by the fact that smaller electrode gaps have an adverse impact on ignition quality. Therefore, there exists an inherent challenge in achieving an appropriate balance between these two disparate design goals.

There are two fundamentally different approaches to reduce the maintenance requirement associated with spark plug replacements: 1) development of longer-life spark plug or 2) reducing the spark energy required to ignite the unburned fuel/air mixture.

The development of longer life spark plugs is an issue that has received and will continue to receive a significant amount of attention for light-duty and stationary power generation applications. The approach centers around designing the spark plug for better heat transfer away from the electrodes, and to use electrode materials that have high melting points and also resist oxidation and/or produce a stable oxide. Specifically, high nickel-chrome electrodes with copper cores (for improved heat transfer) and platinum tips have been commercialized. For light-duty applications where typical in-use duty cycles are dominated by part-load and light-load operation, advanced spark plug designs (such as platinum tip) have enhanced the spark plug durability to the order of 100,000 miles. However, for lean-burn stationary natural gas applications, the situation is exacerbated by highly boosted operation and much higher average engine loads for typical duty cycles (i.e., on average significantly higher cylinder pressure which leads to faster wear). Consequently, while longer life spark plugs continue to be important for light-duty applications, it is not likely that this will be sufficient to meet the performance criteria for stationary natural gas engines.

Alternative solutions aiming at elimination of the spark plug altogether are attracting some attention. One near-term possibility is the use of a Diesel micro-pilot to initiate combustion. However, the need to carry two fuels makes this option inherently unattractive. Laser ignition is another option that obviously would eliminate the issue of spark plug maintenance if successful. By enabling plasma to be generated at an arbitrary position within the combustion chamber (i.e.,

${ }^{6}$ The spark current causes the electrode material to heat up locally, during the spark, in so-called hotspots (10-50 microns in diameter), where the temperature reaches the evaporation temperature of the cathode material and, thus, creates small pools of molten metal.

${ }^{7}$ Paschen's Law describes the dependence of the breakdown voltage between two flat electrodes on the product of the gas pressure and the electrode distance. 
minimizing heat loss to the cylinder walls) and depositing energy in just a few nanoseconds, laser ignition holds the potential for excellent ignitability and precise ignition timing ${ }^{8}$. However, there are significant technical barriers as well as practical implementation challenges yet to overcome with respect to the development of a robust and reliable laser ignition system. The most formidable of these barriers include excessive power consumption and window fouling.

Instead, a more promising practical solution to the spark plug replacement issue in lean-burn stationary natural gas engines is to reduce the ignition or spark energy required to initiate combustion. If the minimum ignition energy could be significantly reduced, the ignition system could be redesigned for minimal spark plug wear by reducing the electrode gap and shortening the spark duration. Fractional hydrogen supplementation is particularly interesting in this respect since hydrogen has a significantly lower ignition energy than natural gas. For quiescent stoichiometric mixtures the minimum ignition energy for hydrogen is $0.019 \mathrm{~mJ}$ compared to $0.34 \mathrm{~mJ}$ for methane, which is the main constituent of natural gas (the minimum ignition energy for the other significant hydrocarbon components in natural gas are: $0.29 \mathrm{~mJ}$ for ethane, and $0.30 \mathrm{~mJ}$ for propane) ${ }^{9}$.

\subsubsection{Hydrogen Assisted Operation Addresses the Central Challenges of Lean-burn}

Moderate lean-burn has been successfully demonstrated (at the expense of spark plug life) with high-turbulence / high-energy ignition concepts. However, when approaching ultra-lean operation (which is required for near zero engine-out $\mathrm{NO}_{\mathrm{x}}$ emissions), partial burn and misfires are frequently encountered, resulting in excessive emissions of unburned hydrocarbons and poor thermal efficiency.

An effective alternative approach to accelerate the burn rate of ultra lean mixtures and thereby extend the lean operating limit is to utilize hydrogen as a supplement to conventional fossil hydrocarbon fuels. Hydrogen assisted operation can successfully address both reduced engineout $\mathrm{NO}_{\mathrm{x}}$ emissions and increased spark plug durability by making ultra-lean operation possible without the need for high energy ignition.

Fractional hydrogen substitution in spark ignited engines burning natural gas, liquefied petroleum gas, or gasoline has been investigated by a number of researchers ${ }^{10,11,12,13,14,15,16,17,18,19}$

${ }^{8}$ Kopecek, H., Charareh, S., Lackner, M., Forsich, C., Winter, F., Klausner, J., Herdin, G., and Wintner, E. (2003), "Laser ignition of methane-air mixtures at high pressures and diagnostics," ICES 2003-614, 2003 Spring Technical Conference of the ASME Internal Combustion Engine Division, Salzberg Austria, May 11-14, 2003.

${ }^{9}$ Rose, J. W., and Cooper, J. R.: "Technical Data on Fuel", Seventh Edition, 1977, Published by The British National Committee World Energy Conference.

10 Apostolescu, N., and Chiriac, R., "A Study of Hydrogen-Enriched Gasoline in a Spark Ignition Engine," SAE Paper No. 960603, in "Advances in Engine Combustion and Flow Diagnostics," SP1157, 1996.

11 Rauckis, M. J., and McLean, W. J., "The Effect of Hydrogen Addition on Ignition Delays and Flame Propagation in Spark Ignition Engines," Combustion Science and Technology, 19, pp. 207-216, 1979.

12 Houseman, J., and Hoehn, F. W., "A Two-Charge Engine Concept: Hydrogen Enrichment," SAE Paper No. 741169, 1974. 
and have been demonstrated to offer a number of advantages, primarily as a result of increased laminar flame speeds. Key advantages include; (i) operation at very lean mixtures, (ii) enhanced combustion stability, (iii) increased thermal efficiency and (iv) potential for ultra-low $\mathrm{NO}_{\mathrm{x}}$ emissions but increased HC emissions, depending on equivalence ratio. Negative influences arise from reduced volumetric efficiency (due to displacement of air) and decreased maximum power output.

While these previous studies have demonstrated that HALO can enable ultra-lean operation, they have not explored whether HALO could simultaneously also address the other key issue for natural gas engines, namely spark plug life by reducing the ignition energy requirement.

Natural gas engines with prechambers can achieve $\mathrm{NO}_{\mathrm{x}}$ levels of $0.4 \mathrm{~g} / \mathrm{bhp}-\mathrm{hr}$ if the engine is operated at a relative air/fuel ratio (lambda) of 2 . The lean limit for natural gas combustion with a homogeneous charge engine typically occurs at a lambda of $1.6(\phi \approx 0.6)$, which is not lean enough for $\mathrm{NO}_{\mathrm{x}}$ emissions to reach ultra low levels. Since the homogeneous charge HALO approach eliminates the hot, near stoichiometric $\mathrm{NO}_{\mathrm{x}}$ promoting prechamber, the homogenous charge HALO engine can achieve lower $\mathrm{NO}_{\mathrm{x}}$ emissions at an equivalent lambda. Based on our modeling of a natural gas/hydrogen engine, a lambda of $2(\phi=0.5)$ will achieve $0.032 \mathrm{~g} / \mathrm{bhp}-\mathrm{hr}$ (0.01 lb/MMBtu). A slightly leaner configuration will result in $\mathrm{NO}_{\mathrm{x}}$ levels of $0.02 \mathrm{~g} / \mathrm{bhp}$-hr that is as low as the levels from new central station power plants equipped with best available control technology (BACT).

A comparison between emissions from a prechamber and homogeneous charge engine is illustrated in Figure 1. The addition of hydrogen allows the homogeneous charge engine to operate without misfire at lambda values up to $2.5(\phi=0.4)$, where $\mathrm{NO}_{\mathrm{x}}$ is virtually eliminated. Our modeling results show that $\mathrm{NO}_{\mathrm{x}}$ levels drop rapidly as the engine runs leaner. The lean operation is enabled with the addition of hydrogen. The higher flame speed of hydrogen allows the initial combustion in the cylinder to propagate faster and allows for engine operation without misfire.

Our modeling combined with laboratory engine testing indicates that 6.75 percent of the total heat input from hydrogen allows for lean operation to a lambda of 2.

13 Stebar, R. F., and Parks, F. B., "Emission Control with Lean Operation Using Hydrogen-Supplemented Fuel," SAE Paper No. 740187, 1974.

${ }^{14}$ Lucas, G. G., and Richards, W. L., "The Hydrogen / Petrol Engine - The Means to Give Good Part Load Fuel Economy," SAE Paper No. 820315, 1982.

15 Newkirk, M. S., and Abel, J. L., "The Boston Reformed Fuel Car," SAE Paper No. 720670, 1972.

16 Jamal, Y., and Wyszynski, M. L., "On-Board Generation of Hydrogen-Rich Gaseous Fuels," International Journal of Hydrogen Energy, 19, No. 7, pp. 557-572, 1994.

17 Swain, M. R., Yusuf, M. J., Dulger, Z., and Swain, M. N., "The Effects of Hydrogen Addition on Natural Gas Engine Operation," 1993 SAE Transactions, Section 4, Paper No. 932775, 1993.

18 Timoney, D. J., and Wilson, R. P., "Use Of Supplemental Hydrogen In Spark Ignition Engines: Simulation of Impact on Performance \& Emissions," ISATA Technical Paper No. 98EL016, 1998.

19 Timoney, D. J., Linna J. R., and Wilson, R. P., "Some Measured And Simulated Effects Of Supplemental Hydrogen In A Gasoline Engine," ISATA Technical Paper No. 00ELE036, 2000. 


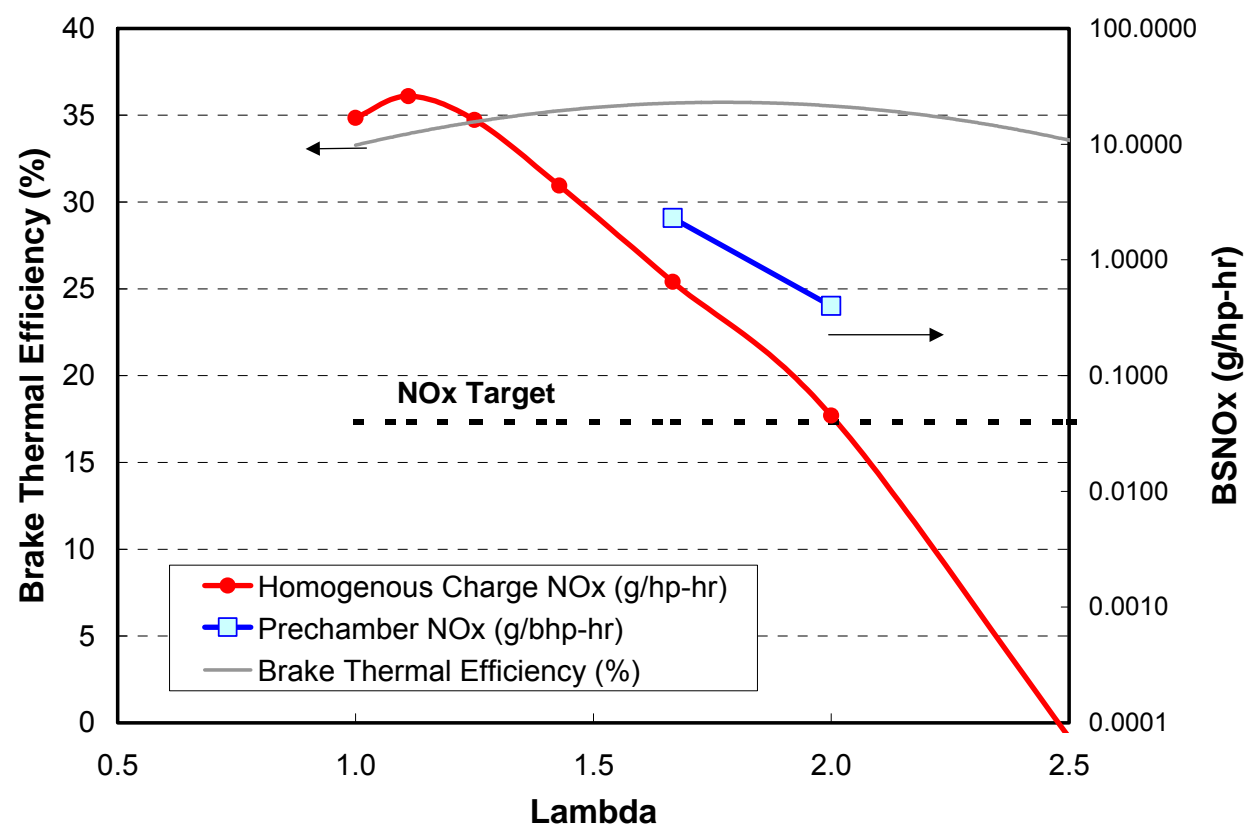

Figure 1. Emissions from IC Engines Vary with Air/Fuel Ratio

\subsection{Problem Statement}

Fractional hydrogen substitution in spark ignited engines burning natural gas, liquefied petroleum gas, or gasoline has been investigated by a number of researchers and have been demonstrated to offer a number of advantages, primarily as a result of increased laminar flame speeds. The primary advantage, as noted above, is the ability to offer stable combustion at much higher $\mathrm{A} / \mathrm{F}$ ratio, with associated substantial reductions in engine $\mathrm{NO}_{\mathrm{x}}$ emissions. Our own engine modeling predictions show that $90 \% \mathrm{NO}_{\mathrm{x}}$ emission reductions from the $0.4 \mathrm{~g} / \mathrm{bhp}-\mathrm{hr}$ BACT levels noted above will be easily achievable. In fact, we expect to operate the engine at an overall equivalence ration of less than or equal to 0.5 , which according to our modeling results will adequately lower engine $\mathrm{NO}_{\mathrm{x}}$ emissions.

While these previous studies have demonstrated that HALO can enable ultra-lean operation, they have not explored whether HALO could simultaneously address the other key issue for natural gas engines: spark plug life. Hydrogen supplementation has potential to reduce the ignition energy requirement (thereby increasing spark plug life) because of its easy ignitability. The key area of focus for this proposed study was therefore to explore and resolve the trade-off between lean-operating limit and ignition energy for various levels of fractional hydrogen supplementation in a representative natural gas engine.

\subsection{Project Goals and Objectives}

The overall objective of the proposed program was to explore and demonstrate the potential for fractional hydrogen supplementation as a key enabler for operating a natural gas engine at ultra- 
lean engine conditions ( $\lambda$ at or equal to 2 ) to produce ultra-low $\mathrm{NO}_{\mathrm{x}}$ emissions, while at the same time reducing the spark energy to increase the spark plug durability and reliability.

Specifically stated this project had two distinct goals and objectives and has successfully met them:

- To perform necessary engine experiments to obtain information regarding the lean operating limit for different spark ignition energy levels for a natural gas engine operating with various amounts of fractional hydrogen supplementation

- To analyze and synthesize the engine test data so that the trade-off between lean-operating limit and ignition energy for various levels of fractional hydrogen supplementation in a representative natural gas engine can be resolved

\section{Technical Approach}

The technical investigation of the HALO approach occurred at TIAX's facilities in Cambridge, MA, using a representative Hess-Microgen natural gas engine typical of cogeneration unit prime movers. Hydrogen was supplied from gas cylinders and bled into the intake system of the engine. The ignition systems was a highly controllable and specially modified spark ignition system, SmartFire $^{\mathrm{TM}}$, from Adrenaline Research. The SmartFire system features ionization feedback which provides real-time misfire and knock detection.

While TIAX, Adrenaline Research, and Hess-Microgen have significant experience in their respective fields of expertise to make the proposed project technically viable, they are fully aware that HALO with NG as the fuel poses certain specific technical challenges that had to be overcome for the project to be successful. These challenges (as stated in the proposal) are listed below:

1. "To achieve the target levels of $\mathrm{NO}_{\mathrm{x}}$, the $\mathrm{NG}$ engine has to be operated considerably lean. Natural gas engines have to be operated at a lambda of 2.1 to achieve the target levels of $\mathrm{NO}_{\mathrm{x}}$ emissions. By itself, at this level of dilution, stable combustion will not be supported. However, augmented by hydrogen, at nominally $7 \%$ of the total heat input to the engine, the engine can be operated at a lambda of 2.1.” The hydrogen needed was found to be $8 \%$, but the engine was able to be run at ultra-lean conditions.

2. "The very wide flammability limit of hydrogen, which is being taken advantage of in the HALO concept, also poses some inherent safety risks. One important consideration is the danger of pre-ignition of the hydrogen-NG-air mixture in the intake manifold of the engine. Temperature and other activated components within the manifold could trigger the preignition of the fuel mixture.”

These challenges were met and overcome during this project, and the risk was mitigated.

The strategy for our proposed technical approach is outlined in Figure 2, with the individual tasks described in detail. 


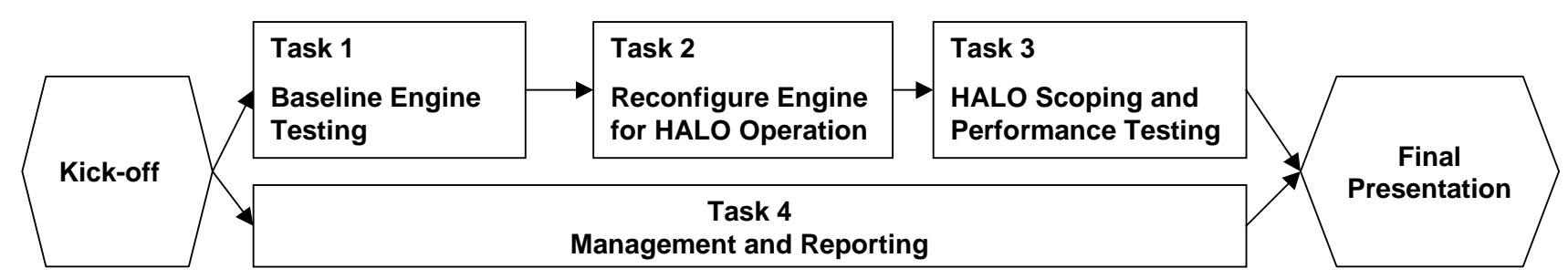

Figure 2. Technical Tasks Flow Chart

\section{Engine Testing}

Engine testing was comprised of three phases spread out over two project tasks: Phase 1: Establishing a baseline (Task 1 Baseline Engine Testing), Phase 2: HALO Testing (Task 3 HALO Scoping and Performance Testing) and Phase 3: HALO Testing with reduced spark plug energy (Task 3 HALO Scoping and Performance Testing). The objective of test program was to establish a baseline for engine operation and then systematically map out spark plug energy over various levels of hydrogen supplementation.

At the end of Task 1, baseline engine data was established regarding performance of the engine. After the baselining was accomplished and the data found to be satisfactory, then the engine was reconfigured for HALO operation in Task 2 by supercharging and switching over to the Adrenaline Research spark ignition system. Following that exercise, the Task 3 HALO scoping gave insight into various levels of hydrogen supplementation and the relationship to spark energy reduction.

\subsection{Experimental Design}

The experimental program was designed to provide a robust method of separating each level of experimental complexity into separate phases which allow a logical approach from which clear conclusion may be drawn. The Phase I testing was done to establish a baseline and reference condition. The next level of complexity was then added in Phase 2, that of establishing the performance of this engine with the addition of hydrogen. Finally, the Phase 3 testing allowed the highest level of complexity, that of testing with reduced spark energy as well as reduced $\mathrm{NO}_{\mathrm{x}}$ achievable due to hydrogen supplementation. Figure 3 shows an overview of the experimental test program and how it builds on the previous phase: 


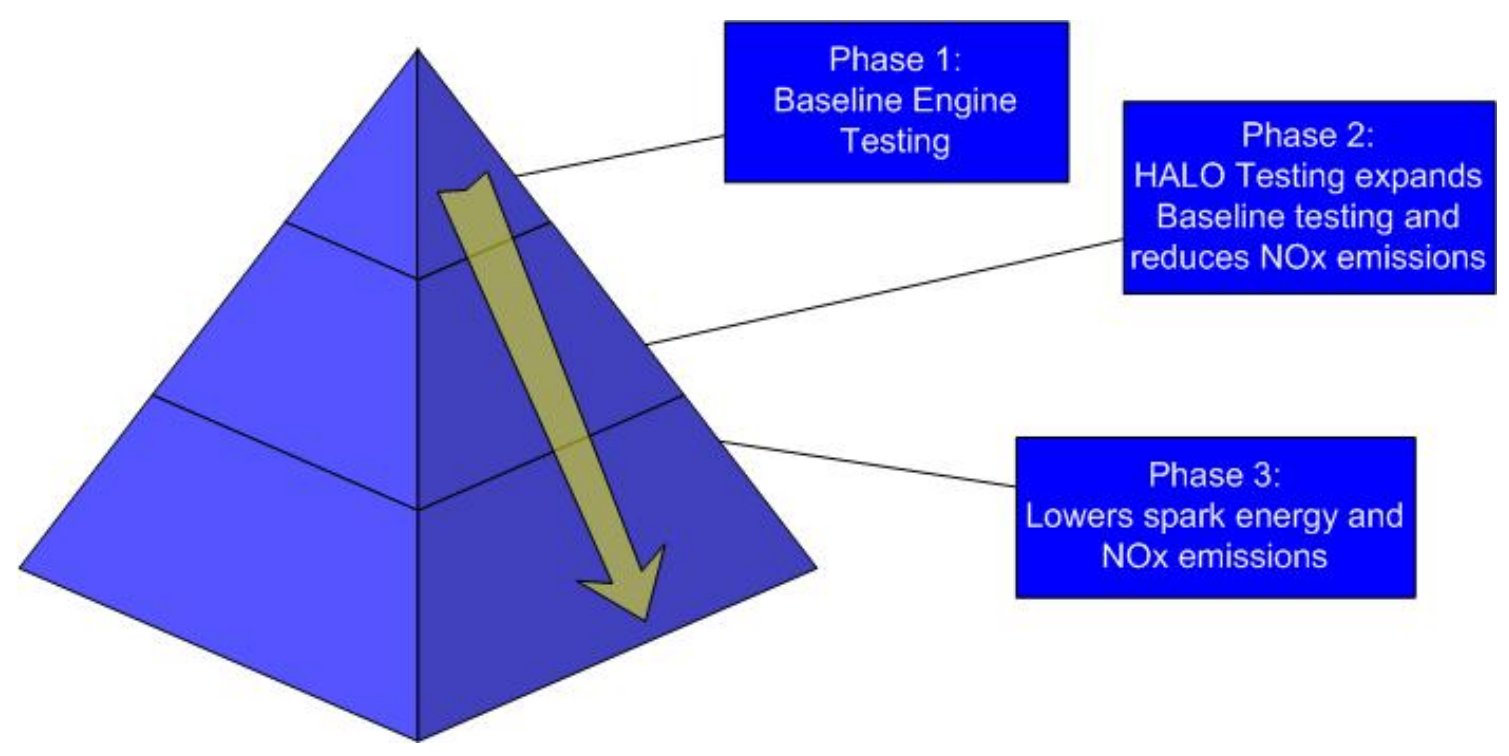

Figure 3. Overview of Experimental Test Program

\subsection{Engine Description}

The engine chosen for this test program was selected due to its being a typical engine used in the small $(<100 \mathrm{~kW})$ engine range as well as for experimental convenience and ease of use. As for testing the engine, it was determined that testing the engine outside of the generator package (i.e: the box the engine generator would ship in) would be provide a broader range of test capabilities and facilitate a successful completion of project goals and objectives.

Table 2. Comparison of Engine Test Facility vs. Generator

\begin{tabular}{|l|l|}
\hline \multicolumn{1}{|c|}{ Engine Test Facility } & \multicolumn{1}{c|}{ Genset } \\
\hline 8-cylinder capability for pressure monitoring & 1 cylinder capability for pressure monitoring \\
Integrated data acquisition system & Separate data acquisition systems \\
Fully Instrumented engine & Partially Instrumented engine \\
dSPACE engine control installed & MOTEC engine control \\
Controlled intake, lube, coolant conditions & Reliance upon ambient conditions \\
\hline
\end{tabular}

As can be seen from Table 2, the engine test facility allows a more controlled environment for testing as opposed to testing in the cogeneration package. Testing in the engine test facility would lead to more accurate and repeatable results. Also, the ability to measure 8 cylinders of combustion pressure will be extremely useful to monitor hydrogen distribution from cylinder to cylinder, as hydrogen injection will be performed before the throttle. This would not be possible in the cogeneration unit due to instrumentation limitations of only being able to measure one cylinder.

Specifications for the engines are given in Table 3. 
Table 3. Relevance of Selected Engine to Cogeneration Unit

\begin{tabular}{|l|l|l|}
\hline \multicolumn{1}{|c|}{ Specification } & \multicolumn{1}{|c|}{ Cogeneration Unit } & \multicolumn{1}{c|}{ Selected Engine } \\
\hline \hline Engine type & Ford V10, 2-valve per cyl. & Ford V8, 2-valve per cyl. \\
Bore and Stroke, mm (in) & $90.2 \times 105.8(3.55 \times 4.17)$ & $90.2 \times 89.9(3.55 \times 3.54)$ \\
Displacement, L (CID) & $6.8(415)$ & $4.6(280)$ \\
Compression ratio & $9: 1$ & $9.3: 1$ \\
Ignition system & Coil on Plug & Coil on Plug \\
\hline
\end{tabular}

As may be seen from Table 3, the engine installed in the Engine Test Facility is comparable to the typical engine found in cogeneration units of this size range. The cogeneration unit prime mover is in the same engine family as the selected engine, and differs only in stroke length and slightly in compression ratio.

\subsection{Engine Test Facility}

Since the outcome of the testing is highly dependant on the engine test facilities, a brief description of TIAX's Engine Test Facility follows. A photograph of the facility is shown below in Figure 4. The facility uses five separate computers to control test equipment, the engine, as well as provide data acquisition capabilities. The control room is shown on the left, and the dynamometer room is shown on the right. The engine shown in the dynamometer room is not the one used in the testing (although it is similar); the engine used will be detailed later.

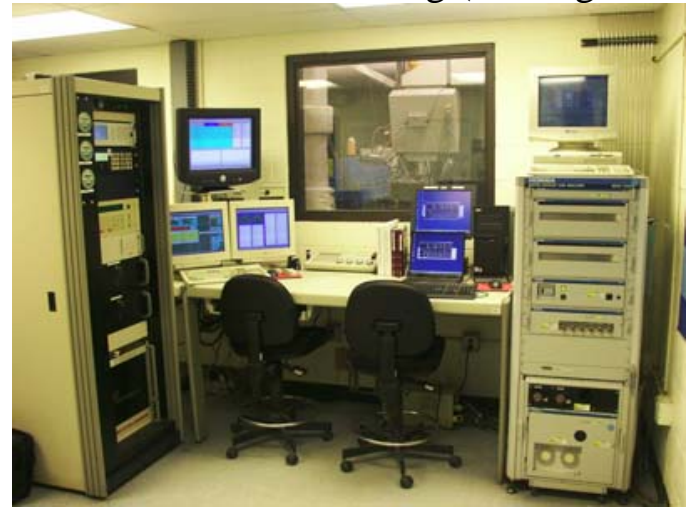

Engine Test Facility Control Room

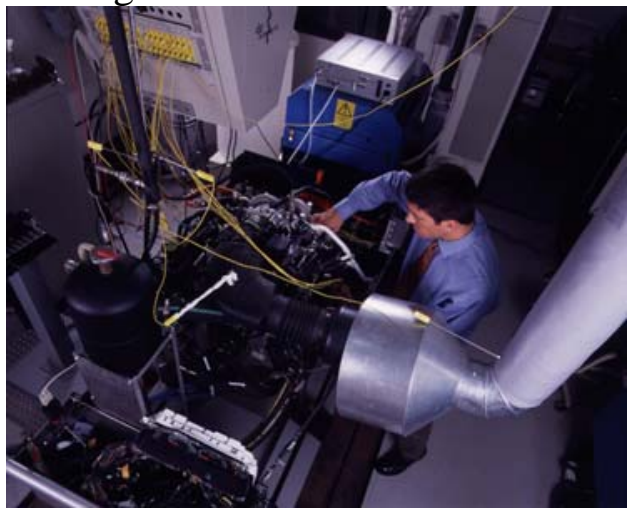

Engine Test Facility Dyno Room

Figure 4. Photographs of TIAX's Engine Test Facility

The TIAX Engine Test Facility is a \$1.4 MM Test Facility commissioned in 1999 for the purpose of advanced engine testing. In our advanced engine laboratory, repeatable transient testing, including a simulated Federal Test Procedure is achievable. This laboratory is also climate-controlled, so that testing may be done in simulated climates ranging from Arctic winters to desert heat. Throughout testing, insight into combustion characteristics is gained by monitoring the in-cylinder pressure with heat release analysis software. A summary of the laboratory's capabilities is shown below in Table 4. 
Table 4. TIAX LLC Engine Test Facility Capabilities

\begin{tabular}{|c|c|c|}
\hline Dynamometer & Emissions Analysis & Intake Air Conditioning \\
\hline $\begin{array}{l}\text { Type: Asynchronous A/C } \\
\text { Absorption } \\
\text { - Torque }{ }_{\max }=525 \mathrm{Nm}(424 \mathrm{ft}-\mathrm{lb}) \text { from } \\
0 \text { to } 4,000 \mathrm{RPM} \\
\text { - } \text { Power }_{\max }=220 \mathrm{~kW}(295 \mathrm{HP}) \text { from } \\
4,000 \text { to } 8,500 \mathrm{RPM} \\
\text { - Speed } \\
\text { Motoring } \\
\text { - } \text { Torque }_{\max }=478,000 \mathrm{RPM} \\
0 \text { to } 4,000 \mathrm{RPM} \\
\text { - } \text { Power }_{\max }=200 \mathrm{~kW}(268 \mathrm{HP}) \text { from } \\
4,000 \text { to } 8,500 \mathrm{RPM} \\
\text { - } \text { Speed }_{\max }=10,000 \mathrm{RPM}\end{array}$ & $\begin{array}{l}\text { Horiba MEXA } 7500 \\
\text { - Two channel engine-out and tailpipe } \\
\text { analytical system with heated } \\
\text { analyzers for THC and } \mathrm{NO}_{x} \\
\text { AVL Smoke Meter } \\
\text { - Bosch smoke numbers } \\
\text { GC } \\
\text { - Bag Samples } \\
\text { O2 Sensors } \\
\text { High-Speed Instrumentation } \\
\text { - Cambustion FastFID }\end{array}$ & 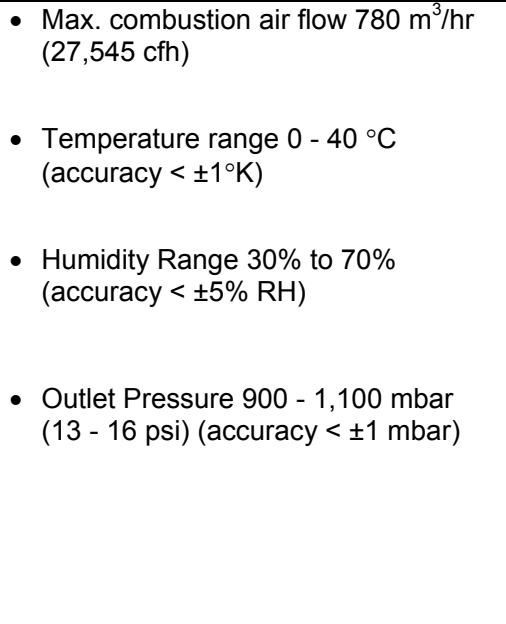 \\
\hline $\begin{array}{l}\text { Coolant and } \\
\text { Lubricant Conditioning }\end{array}$ & $\begin{array}{l}\text { Fuel Metering and } \\
\text { Conditioning }\end{array}$ & $\begin{array}{l}\text { Engine Control and } \\
\text { Data Acquisition }\end{array}$ \\
\hline $\begin{array}{l}\text { Temperature range: } 0-130^{\circ} \mathrm{C} \\
\text { (steady-state conditions: accuracy } \\
< \pm 1^{\circ} \mathrm{K} \text { ) } \\
\\
\text { - Temperature range } 5-130^{\circ} \mathrm{C} \\
\text { (steady-state conditions: accuracy } \\
< \pm 1^{\circ} \mathrm{K} \text { ) }\end{array}$ & $\begin{array}{l}\text { - Flow range: } 0.3-60 \mathrm{l} / \mathrm{h}(0.01-2.1 \mathrm{cfh}) \\
\text { - Pressure loss: } 0 \Delta \mathrm{P} \\
\text { Fuel Heat Exchanger } \\
\text { - Working temperature range: }-38 \text { to } \\
200^{\circ} \mathrm{C} \\
\text { Components selected to handle gasoline, } \\
\text { diesel, methanol, and ethanol }\end{array}$ & $\begin{array}{l}\text { DSP Adapt Data Acquisition and engine } \\
\text { control } \\
\text { - } 64 \text { Analog Inputs/16 Analog Outputs } \\
\text { - } 16 \text { Digital Inputs/48 Digital Outputs } \\
\text { - } 5 \text { Input frequency Channels } \\
\text { Programmable Engine Computers } \\
\text { - MOTEC ECU } \\
\text { - DSPACE }\end{array}$ \\
\hline
\end{tabular}

\subsection{General Test Procedures}

For each phase of testing during this program a general set of test procedures and quality assurance procedures were followed to ensure excellent data even though the testing required in each phase was different. Details of each phase of testing will be described in depth later, but a general discussion of test procedures follows.

\subsubsection{Test Measurements}

The engine operating parameters to be measured for each test, along with the instrumentation to be used to measure these are listed in Table 5. The output from each measurement instrument was recorded in a data acquisition computer. This computer is equipped with state of the art commercially available combustion analysis system. This software allows tracking the variation 
of cylinder pressure with engine crank angle for each cycle and calculating the IMEP for each cycle based on these data. IMEP is defined as shown below ${ }^{20}$ :

$$
I M E P=\frac{2 P}{V_{d} N}
$$

Where $\mathrm{P}$ is the power, $\mathrm{V}_{\mathrm{d}}$ is the displaced volume, and $\mathrm{N}$ is the engine revolutions per second. The power was calculated from the cylinder pressure, which makes it an indicated value. The units of IMEP are pressure units, and it is in essence a normalized torque which allows a fair comparison of engines regardless of size.

The software also allows performing statistical analyses to calculate the coefficient of variance (COV) of the IMEP and the lowest normalized value (LNV) of the IMEP over a number of engine cycles, the results of which will be discussed later. These measures can be used to identify when engine combustion begins to become unstable as the lean limit of combustion is approached. The software also identifies the location (crank angle) of the peak cylinder pressure, the location of the $50 \%$ combustion completeness point, and the crank angle range of $10 \%$ to $90 \%$ combustion completeness. These are also indicators of combustion performance and flame propagation speed.

Table 5. Measured Engine Operating Parameters

\begin{tabular}{|l|l|}
\hline \multicolumn{1}{|c|}{ Parameter } & \multicolumn{1}{c|}{ Measurement Method } \\
\hline Cylinder pressure versus time & 8 Kistler 6125 pressure transducers \\
Engine crank angle versus time & Shaft encoder \\
Engine power output & Measured at dynamometer \\
Engine speed & Engine tachometer \\
Exhaust $\mathrm{O}_{2}$ concentration & Oxygen sensor and readout \\
Exhaust temperature & Thermocouple in tap in engine exhaust \\
Hydrogen Flowrate & Sierra Mass Flow meter \\
Hydrogen flowrate & Mass flow meter in reformate feed line \\
lon Current & Adrenaline Research system (Smartfire) \\
NG fuel flowrate & Mass flow meter in fuel feed line \\
Manifold air pressure (MAP) & Boost pressure transducer \\
Manifold charge temperature & Thermocouple in tap in intake manifold \\
Supercharger intake temperature & Thermocouple in tap in engine intake \\
\hline
\end{tabular}

${ }^{20}$ Heywood, J.B. Internal Combustion Engine Fundamentals. McGraw-Hill, Inc. New York, 1988. 
For all tests, engine exhaust concentrations of $\mathrm{O}_{2}, \mathrm{CO}_{2}, \mathrm{CO}, \mathrm{NO}_{\mathrm{x}}$, and total hydrocarbon (THC) was continuously monitored. The engine test facility at the TIAX Cambridge laboratories is equipped with a Horiba MEXA 7500 dual channel continuous emission monitoring system that will be used to continuously monitor engine exhaust. This system includes a paramagnetic $\mathrm{O}_{2}$ analyzer, non-dispersive infrared (NDIR) $\mathrm{CO}$ and $\mathrm{CO}_{2}$ monitors, a heated chemiluminescence $\mathrm{NO}_{\mathrm{x}}$ monitor, and a flame ionization detector (FID) THC monitor.

Mass flowmeters, pressure transducers, and thermocouples were calibrated before installation on the engine and held calibration throughout the project. The continuous emission monitors (CEMs) were calibrated using zero and span gas at the beginning of each test day. Zero and span drift will be calculated and compared to reference method specifications. Due to the extremely lean levels of engine operation causing large $\mathrm{O}_{2}$ fractions in the exhaust, the oxygen sensing instrumentation was calibrated with a higher level of span gas $\left(16 \% \mathrm{O}_{2}\right)$ than normal. Also, due to the low levels of measured $\mathrm{NO}_{\mathrm{x}}$, the $\mathrm{NO}_{\mathrm{x}}$ analyzer was calibrated using a gas divider to ensure accurate $\mathrm{NO}_{\mathrm{x}}$ measurement at low levels.

Ambient temperature, barometric pressure, and relative humidity were recorded periodically during each testing period. These measurements were used to correct all affected engine operating parameters.

\subsection{Data Analysis Procedures}

Commercially available heat release and engine combustion analysis software (Adapt CAS) was used to analyze test data obtained from the in-cylinder pressure monitoring. The dynamometer control software controls the engine speed and load as well as logs all engine performance parameters such as speed, manifold pressures, engine torque, and emissions. High speed data $(10.8 \mathrm{kHz})$ from the combustion analysis system as well as low speed data $(1 \mathrm{~Hz})$ was synchronized to allow appropriate comparisons to be drawn. This data was analyzed using industry standard data analysis to synthesize the data into meaningful plots.

\subsection{Quality Assurance Procedures}

During test setup and engine testing, a bound laboratory notebook was kept. In this notebook each test's setup was documented using photographs, technical drawings, and text that describes the setup with sufficient completeness that a given test can be duplicated in future. During testing, daily entries were made that described each test's objective, then each test's observations with time stamps associated with each observation. Any abnormal or unexpected events were also noted, with possible explanations and expected effects on the test data or the achievement of test objectives.

In any experimental program there will always be test-to-test variations in the measurement results obtained from repeated tests at the same test conditions. Naturally, it is preferable to minimize this variability. In well-controlled laboratory engine test facilities, it is usually possible to achieve test-to-test repeatability of key performance parameters to within $1 \%$. Nevertheless, it is important to measure the day-to-day variability in key performance parameters over time and use these measurements as a quality check threshold to verify the integrity and 
consistency of the engine setup and the testing hardware and instrumentation. To this end, the baseline test (Test 1) will be performed at the beginning of each test day, as noted above. The combustion stability for this condition, as determined by COV and the LNV of the IMEP, will be compared to that for previous test days. If the difference exceeds the quality check threshold, a cause for the difference will be sought and corrective action taken. If no cause can be found, testing will proceed, but the discrepancy will be noted in the test program laboratory notebook.

The Cambridge, MA office of TIAX is ISO 9001 certified. The TIAX ISO 9001 laboratory and testing procedures with regard to data acquisition, storage, backup, and evaluation were followed throughout the testing.

\section{Baseline Testing}

\subsection{Baseline Experimental Setup}

For the baseline testing, the engine testing was done with the naturally aspirated V8 with the hydrogen injection system installed. The hydrogen injection system was not used during this phase of testing, but was installed during a convenient phase of the project. Table 6 highlights the specifications of the V8 used. These specifications are typical of the $50-80 \mathrm{~kW}$ engine range for stationary natural gas engines. The natural gas engines used in power generation for this power range are usually derived from the transportation sector. For this project, natural gas port fuel injectors (from a MY1998 Ford Crown Victoria NG engine) were installed for precise fueling control. The typical mixing valve used in stationary power generation applications would not have supplied the precise fueling control necessary for all ranges of this project. Figure 5 shows a photograph of the baseline setup as well as a close-up of the fuel injectors and the Smartfire ignition coil.

Table 6. Engine Specifications

\begin{tabular}{|l|l|}
\hline & \multicolumn{1}{|c|}{ Specification } \\
\hline \hline Engine type & Ford V8, 2-valve per cylinder \\
Bore and Stroke, mm (in) & $90.2 \times 89.9(3.55 \times 3.54)$ \\
Displacement, L (CID) & $4.6(280)$ \\
Compression ratio & $9.3: 1$ \\
Ignition system & Smartfire \\
Fueling System & Multi-point Natural Gas Injectors \\
\hline
\end{tabular}




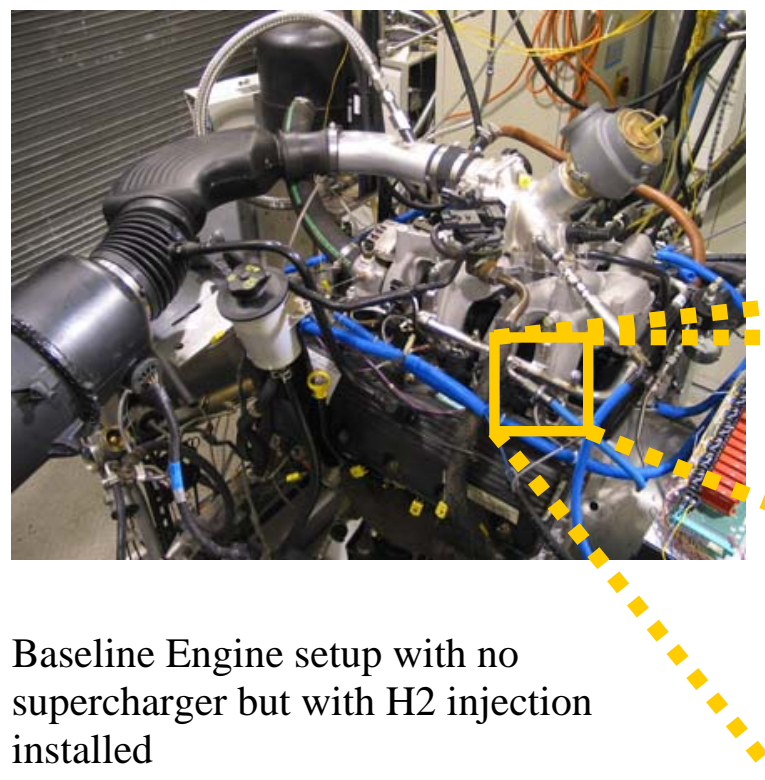

installed

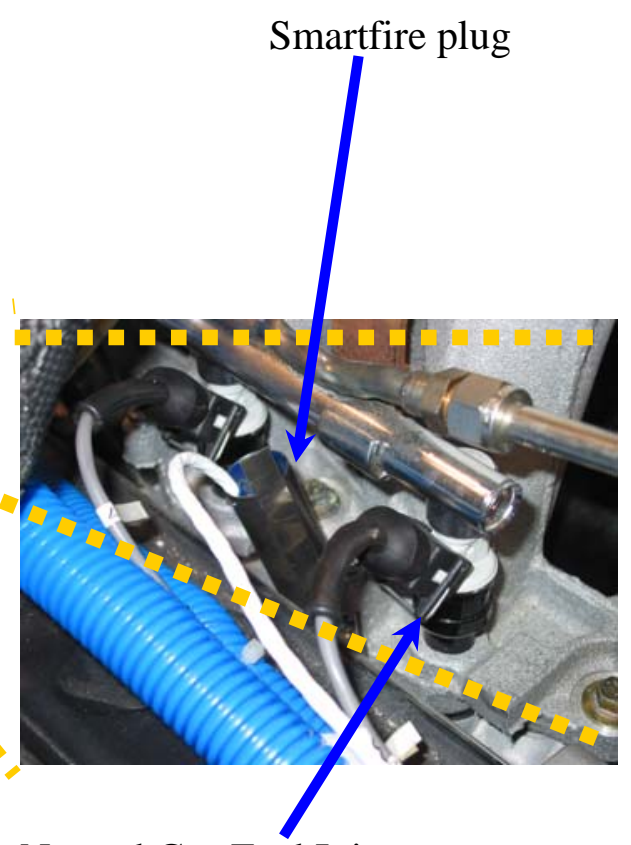

Natural Gas Fuel Injector

Figure 5. Baseline Engine Setup with Close-up of Fueling and Spark Ignition System

For the control of the engine system, a dSPACE Autobox was used to read in position signals into the engine and output fueling and spark control. The Adrenaline system was run as in slave mode to the dSPACE system. The dSPACE system would send a Transistor-Type Logic (TTL) signal to the Adrenaline research system for the start of cylinder \# 1 spark, and then the SmartFire system would fire the cylinders in the engine firing order of 1-3-7-2-6-5-4-8. Smartfire specifications are shown in Table 7.

Table 7. Ignition System Specifications

\begin{tabular}{|l|l|}
\hline & \multicolumn{1}{|c|}{ Specification } \\
\hline \hline Ignition Type & Capacitive Discharge \\
Cylinder capability & $1-12$ \\
Software Control & Windows-based Winfire \\
Combustion Feedback & lon current sensing \\
Spark Plug & Standard J-type \\
\hline
\end{tabular}

The Smartfire system works by discharging a 600 Volt capacitor into a coil, which steps up the voltage up to several thousand volts within one microsecond. This large voltage jumps the gap and ignites the combustible mixture in the cylinder. The spark reaches 1 amp and then decays for the order of 40 microseconds. The Smartfire system also has the ability to detect combustion, as highlighted in Table 7. Combustion feed back is achieved using ion-current feedback. After the initial spark, a second capacitor is charged, which applies a constant voltage to the plug gap. Combustion, which is occurring as this constant voltage is applied, produces ions. These ions 
induce a trickle current, which is measured and processed. If combustion does not occur, then there will be no ion current produced, and this will be detected by the Winfire software.

A schematic of the overall process for the engine control is shown in Figure 6.

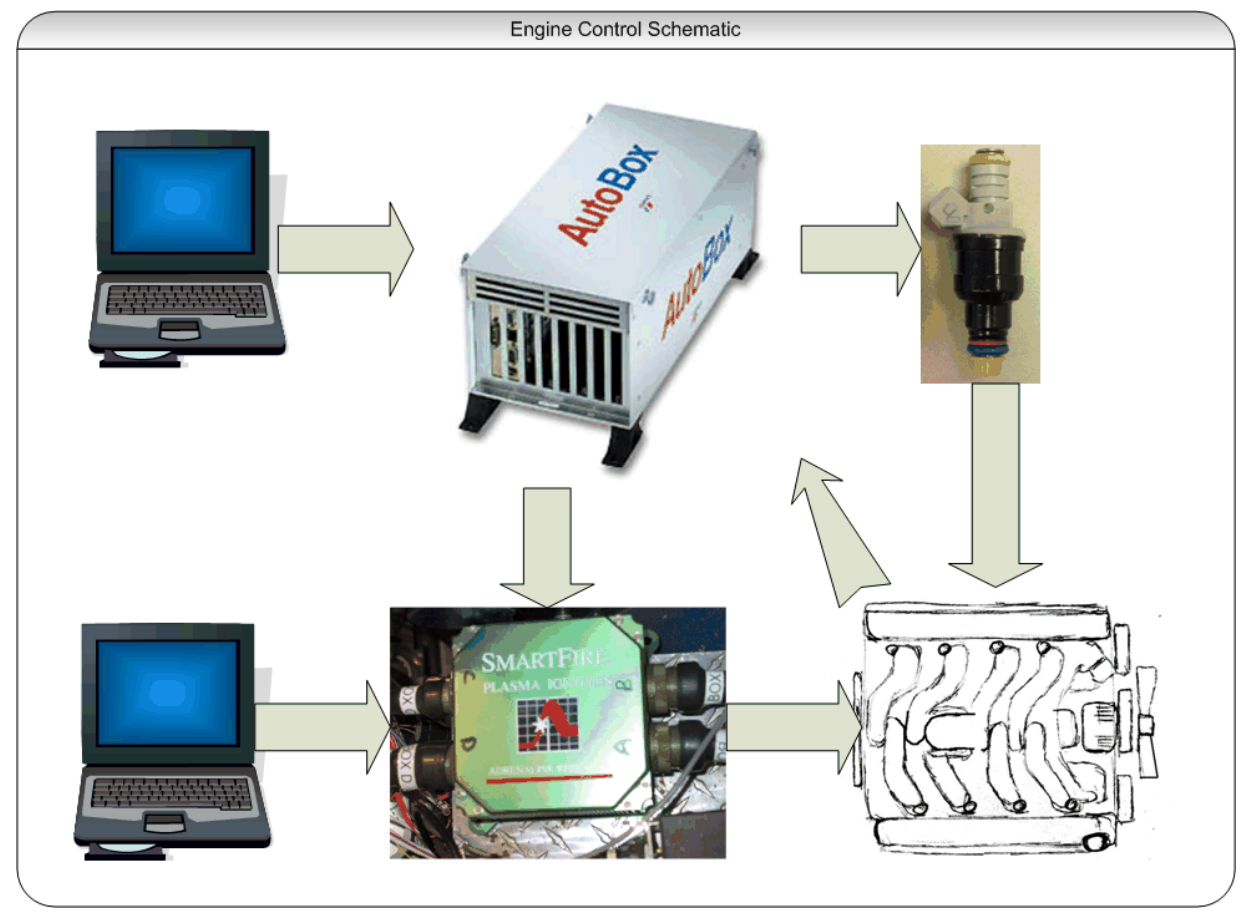

Figure 6. Engine Control Schematic

As mentioned previously, the Smartfire system (shown on the bottom middle row of Figure 6, is a slave to the dSPACE system. The dSPACE system directly controls the fuel injectors, and the engine provides crank and cam information to dSPACE system so that it may be orientated properly in the engine cycle.

Table 8. Natural Gas Composition Used in all Tests

\begin{tabular}{|l|c|}
\hline \multicolumn{1}{|c|}{ Constituent } & Volume Concentration \\
\hline \hline Methane & $93 \%$ \\
Nitrogen & $3 \%$ \\
Carbon Dioxide & $1 \%$ \\
Ethane & $2.4 \%$ \\
Propane & $0.5 \%$ \\
N-butane & $0.1 \%$ \\
\hline
\end{tabular}

The composition of the natural gas used throughout testing is shown in Table 8. The natural gas was supplied in six-packs of $300 \mathrm{ft}^{3}$ cylinders by Linde Gas. The 1994 US average composition 
of natural gas (highly flammable components only) is: $3.2 \%$ ethane, $0.7 \%$ propane, and $0.4 \%$ $\mathrm{N}$-butane $\mathrm{e}^{2 \mathrm{P}}$, so the composition used is representative of commercially available natural gas.

The system described above was used to conduct the baseline testing. The test matrix that was run is shown in Table 9:

Table 9. Baseline Test Matrix

\begin{tabular}{|c|c|}
\hline Task & Description \\
\hline 1 & $\begin{array}{l}\text { Baseline Test. The baseline testing was comprised of the following: } \\
\text { - Engine brought to fully warmed-up conditions ( } 90 \text { deg } \mathrm{C} \text { coolant/lubricant } \\
\text { temperatures) @ } 1800 \text { RPM. At wide open throttle (WOT), perform a spark timing } \\
\text { swing to determine MBT, first in coarse } 5 \text { deg increments then decrease to } 1 \text { degree } \\
\text { increments after peak IMEP is realized. Result: MBT Timing } \\
\text { - At the same operating conditions as mentioned above, perform injection timing } \\
\text { sweep in } 180 \text { degree increments at the MBT found above. The impact of this test is } \\
\text { expected to be minimal on IMEP. Result: Best Injection Timing } \\
\text { - With the Adrenaline system installed on the engine, determine the lean operating } \\
\text { limit by increasing the percent } \mathrm{O}_{2} \text { in the exhaust (measured using the HORIBA) } \\
\text { from } 4 \% \text { to stability limit in } 2 \% \text { increments. At each point, strive to keep the location } \\
\text { of peak pressure (LPP) the same as in the baseline system. Result: Baseline } \\
\text { Conditions }\end{array}$ \\
\hline
\end{tabular}

The first objective of Task 1 was to determine optimum spark timing and injection timing. This was accomplished by performing a sweep of each variable. A further objective of this Task was to determine the operating envelope of the engine. Once the optimum spark and injection timing are determined, a baseline for the engine at the rated standard design operating conditions was established. The baseline engine operating characteristics provided insight into the allowable combustion stability criteria for the engine. This baseline engine operating condition was repeated at the beginning of each test day to ensure the integrity and consistency of the experimental setup, instrumentation, and engine performance.

\subsection{Baseline Test Results and Conclusions}

Per the baseline test matrix outlined in Table 9, the engine was taken to a steady state operating condition of 1800 RPM, fully warmed up engine conditions, and run at fixed air/fuel ratio while varying the spark timing to determine the Maximum Brake Torque (MBT) timing for the test series. MBT timing is a balance of start of combustion and piston motion; if the spark occurs too early in the cycle, then the pressure rise due to combustion will counteract the rising piston and result in loss of pressure-volume work. If the spark occurs too late in the cycle, then the pressure rise due to combustion will occur in the ever-expanding volume of the combustion chamber (due to the piston motion) and work output will be lost. The optimum timing takes full advantage of

${ }^{21}$ Liss, W., et al. Variability of Natural Gas Composition in Select Major Metropolitan Areas of the US. Gas Research Institute Final Report, March 1992. 
the piston motion. This optimum timing may be determined by sweeping a range of spark timings and seeing which point gives the highest torque output (IMEP is a measure of torque normalized by engine displacement).

As shown in Figure 7, there is a clear peak at approximately 28 degrees before top dead center so this is where the optimum spark timing is located for this operating condition.

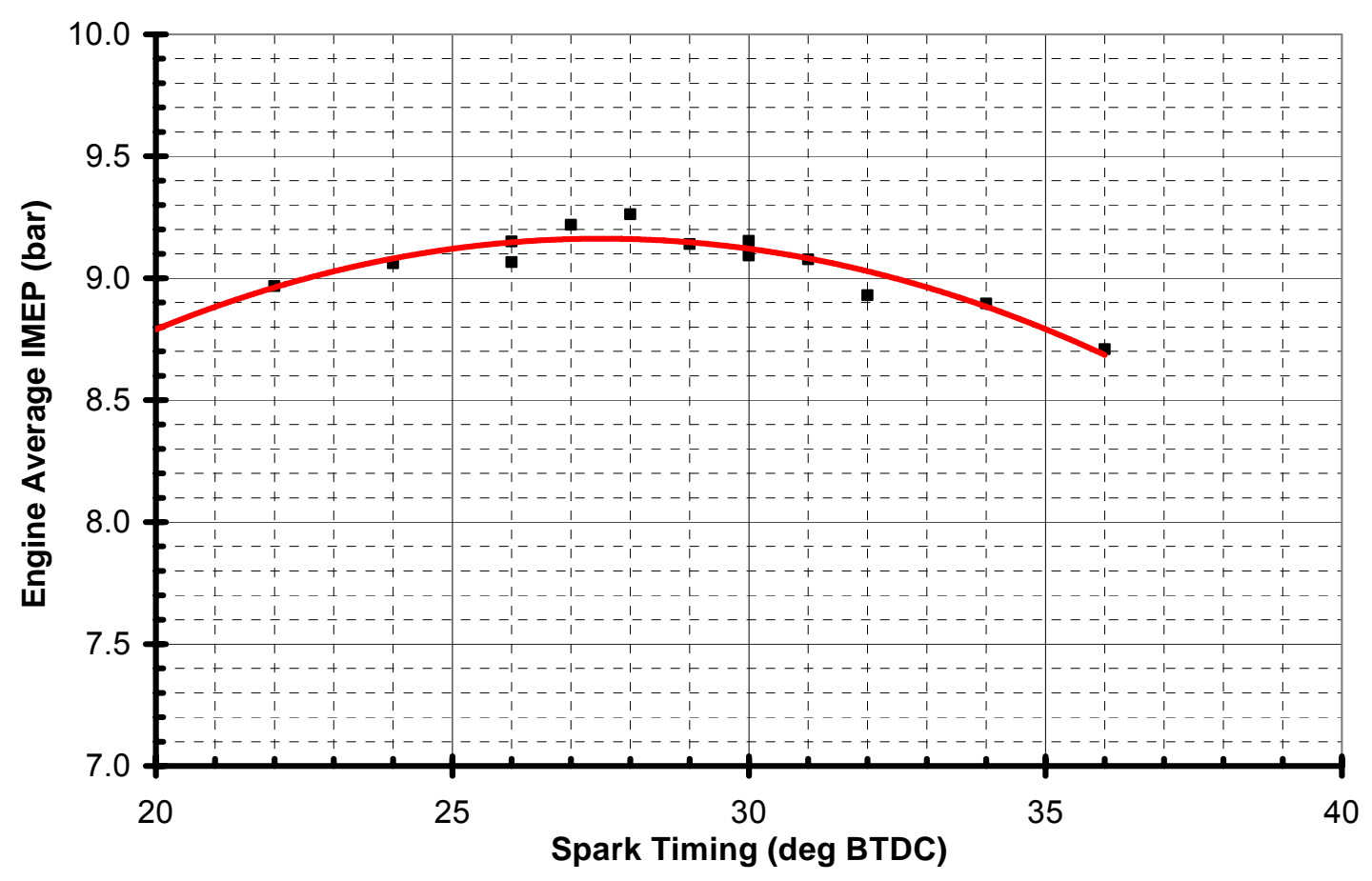

Figure 7. MBT Timing Sweep

A similar test was done with fuel injection timing, which has negligible impact in IMEP and emissions. The fuel injection timing that was chosen was 180 deg BTDC compression, which for this engine is open valve injection. This result and the rest of the pertinent results are summarized in Table 10. 
Table 10. Baseline Test Results

\begin{tabular}{|l|c|}
\hline \multicolumn{1}{|c|}{ Parameter } & Result \\
\hline Brake Power Output & $54 \mathrm{~kW}$ \\
Spark Timing & $28 \mathrm{deg}$ BTDC \\
Injection Timing & 180 deg BTDC compression \\
Manifold Pressure & $99 \mathrm{kPa}$ \\
Engine Speed & $1800 \mathrm{RPM}$ \\
$\mathrm{CO}, \mathrm{CO}_{2}, \mathrm{O}_{2}$ & $0.2 \%, 11 \%, 0.7 \%$ \\
$\mathrm{NO}_{\mathrm{x}}$ & $3300 \mathrm{ppm}$ \\
$\mathrm{Relative} \mathrm{Air/Fuel} \mathrm{Ratio}$ & $1.0[-]$ \\
Exhaust temperature & $630 \mathrm{deg} \mathrm{C}$ \\
Location of Peak Pressure & 10 deg ATC \\
$10-90$ Burn Time & 32 degrees \\
\hline
\end{tabular}

From the in-cylinder pressure traces which were recorded during testing, extremely useful information may be obtained that provides insight into the combustion characteristics as well as the combustion stability (COV). A typical combustion pressure trace is shown in Figure 8.

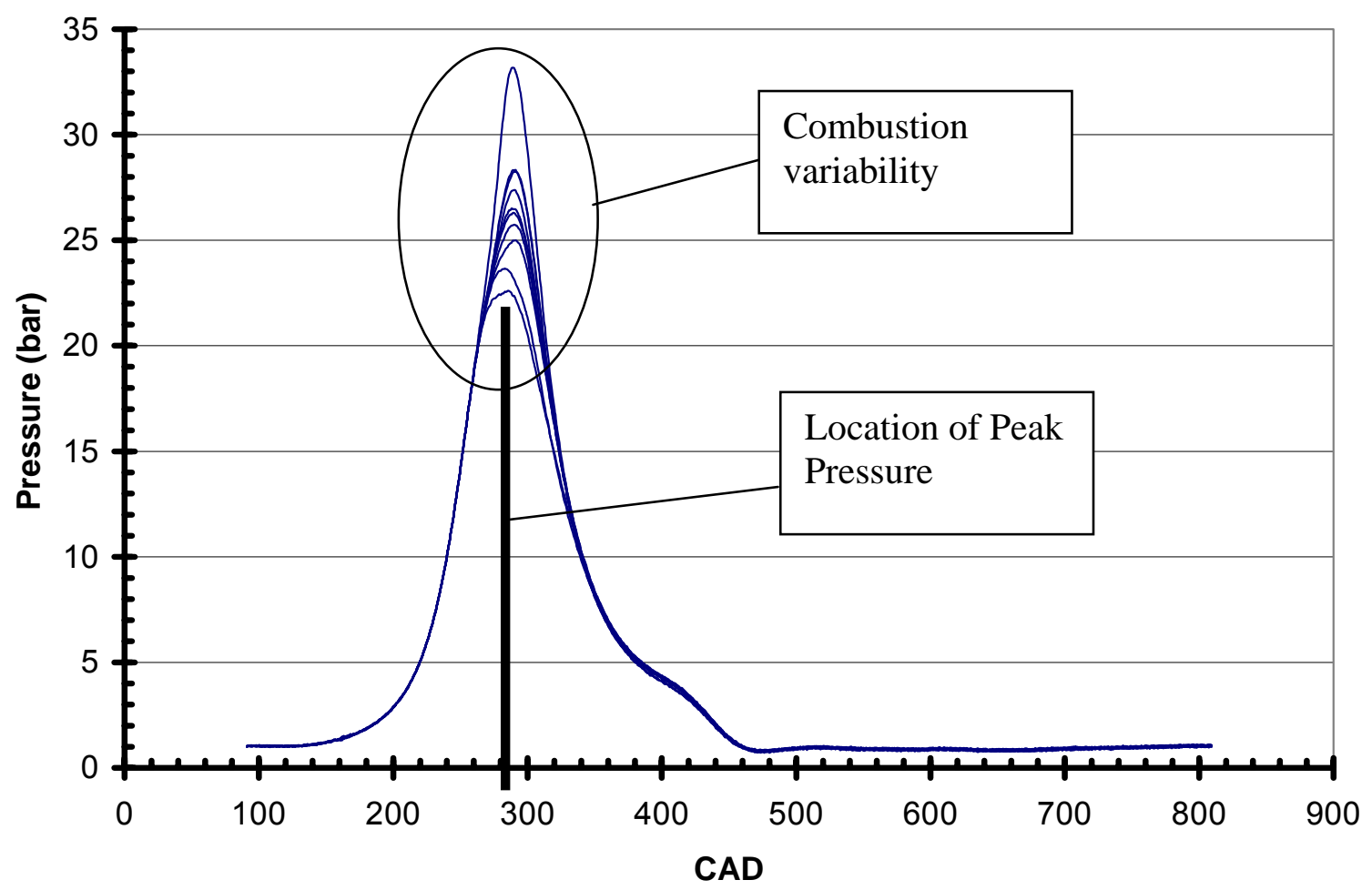

Figure 8. Representative Pressure Traces from Ten Consecutive Cycles 
As may be seen even from the limited number of cycles (10 are shown), there are variations in the pressure curve, especially noticeable at the peak conditions. IMEP COV is a measure of the combustion differences, as evidenced by the cycle-to-cycle variability of the pressure trace. For the graph shown in Figure 8, IMEP COV was 6\%. The location of peak pressure (LPP) is an essential tool when comparing $\mathrm{NO}_{\mathrm{x}}$ levels, as the phasing (the results of which are reflected in the LPP) affects the $\mathrm{NO}_{\mathrm{x}}$ production. During this experimental effort, care was taken to keep LPP as constant as realistically possible.

The lean limit capability and the $\mathrm{NO}_{\mathrm{x}}$ emission of the baseline engine (without HALO) are summarized in Figure 9 and Figure 10. The engine was leaned out by fuel reduction, so the power output dropped as the engine became more fuel-starved (the baseline engine was not boosted, so power output could not be kept fixed).

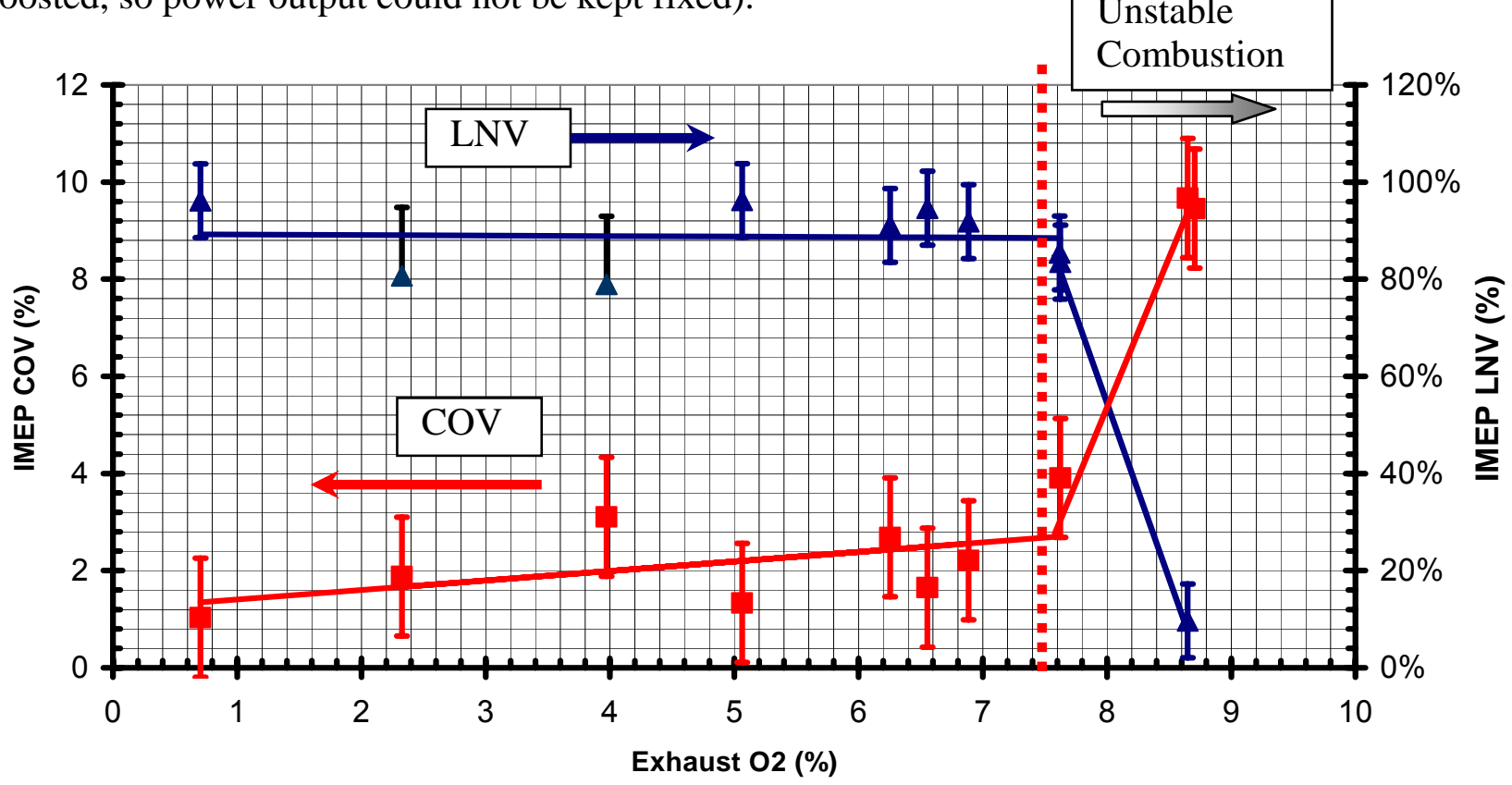

Figure 9. Baseline Engine Lean Operation Capability

Figure 9 shows a plot of IMEP LNV and IMEP COV versus Exhaust $\mathrm{O}_{2}$ concentration. IMEP is a measure of normalized torque output calculation from the in-cylinder pressure. A stable IMEP value thus indicates stable and repeatable combustion. For stable engine operation, a typical value of IMEP COV is less than $8 \%$, which at the last point, there is an obvious rise in COV. The LNV, which is a measure of the minimum IMEP over the 500 compared cycles, should be above $75 \%$, and at the last operating point is down to $10 \%$. Thus, the lean operating limit of the baseline engine is around an excess air concentration of $7.5 \% \mathrm{O}_{2}$ in the exhaust. The values shown on the graph are averaged over all eight engine cylinders due to the fact there were no cylinder outliers as was the case with the hydrogen supplementation (see HALO Testing section). 


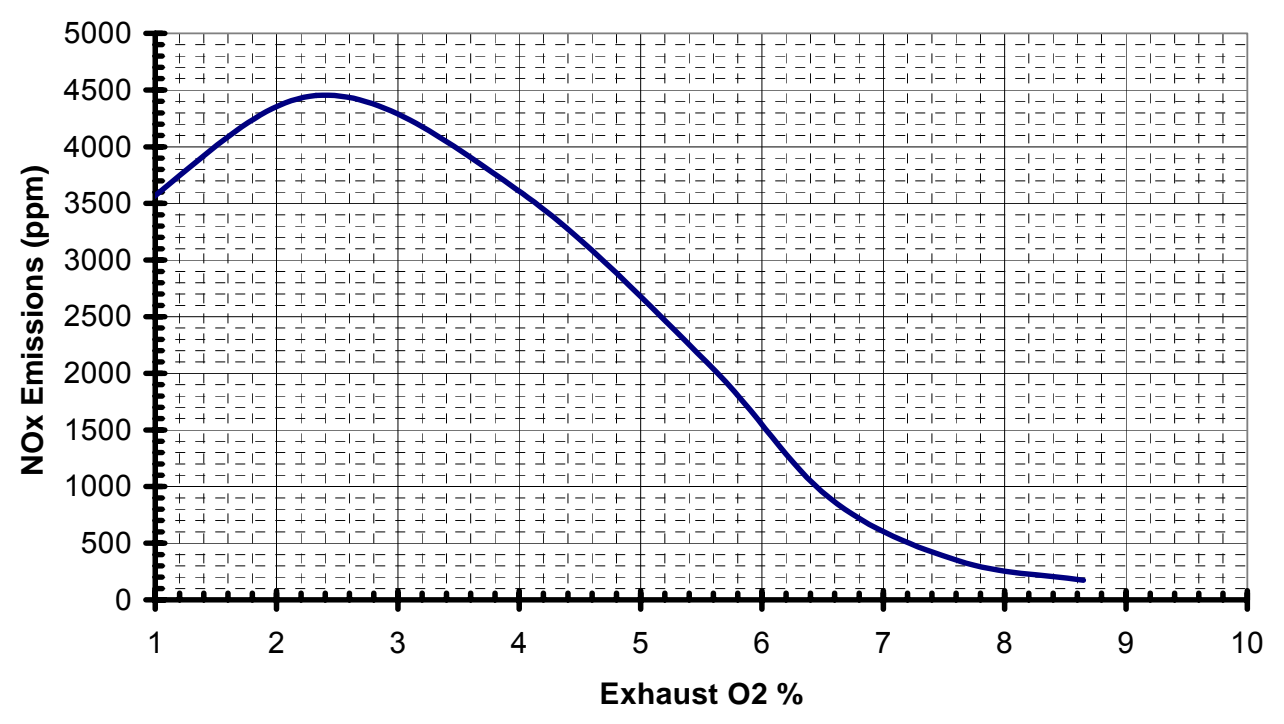

Figure 10. Baseline Engine NOx Emissions

As shown in Figure 10, the $\mathrm{NO}_{\mathrm{x}}$ drops dramatically as the engine become more fuel-starved. As the fueling is decreased to the engine, there is extra oxygen in the cylinder, which makes the reduction of $\mathrm{NO}_{\mathrm{x}}$ difficult, causing the increase shown at the beginning of the curve. The chemistry dominates initially, as reduction does not occur normally in a lean environment, but as the mixture is further leaned out, the extra air causes the peak in-cylinder temperatures to decrease, lowering the $\mathrm{NO}_{\mathrm{x}}$ formation (the temperature effects dominate the chemical effect). All NOx emissions have been humidity corrected using the procedure described in Appendix A.

From the pressure trace, analysis may be done to determine the approximate amount of fuel burned. This results in a mass fraction burned curve. The Adapt software uses the following equation in evaluating the mass fraction burned, which is known as the Rassweiler/Withrow method $^{22}$ :

$$
M F B=\left[P(i)-\left(\frac{V_{(i-1)}}{V(i)}\right)^{\gamma} P_{(i-1)}\right] \frac{V_{(i-1)}}{V_{d}}
$$

A typical example is shown in Figure 11. This analysis is extremely useful to compare burn times, as well as time of ignition. The 10-90 burn time is shown on the curve; the other burn times touched upon in this report (e.g., 00-10) apply the same principle as shown on the graph.

${ }^{22}$ MTS Systems Corporation. "Combustion Analysis Basics" Redline Adapt CAS Workshop 


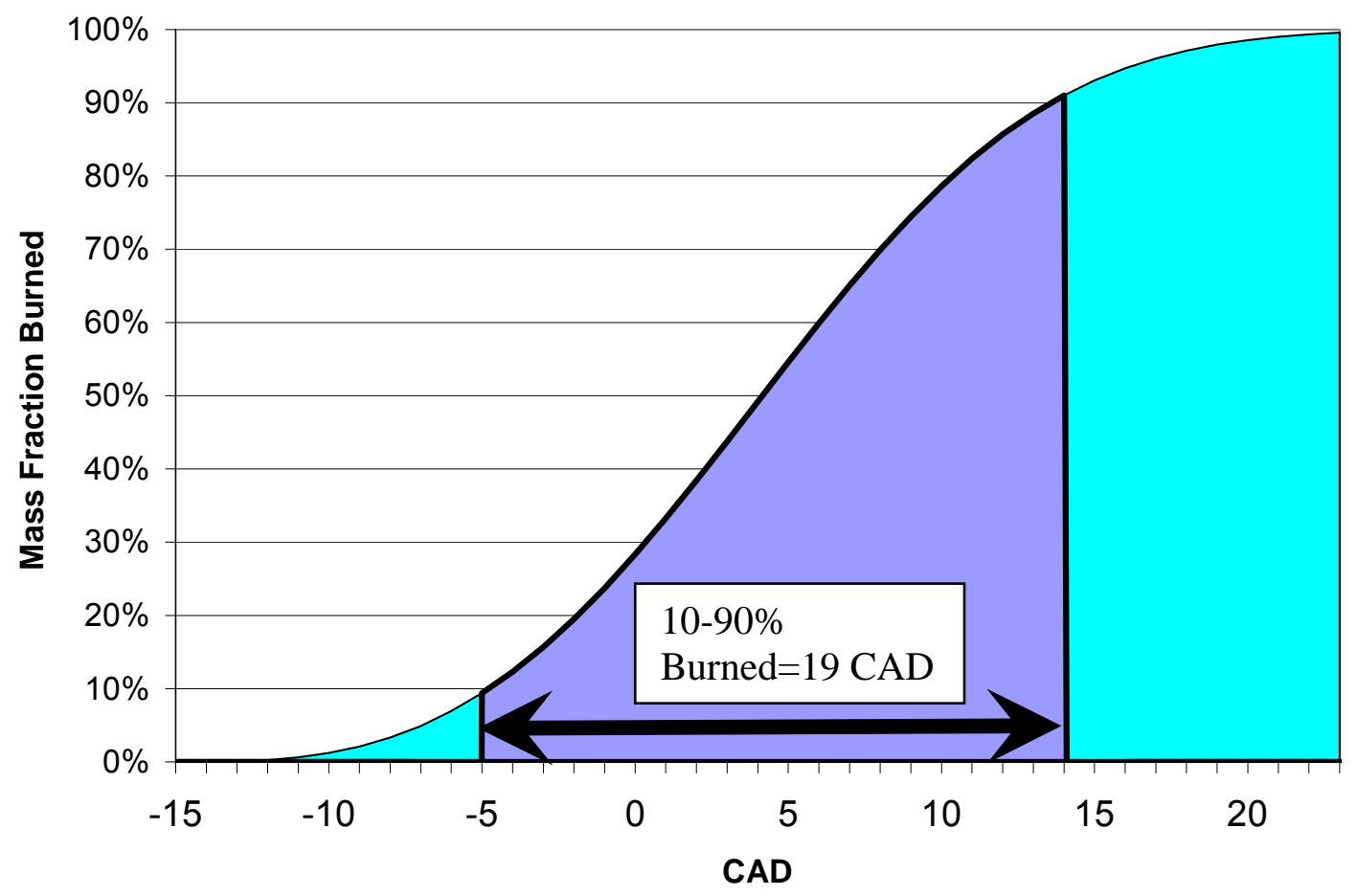

Figure 11. Typical Mass Fraction Burn Curve with 10-90 Highlighted

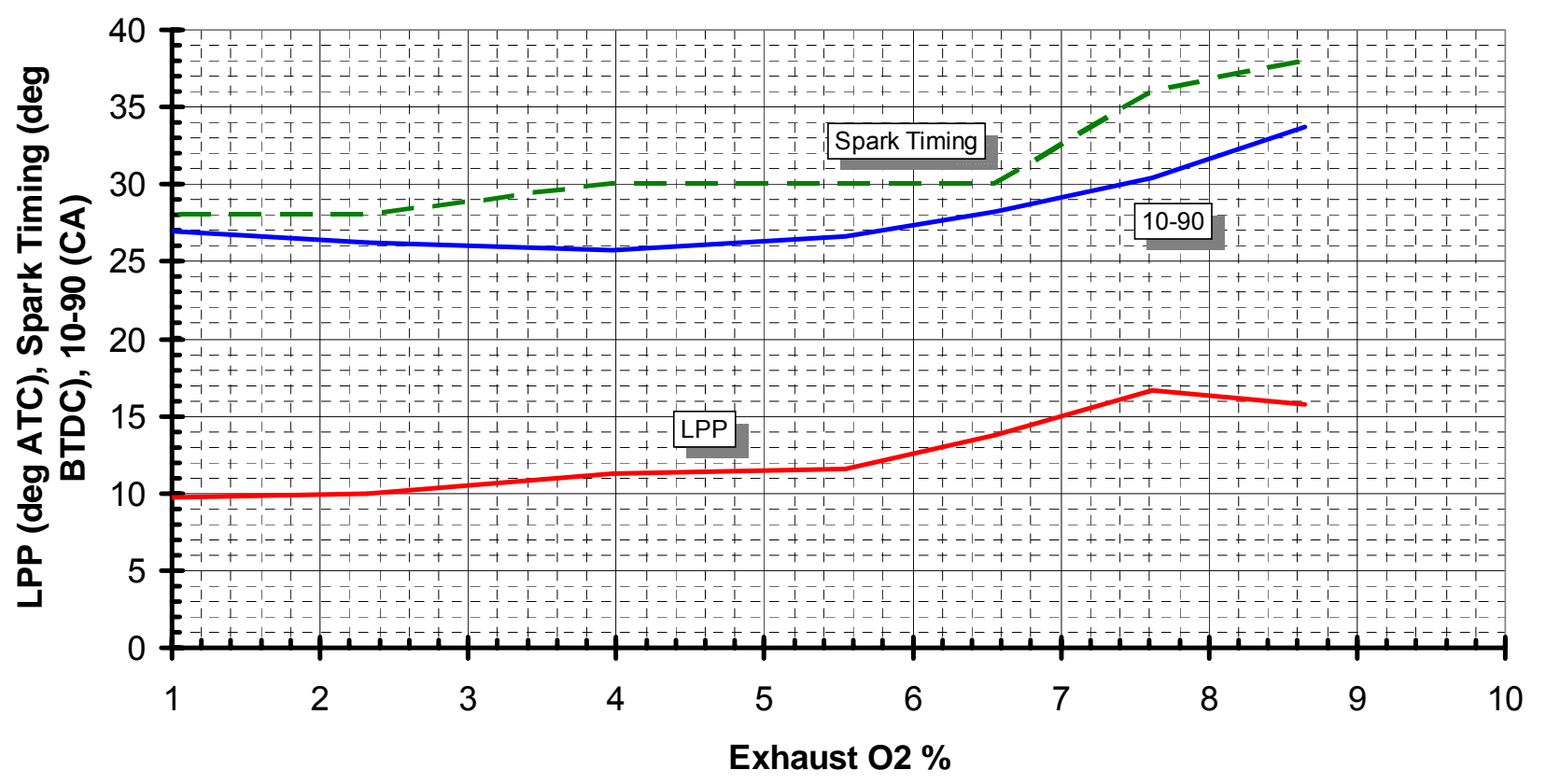

Figure 12. Baseline Engine Results for LPP and 10-90 Burn Times 
Figure 12 shows location of peak pressure (LPP), Spark Timing, and, 10-90 burn time for the baseline case. As the air/fuel mixture becomes leaner, attempts are made to keep the LPP in a constant location by advancing the spark timing, but the LPP still shifts 6 degrees even though the spark timing was advanced 10 degrees over the interval shown. The reason for this may be seen by the increase in the 10-90 burn times - the leaner mixture reduces the flame speed noticeably. In addition to the 10-90 burn time, the ignition time (the 00-10) increases as the mixture is leaned out, as well as other burn times, as shown Figure 13.

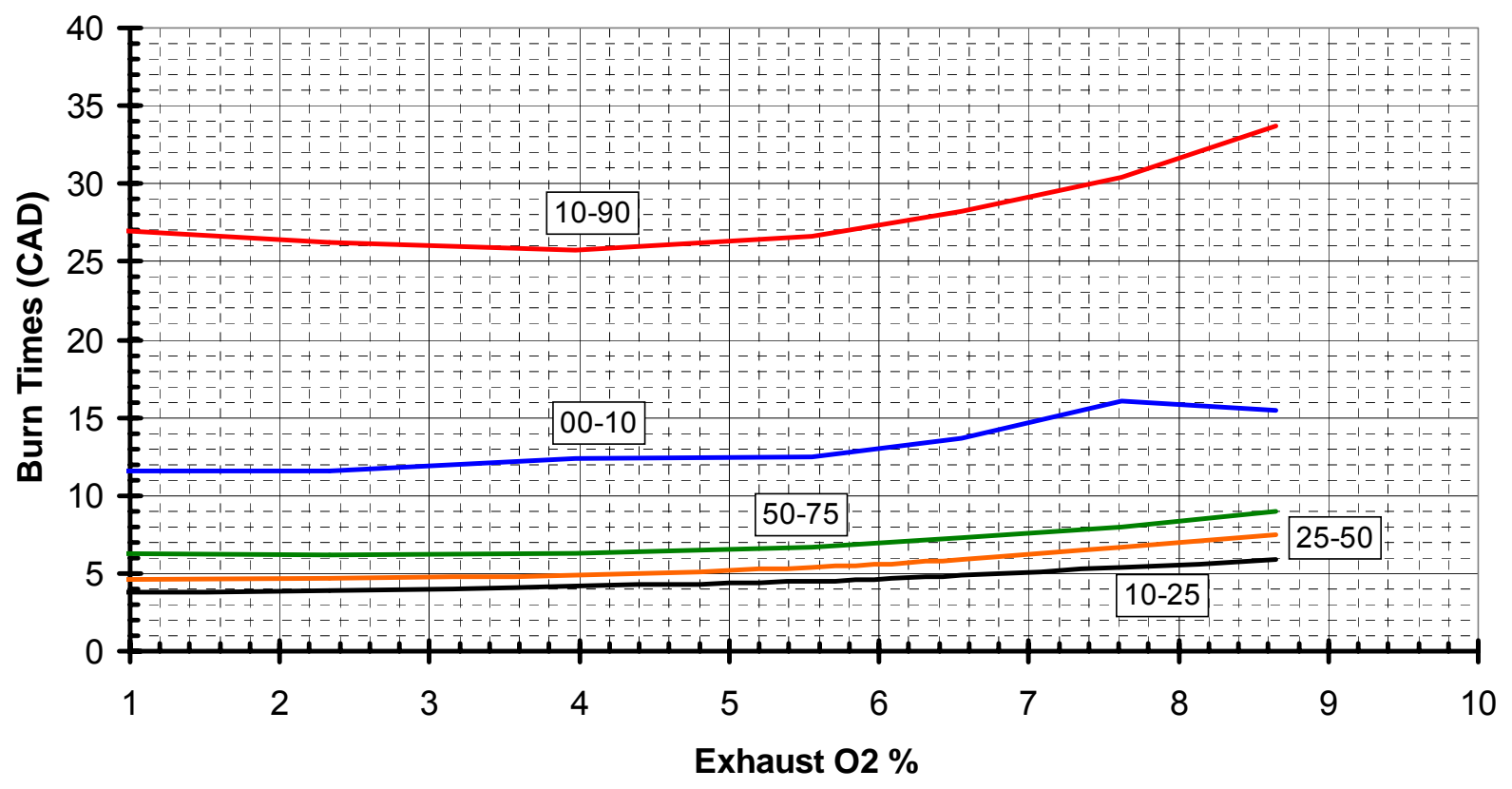

Figure 13. Baseline Burn Times

The driver for adding hydrogen is obvious from these two figures: hydrogen greatly increases the flame speed. A comparison of hydrogen properties to natural has properties is shown Table 11 .

Table 11. Property Comparison of Natural Gas and Hydrogen ${ }^{23}$

\begin{tabular}{|l|cc|}
\hline \multicolumn{1}{|c|}{ Parameter } & Natural Gas & Hydrogen \\
\hline LHV (MJ/kg) & 42 & 120 \\
Lower Flammability Limit (Vol \%) & 5 & 4 \\
Higher Flammability Limit (Vol \%) & 15 & 75 \\
$\begin{array}{l}\text { Stoichiometric Ignition Energy } \\
\text { (mJ) }\end{array}$ & 0.34 & 0.019 \\
$\begin{array}{l}\text { Stoichiometric Laminar flame } \\
\text { speed @ 1 atm (cm/sec) }\end{array}$ & 40 & 200 \\
\hline
\end{tabular}

${ }^{23}$ Glassman, Irvin. Combustion. $3^{\text {rd }}$ Edition. Academic Press, San Diego, 1996. 
As may be seen from Table 11, hydrogen has much wider flammability limits and a much lower ignition energy than that of natural has, which will nicely offset the trends shown in Figure 14 of the 10-90 burn time increasing as well as the 00-10 time taking longer.

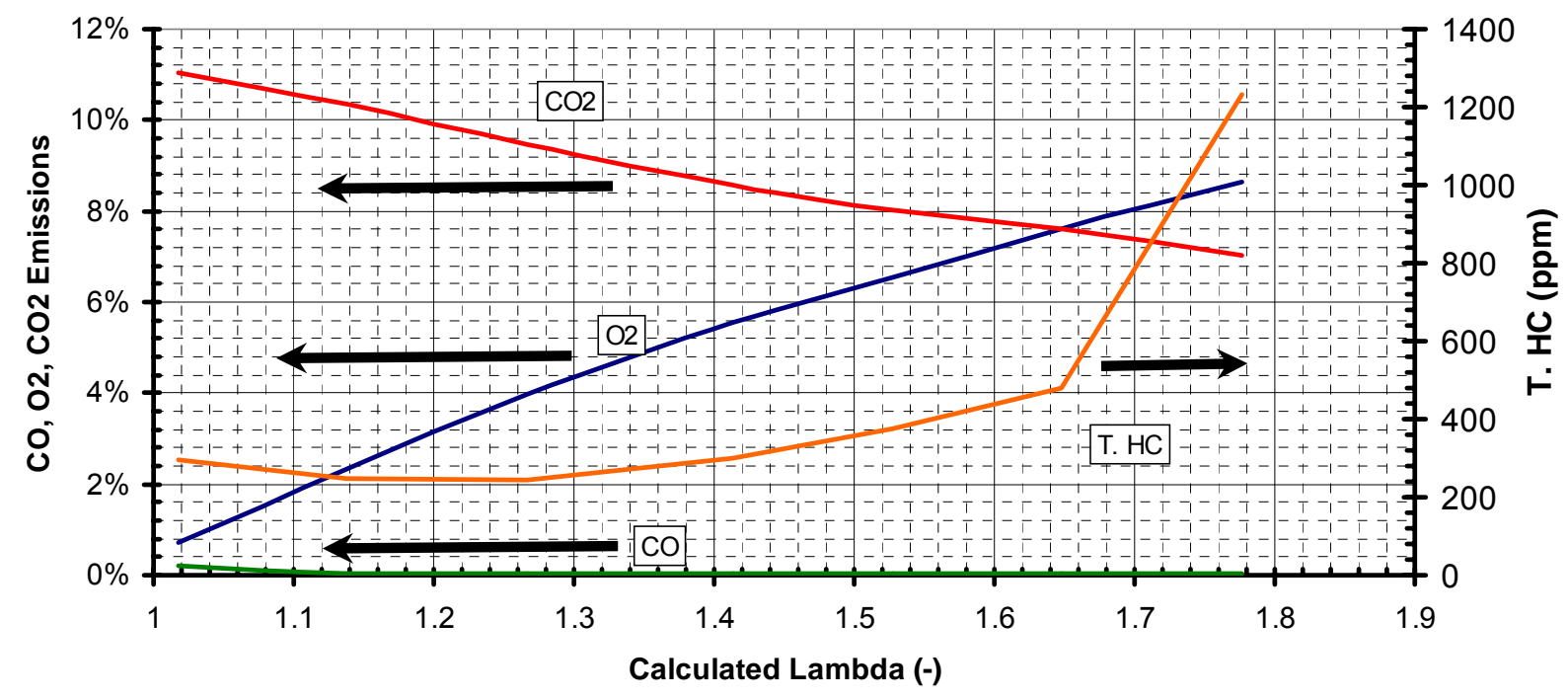

Figure 14. Baseline Emissions as a Function of Relative Air/Fuel Ratio

Figure 14 shows the baseline emissions from the engine. The x-axis shows the calculated lambda, which is calculated from the exhaust emissions using the Spindt method described in Appendix A. Since all of the points are lean, the CO produced from the engine is negligible. The excess oxygen also increases with increasing relative air/fuel ratio. The total hydrocarbons, shown as the curve labeled T.HC, increase at the leaner air/fuel ratios due to decrease in temperature. Increased temperature is needed to foster HC oxidation.

Using the Adrenaline Research Spark Ignition system, data was taken during the lean scoping exercise. This is shown in Figure 15. This is the measured ion current which is measured by using a constant voltage across the electrode gap of the spark plug. This ion current is a useful diagnostic tool for this exercise, as may be seen from the following consideration of the plots. 

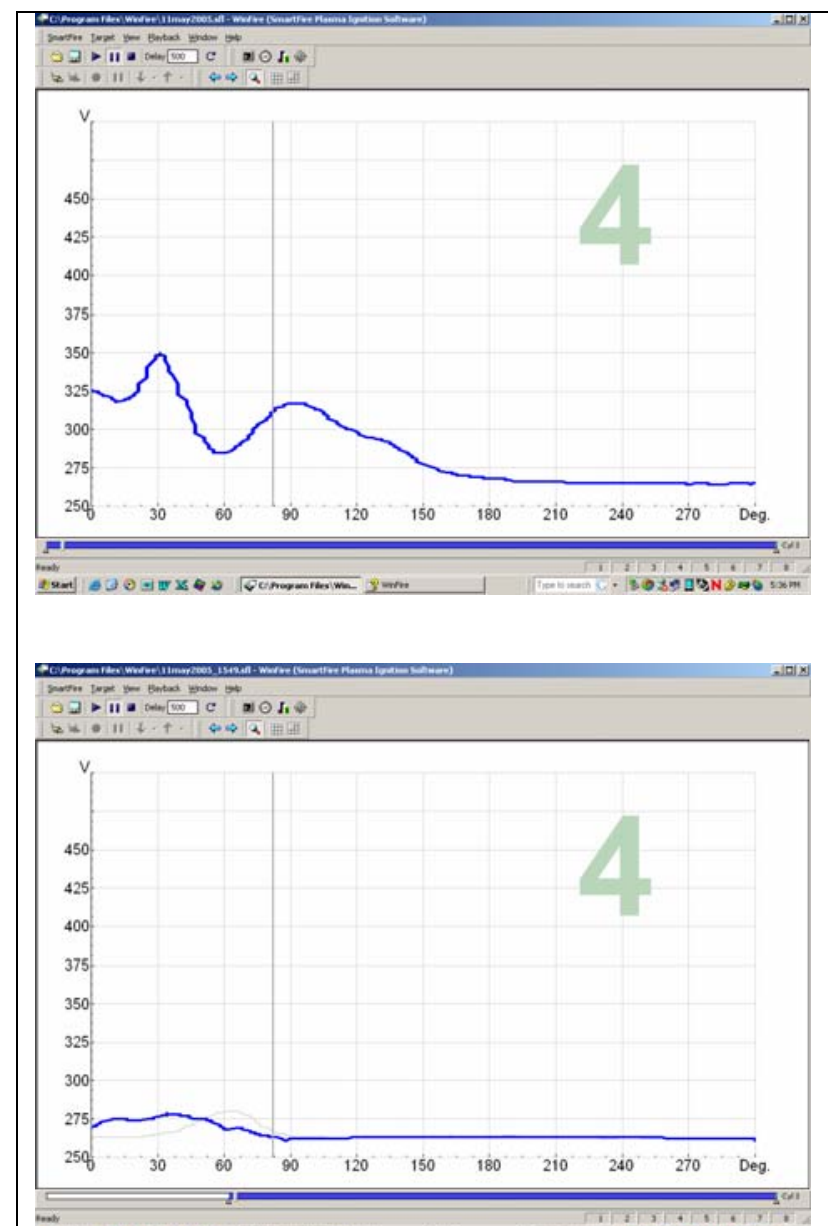

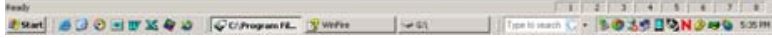

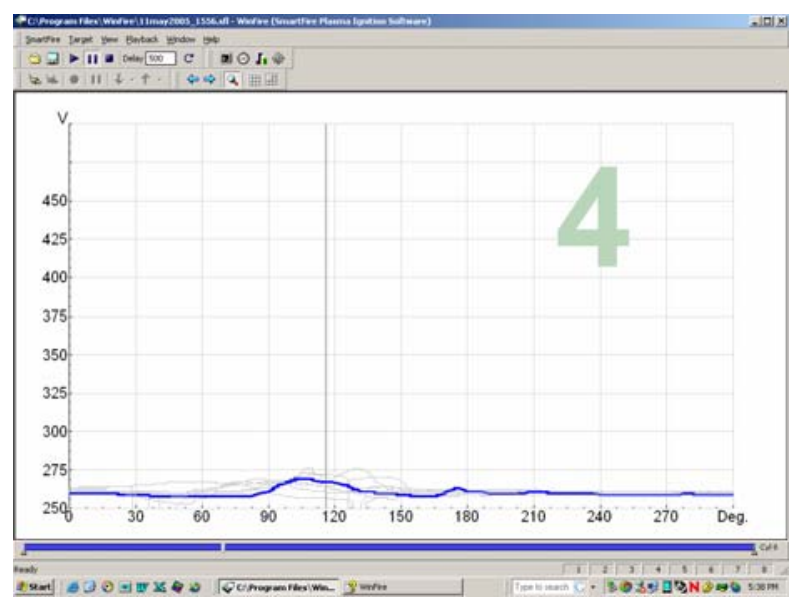

This is for the stoichiometric operating point. The ion current can be seen to have two peaks - the first peak is due to chemi-ionization, and the second peak is due to thermal ionization.

The operating condition shown here is at $\sim 7.5 \% \mathrm{O}_{2}$ in the exhaust. It is of note that the second peak is missing, and the first peak is substantially less. This is due to the extremely dilute mixture the engine is operating at.

This operating condition is the leanest point taken. The initial peak is lower and occurs later than that of the condition shown above. Hydrogen supplementation will give much better combustion, giving higher ion currents as feedback.

Figure 15. Baseline Ion Current Results from Cylinder \#4 


\section{HALO Testing}

The next logical phase of testing according to the experimental plan was to build upon the baseline by the addition of hydrogen. Table 12 provides a summary of the matrix of planned scoping test conditions. The following paragraphs provide discussion of this test matrix.

Table 12. HALO Test Matrix

\begin{tabular}{|c|l|}
\hline Task & \multicolumn{1}{c|}{ Description } \\
\hline $\mathbf{1}$ & $\begin{array}{l}\text { Baseline Test. Run engine at rated IMEP, 1800 RPM, fully warmed up with Adrenaline } \\
\text { Research system installed. From previous testing, the spark timing will be } 28 \text { deg } \\
\text { BTDC. Result: Quality Check }\end{array}$ \\
\hline $\mathbf{2}$ & $\begin{array}{l}\text { HALO Testing. Mapping of performance and emissions response to various levels of } \\
\text { hydrogen supplementation: } \\
\text { Engine brought to fully warmed-up conditions (90 deg C coolant/lubricant temperatures) } \\
\text { @ 1800 RPM. Using the supercharger to supplement the engine airflow and minimize } \\
\text { power loss, hydrogen supplementation was varied to establish operating limits at } \\
\text { standard spark ignition energy. The Adrenaline system was used for experimental } \\
\text { consistency, with care shown to keep the location of peak pressure relatively constant. } \\
\text { Result: } \mathbf{H}_{2} \text { Supplementation Effects }\end{array}$ \\
\hline
\end{tabular}

Task 1 established a baseline for the engine at the rated standard design operating conditions. This baseline engine operating condition was repeated at the beginning of each test day to ensure the integrity and consistency of the experimental setup, instrumentation, and engine performance.

Task 2 established the feasibility of the HALO process. The engine indicated mean effective pressure (IMEP) was kept relatively constant at the maximum level for the test by varying the discharge pressure of the supercharger. Because combustion phasing affects engine $\mathrm{NO}_{\mathrm{x}}$ production, fixed combustion phasing as determined by the location (crank angle) of peak cylinder pressure was used to normalize the test data. Exhaust $\mathrm{O}_{2}$ concentration was used as the test variable to avoid confusion regarding the definition of relative air/fuel ratio from the addition of a secondary fuel (hydrogen).

Hydrogen was introduced pre-throttle so that the throttle could be used as a mixing device to mix the hydrogen well with the air. The intake on the engine is such that the hydrogen/air mix would go through the throttle into the intake plenum, then from there be drawn into individual cylinder runners ending at each individual cylinder. An overhead schematic of the engine and the location of the individual cylinders is shown in Figure 16. Please note the intake runners are not shown for the sake of visual clarity. The intake, as labeled on the Figure, is after the throttle, and is centered among the engine cylinders. The plenum is shown as the dotted line on the figure, and is common to all cylinders. 


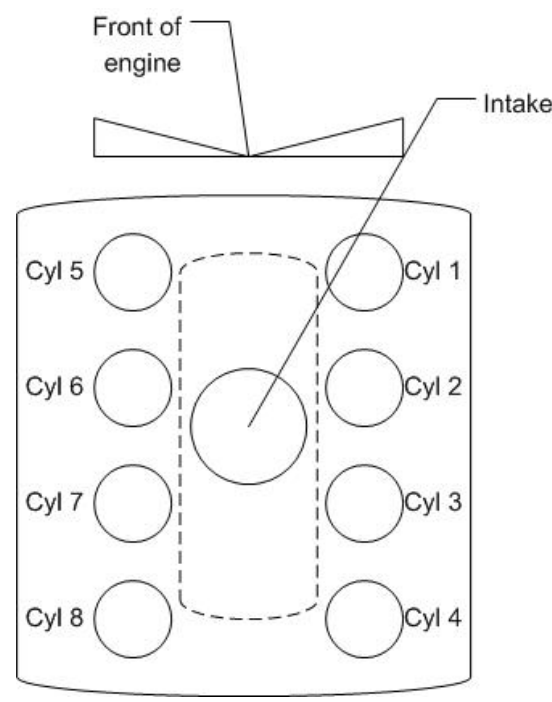

Figure 16. Top View Engine Schematic (Note: intake runners not shown for visual clarity)

Typically with internal combustion engines, there may be cylinder-to-cylinder variation due to minor differences in air flow and fuel flow to each individual cylinder. These differences will lead to minor differences in cylinder torque output and torque fluctuations, but in a welldesigned engine should not exceed $\pm 10 \%$ difference between cylinders over all operating ranges and should be much lower during typical engine operation.

As the hydrogen is being turbulently mixed via the throttle, it is important to note the combustion variability of the engine without hydrogen as well as the combustion variability with hydrogen. This is shown in Figure 17.

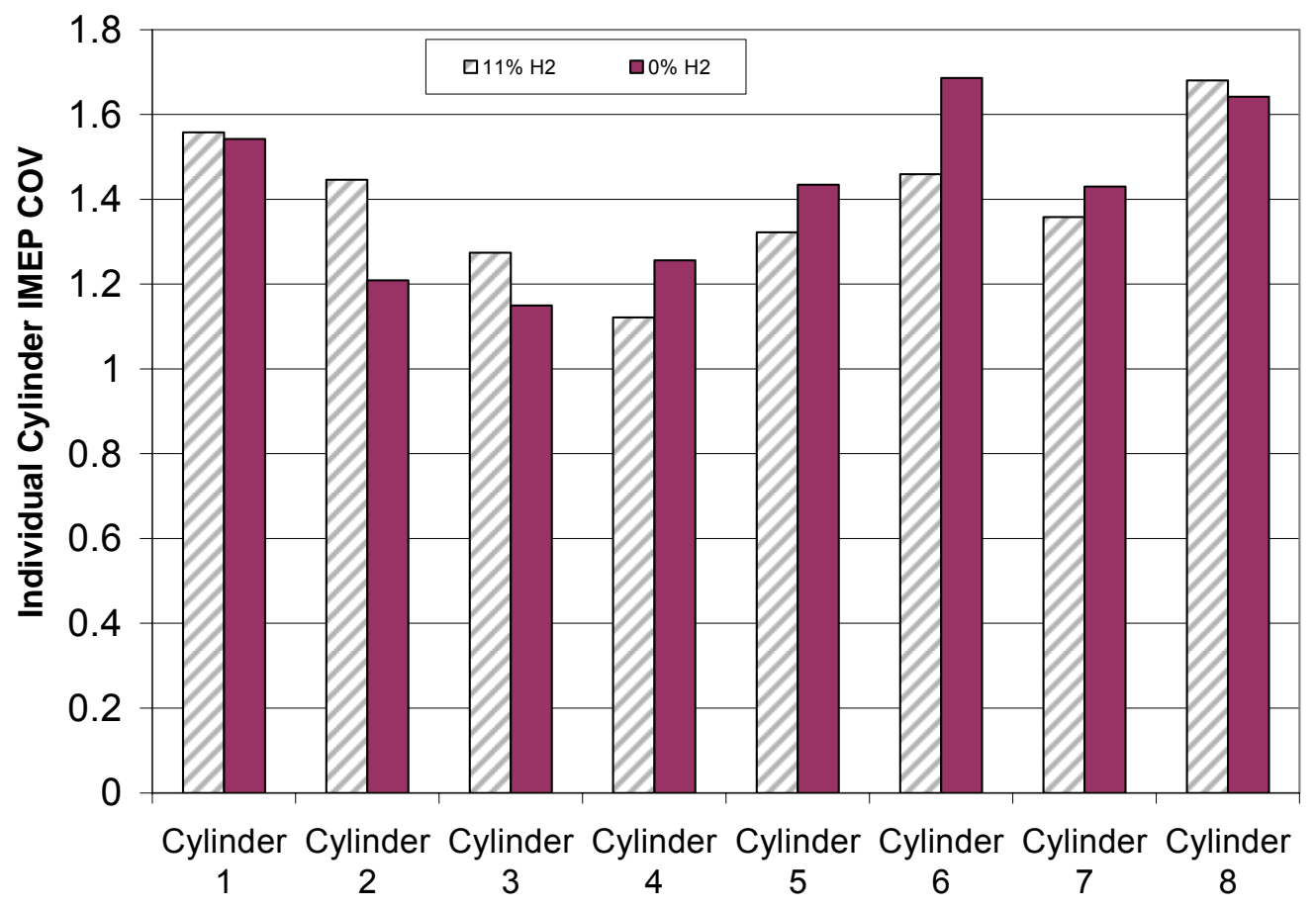

Figure 17. Cylinder-to-Cylinder Distribution of Torque Fluctuation 
The two cases shown here are very stable operating points - they should not be compared to one another, as the overall air/fuel ratio is different for each case, but should be compared across the engine for each case individually. Similar shapes are seen across the engine: the torque fluctuations are lowest for cylinders 3 and 4 for both the hydrogen-supplemented and the NGonly case. This suggests that these two cylinders receive an air/fuel mixture that is less lean (lean meaning excess air over what is needed for complete fuel oxidation) than the other cylinders, as combustion tends to be less stable (leading to a higher IMEP COV) at leaner operating conditions. Thus, these two cylinders receive more fuel than the others, but the combustion is still excellent for all cylinders (an IMEP COV of less than 8\% constitutes repeatable combustion, and these values are all below $2 \%$ ). This was a stable operating point, but as the engine is pushed closer to the operating limits, that minor difference is enough to cause those marginal cylinders to be unstable.

This is shown in the following Figure, where it was clear that two of the cylinders were not keeping within the threshold of $\pm 10 \%$ across the engine. This is shown below in Figure 18 .

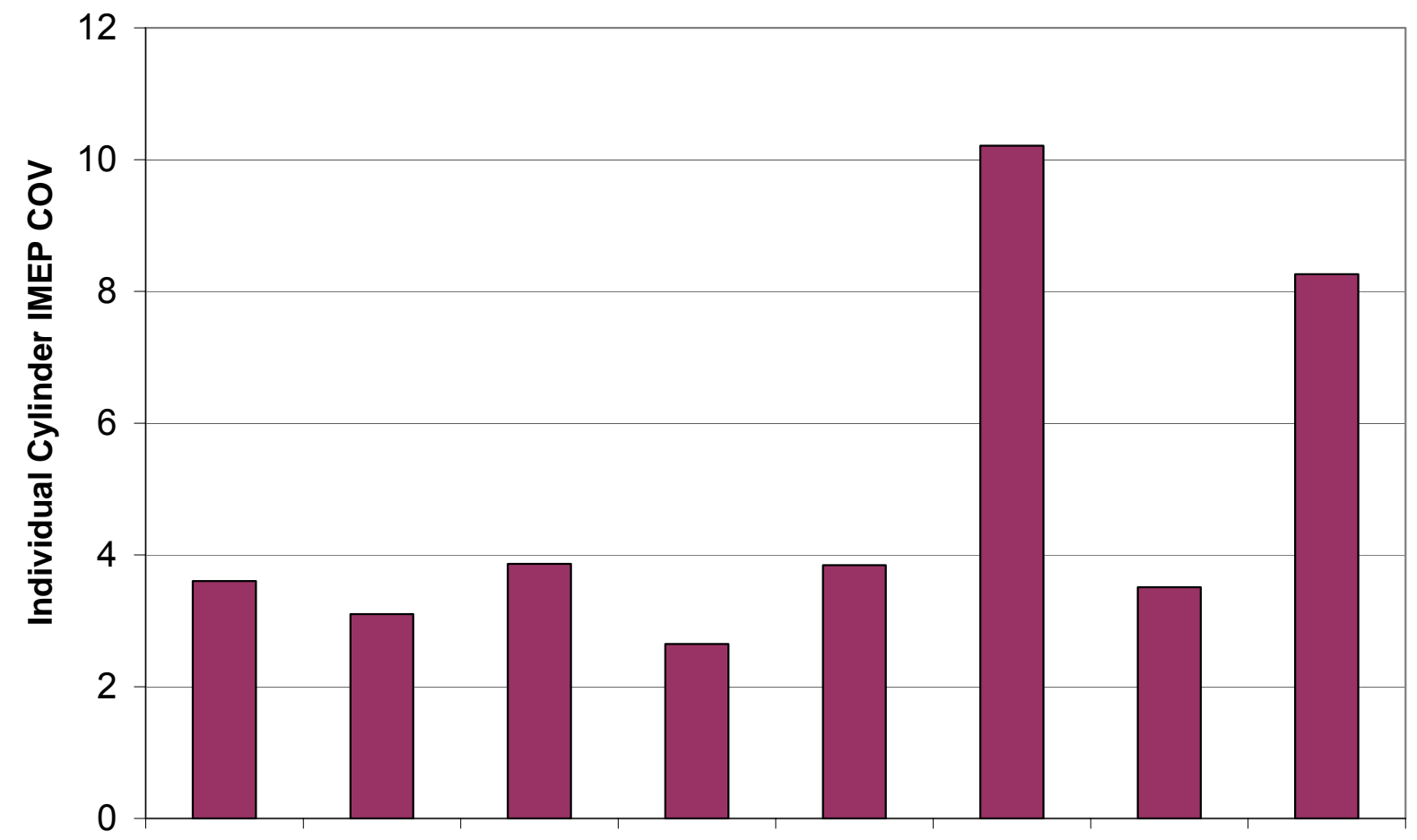

Cylinder 1 Cylinder 2 Cylinder 3 Cylinder 4 Cylinder 5 Cylinder 6 Cylinder 7 Cylinder 8

Figure 18. Cylinder-to-Cylinder Variation for $13 \% \mathrm{H}_{2}$ Supplementation

As is evidenced by the above Figure, cylinders 6 and 8 are above the 10\% cylinder-to-cylinder difference threshold. A Grubbs outlier analysis of the available data clearly eliminates cylinder 8 , with several runs having a $\mathrm{Z}$ value (the difference of the average value and the individual point divided by the standard deviation) over the critical $Z$ value of 2.13 (for 8 samples). Cylinder 6 had a maximum $\mathrm{Z}$ value of 1.98 , so thus comes extremely close to the critical value. However, 
engineering judgment was used to say that this cylinder was not performing in a representative manner, as it exceeds the $\pm 10 \%$ cylinder-to-cylinder variation threshold and was not consistent test to test. Thus, in the data presented throughout the rest of the report, the values are averaged over cylinders 1,2,3,4,5, and 7 to ensure level comparisons. Inclusion of cylinder 6 affects two of the tabulated results shown in Table $15\left(13 \% \mathrm{H}_{2}\right.$ is required for $16 \%$ ignition energy reduction, and $14 \% \mathrm{H} 2$ for $22 \%$ ignition energy reduction - see Appendix D), but the above reasoning still strongly suggests that it should not be included. The reason for these two cylinders to be on the edge of the data is seen from the baseline engine torque fluctuations shown in Figure 17. These two values have the highest IMEP COVs, suggesting that they have the leanest air/fuel mixture. Consequently, when the operating condition is pushed to the limits of operation, these two cylinders are slightly over the edge of the operational limit, while the rest of the engine is operating in a more stable regime.

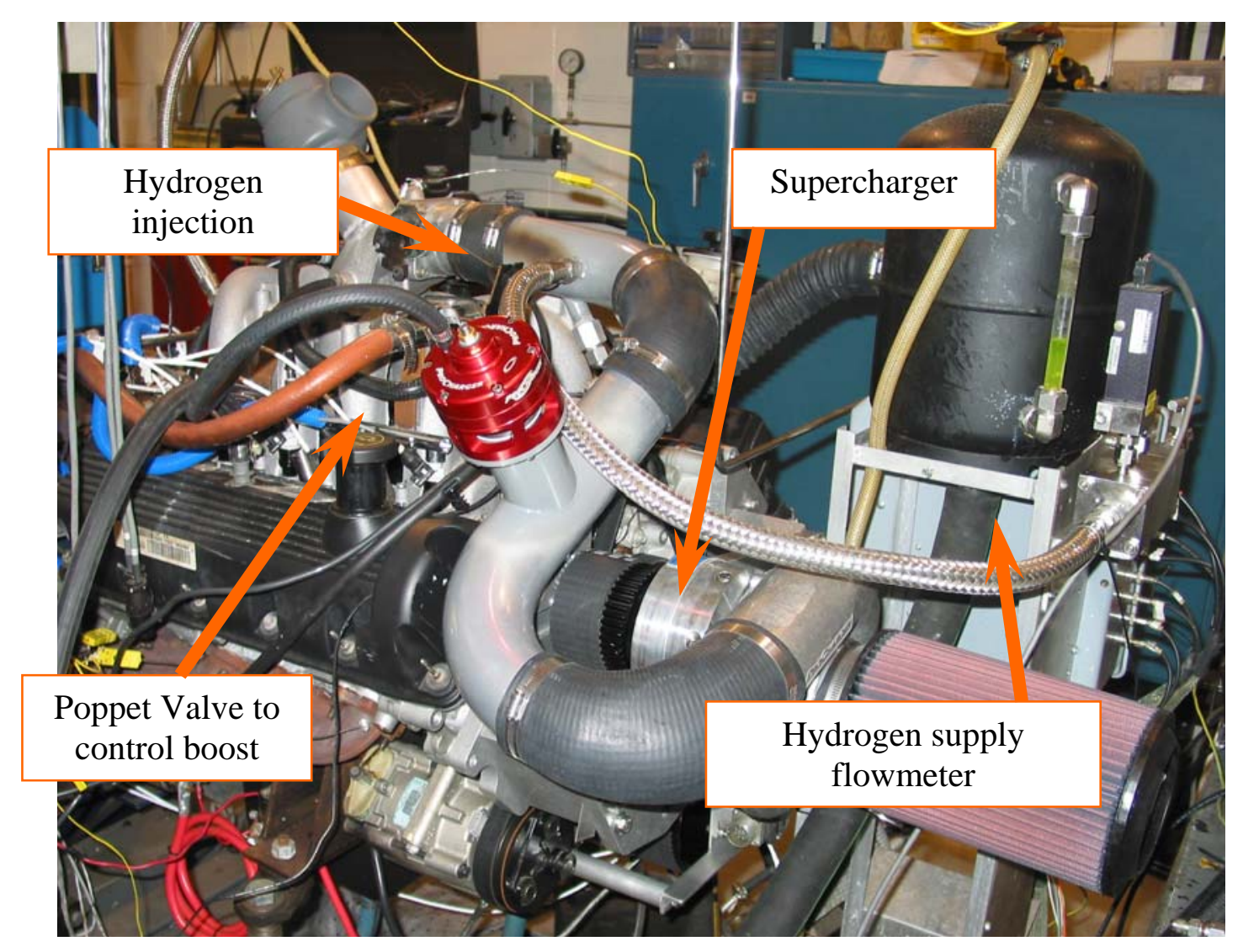

Figure 19. Experimental Setup

For convenient reference, a photograph of the engine setup is shown in Figure 19, displaying the labeled supercharger and poppet valve used to increase engine output while operating at the ultra-lean air/fuel ratios needed for this project.

The supercharger used was a Procharger model F-1R, rated at a maximum flow of $2000 \mathrm{cfm}$ and a maximum boost of 38 psi. 


\subsection{HALO Test Results and Conclusions}

For the HALO testing, the power output was fixed at $38 \mathrm{~kW}$. This decrease from the baseline condition is due primarily to the ultra-lean operating conditions. Without the addition of the supercharger, however, the power output would be even $40 \%$ lower, so the supercharger was crucial. IMEP was fixed throughout all testing, so results can be compared and conclusions can be drawn.

Key results from the HALO tests are summarized in Table 13.

Table 13. General Summary of Hydrogen Supplementation Results

\begin{tabular}{|c|c|c|c|}
\hline $\begin{array}{c}\text { Exhaust } \mathbf{O}_{2} \\
\text { Concentration }\end{array}$ & $\begin{array}{c}\text { Hydrogen } \\
\text { Supplementation } \\
\text { (LHV H2/LHV CH4) }\end{array}$ & $\begin{array}{c}\text { Measure of } \\
\text { Combustion } \\
\text { Variability (IMEP COV) }\end{array}$ & Engine out NO (ppm) $^{(\mathbf{p} \text { ) }}$ \\
\hline \hline $7.5 \%$ & $0 \%$ & $4 \%$ & $400 \mathrm{ppm}$ \\
$10 \%$ & $8 \%$ & $6 \%$ & $10 \mathrm{ppm}$ \\
$10 \%$ & $14 \%$ & $3 \%$ & $15 \mathrm{ppm}$ \\
\hline
\end{tabular}

Table 13 represents the general summary of the operating conditions made possible in this set of scoping experiments. Table 13 shows that from purely a hydrogen supplementation/ $\mathrm{NO}_{\mathrm{x}}$ standpoint, the $8 \%$ supplementation rate gives adequate $\mathrm{NO}_{\mathrm{x}}$ control. Increasing the hydrogen supplementation actually has a trend of increasing the $\mathrm{NO}_{\mathrm{x}}$, most likely due to a slight increase of flame temperature from the combustion of the additional hydrogen fuel.

The lean limit capability and the $\mathrm{NO}_{\mathrm{x}}$ emission of the HALO-configured engine are summarized in Figure 20 and Figure 21.

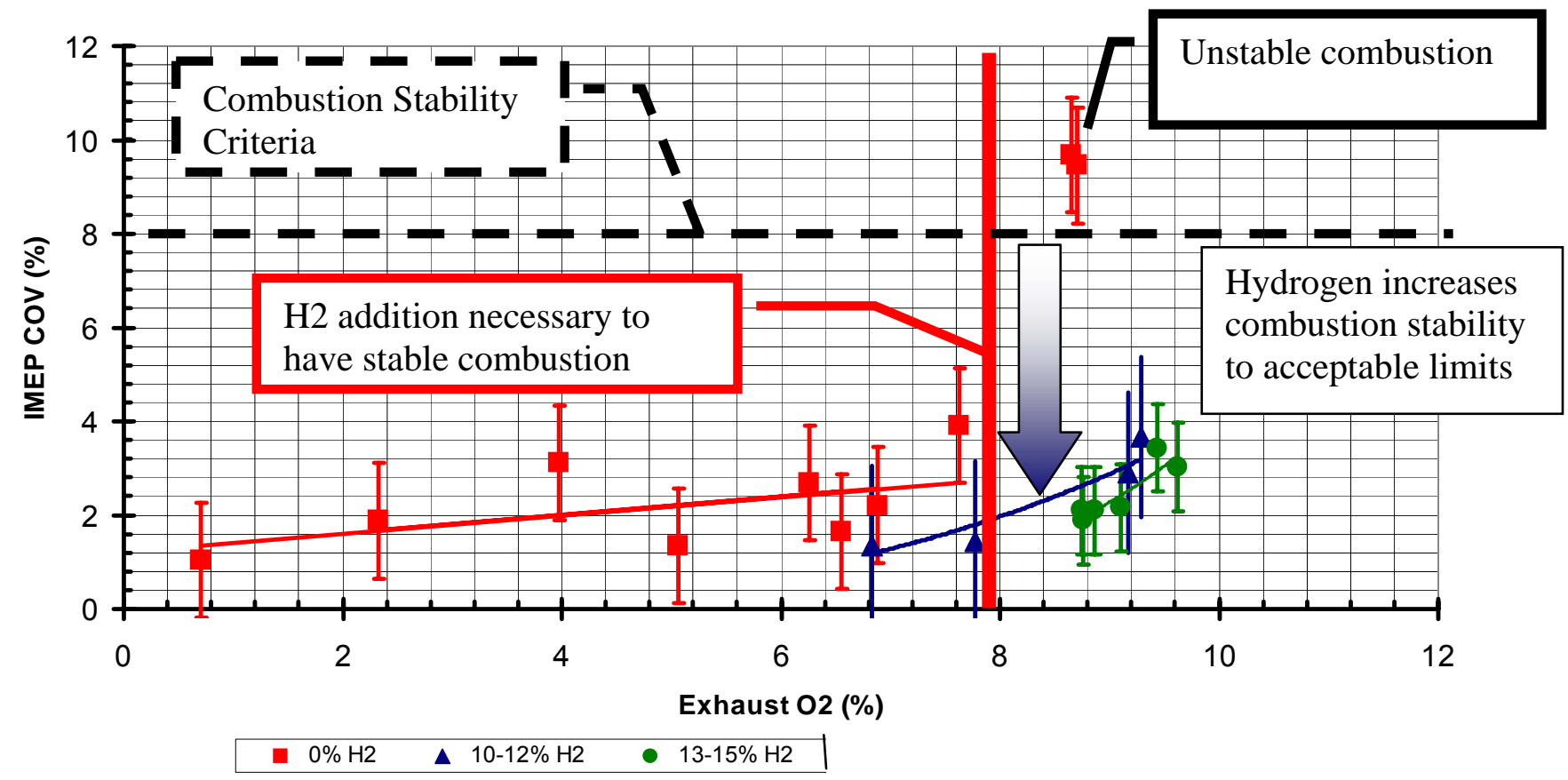

Figure 20. Baseline and HALO Engine Lean Operation Capability 
Figure 20 shows a plot of IMEP COV versus Exhaust $\mathrm{O}_{2}$ concentration. IMEP is a measure of normalized torque output calculation from the in-cylinder pressure, in this case averaged over cylinders 1,2,3,4,5,7 (see HALO Testing section for explanation). A stable IMEP value thus indicates stable and repeatable combustion. For stable engine operation, a typical value of IMEP $\mathrm{COV}$ is less than $8 \%$, which at the last point is an obvious rise in COV above the stable operating limit. Thus, the lean operating limit of the baseline engine is around an excess air concentration of $7.5 \% \mathrm{O}_{2}$ in the exhaust. The baseline case, as reported before, is shown in red squares. However, with the addition of hydrogen this operating limit is extended. The blue triangles shown in Figure 20 show the extension of lean operating limit as a shift to the right. With the addition of more hydrogen, this limit shifts to the right even further as evidenced by the green circles. ANOVA analysis of the H2-supplimented data shows that $\mathrm{F}=0.1$, which is less than $\mathrm{F}_{\text {crit }}$ of 3.7, so indeed the hydrogen supplementation brings the engine performance to a comparable level as standard non- $\mathrm{H}_{2}$ supplemented engine operation.

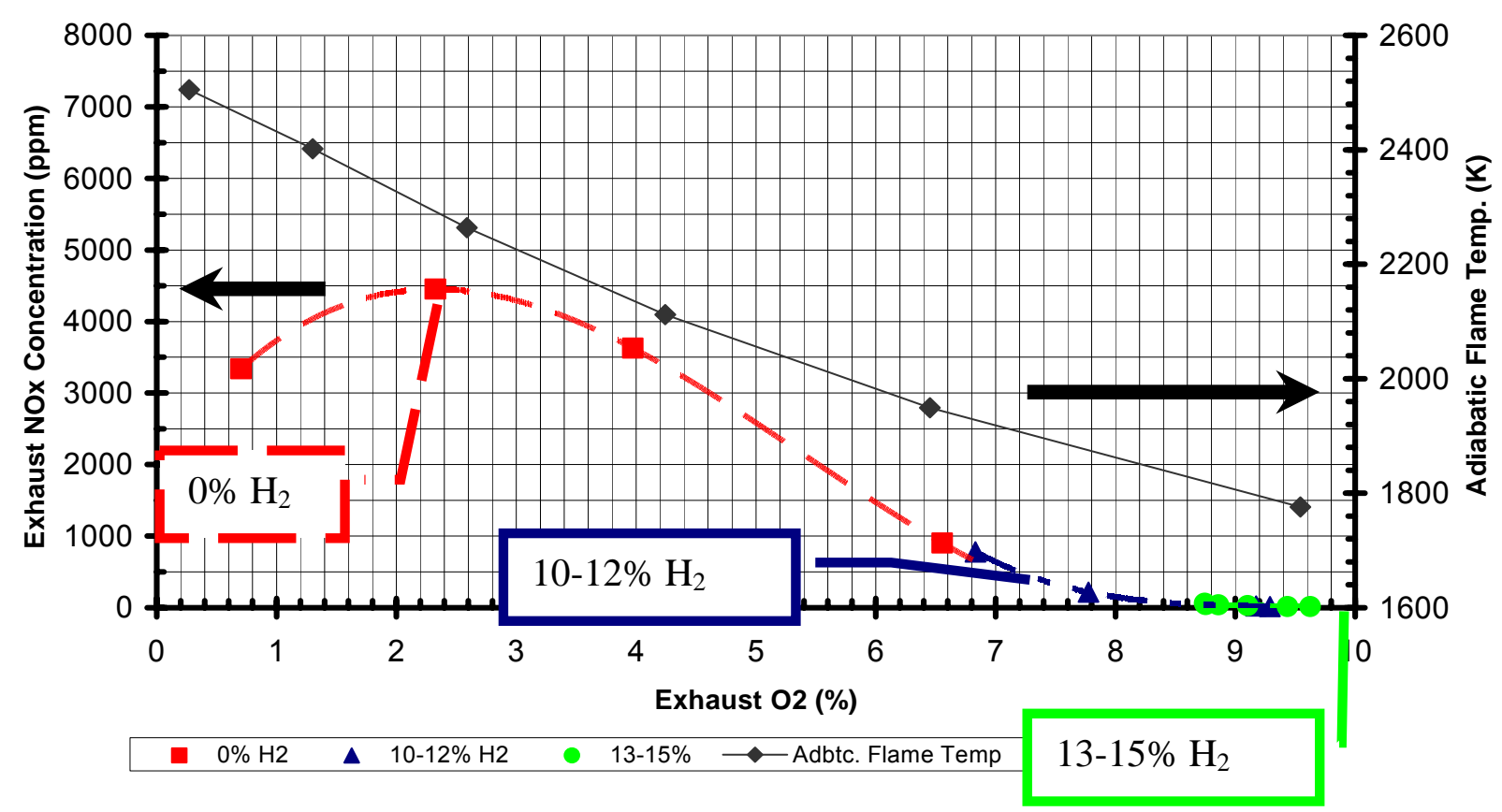

Figure 21. Baseline and HALO Engine Lean Operation Capability

As shown in Figure 21, the reduction in $\mathrm{NO}_{\mathrm{x}}$ is primarily a temperature effect, but at low $\mathrm{O}_{2}$ it is also related to oxygen availability. As the fueling is decreased to the engine, there is extra oxygen in the cylinder which initially offsets the lower peak in-cylinder temperatures causing the slight increase shown at the beginning of the curve. As the mixture is further leaned out, however, the extra air causes the peak in-cylinder temperatures to decrease, lowering the $\mathrm{NO}_{\mathrm{x}}$ formation. The calculated adiabatic flame temperature for methane-air combustion is shown on the right-hand axis of Figure 21 which highlights the decrease in flame temperature leading to the decrease in peak in-cylinder mixture temperature. As the fueling is decreased to the engine, there is extra oxygen in the cylinder which initially offsets the lower peak in-cylinder 
temperatures causing the slight increase shown at the beginning of the curve. As the mixture is further leaned out, however, the extra air causes the peak in-cylinder temperatures to decrease, lowering the $\mathrm{NO}_{\mathrm{x}}$ formation.

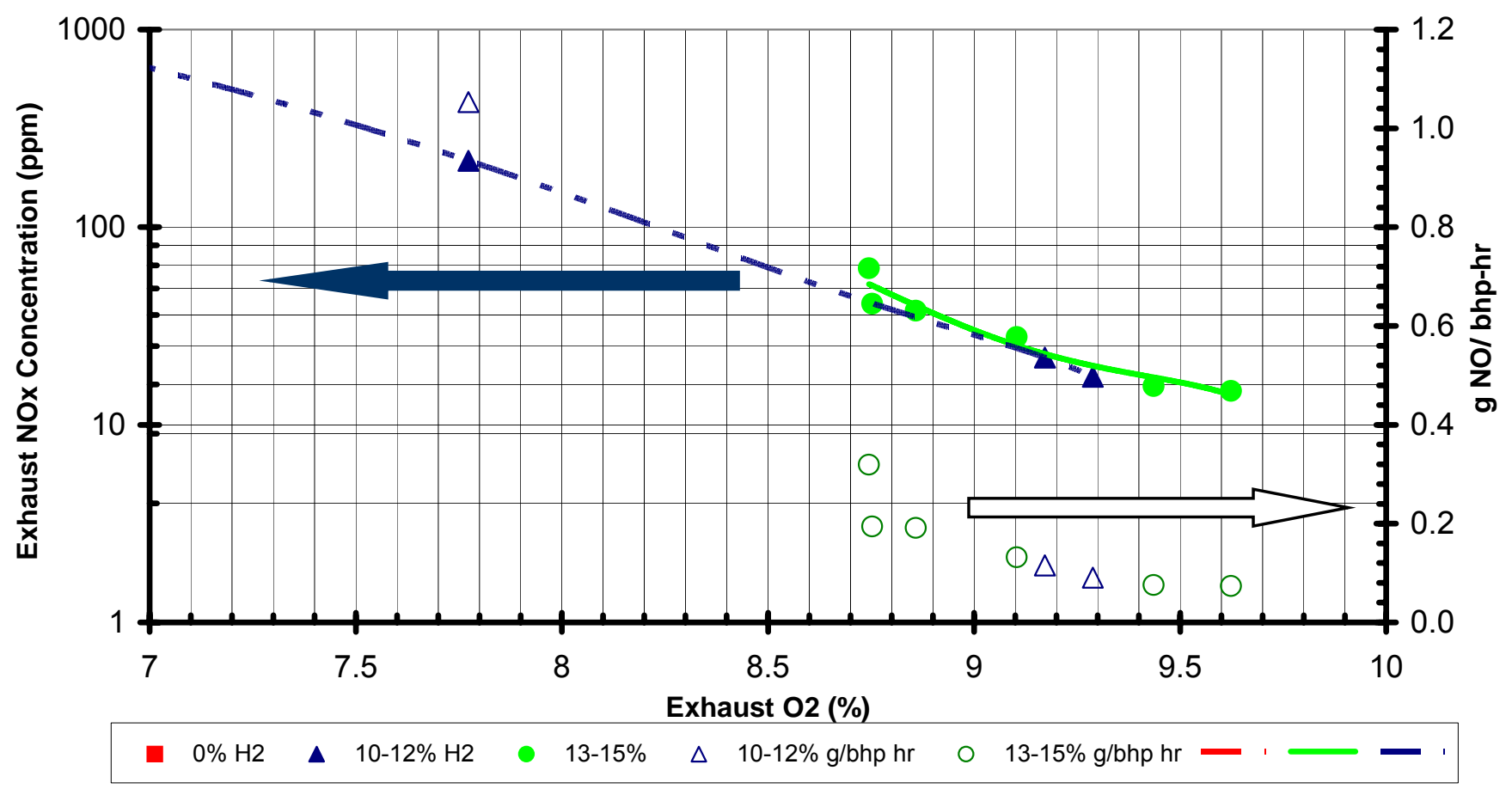

Figure 22. High Exhaust $\mathrm{O}_{2}$ Points Showing Extremely Low NOx

An expanded view of Figure 21 is shown in Figure 22, highlighting the extreme emissions reduction potential of the HALO system. The lowest point achieved was $0.07 \mathrm{~g} / \mathrm{bhp}$ hour $\mathrm{NO}_{\mathrm{x}}$ which corresponds to a value of $10 \mathrm{ppm} \mathrm{NO}_{\mathrm{x}}$ in the exhaust stream with stable combustion. The unfilled points correspond to the right-hand g/bhp-hr axis, and the solid points refer to the lefthand axis of ppm concentration (please note this is a logarithmic scale).

The percentages shown in all graphs represent the energy fraction of hydrogen to that of methane. For application of how this relates to mass and volume fractions, please refer to Appendix C.

\section{HALO/Spark Energy Reduction Testing}

The next phase of testing builds upon the hydrogen supplementation work and completes the experimental program by reducing the supplied ignition energy. The experimental setup for HALO testing with the addition of reducing the spark energy was the same as described in the previous section with the exception that the reduction in spark energy was accomplished by reducing the energy supplied to the coil by voltage reduction. A schematic of the Adrenaline ignition system is shown below: 


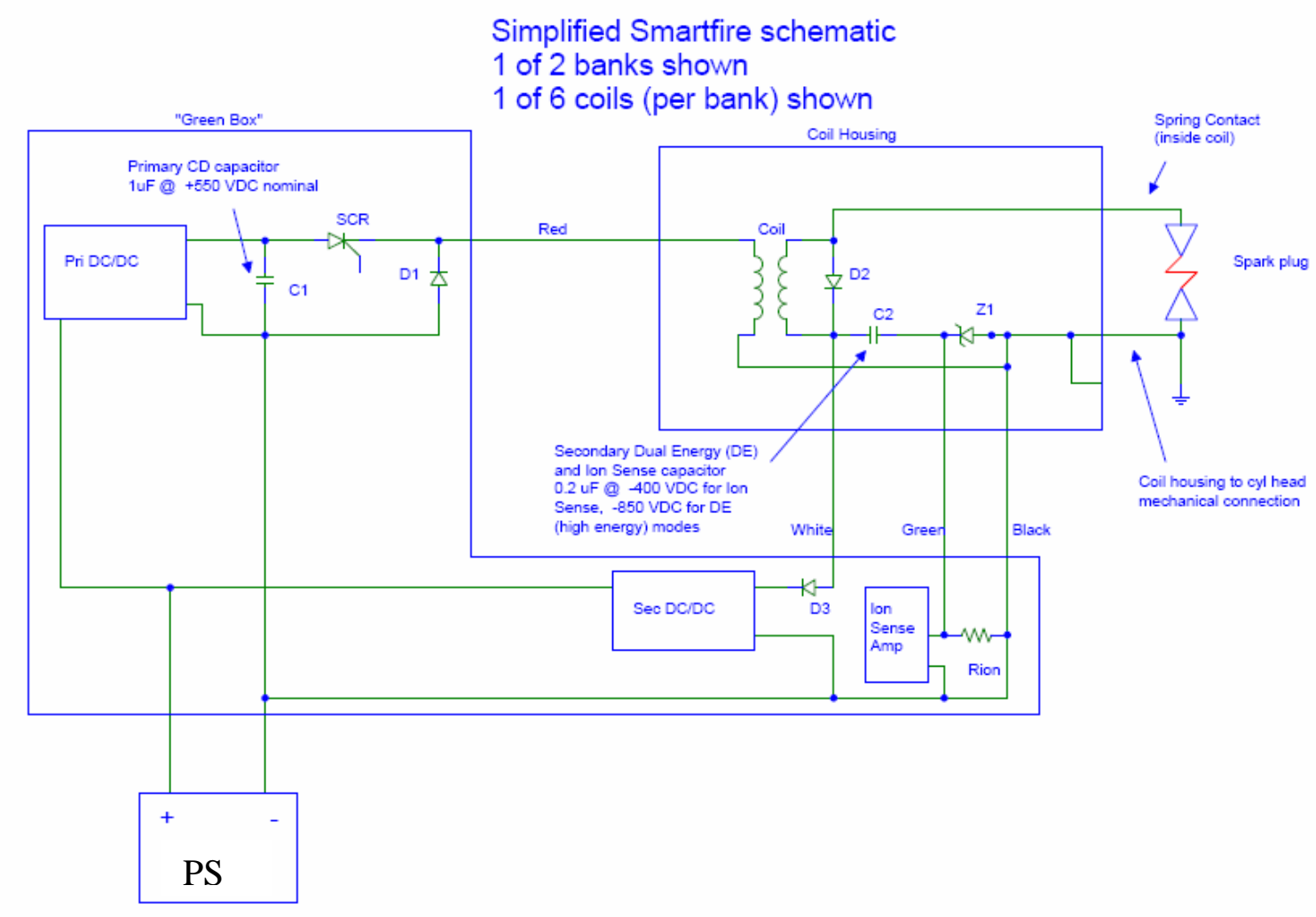

Figure 23. Simplified Smartfire Schematic

The box labeled "PS" shown in the lower left-hand corner of the picture was a high-amperage power supply which allowed the voltage to be regulated to the coil charging system of the primary capacitor. The control circuitry was powered from a separate power supply to give it standard voltage as well as power the fuel injectors and engine sensors. The baseline spark energy supplied to the coils is $151 \mathrm{~mJ}$. J-gap plugs were used to be consistent with field applications. The experimental approach is outlined in Table 14:

Table 14. HALO Testing with Spark Energy Reduction

\begin{tabular}{|c|c|}
\hline Task & \multicolumn{1}{c|}{ Description } \\
\hline \hline $\mathbf{2}$ & $\begin{array}{l}\text { Baseline Test. Run engine at rated IMEP and rated speed with Adrenaline Research } \\
\text { system installed. From previous testing, the spark timing will be 28 deg BTDC. Result: } \\
\text { Quality Check }\end{array}$ \\
\hline $\begin{array}{l}\text { HALO Testing with Spark Energy Reduction. Mapping of performance and emissions in } \\
\text { response to various levels of hydrogen supplementation coupled with reduced spark plug } \\
\text { energy. }\end{array}$ \\
$\begin{array}{l}\text { The engine power output was fixed at approximately } 7 \text { bar IMEP, at a relative } \\
\text { air/fuel ratio of 2, corresponding to 100\% excess combustion air, or } 9 \% \mathrm{O}_{2} \text { in the } \\
\text { exhaust (chosen to have a reduction } \mathrm{NO}_{\mathrm{x}} \text { and still establish a baseline point). }\end{array}$ \\
$\begin{array}{l}\text { The hydrogen supplementation rate was varied from 8\% LHV to a feasible limit in } 2 \% \text { LHV } \\
\text { increments, and at each operation point, spark ignition energy was lowered stepwise until } \\
\text { stable combustion no longer was supported. Engine power output and LPP were kept } \\
\text { fixed at each test point. Result: Effect of H2 Supplementation on Ignition Energy }\end{array}$ \\
\hline
\end{tabular}


Task 1 established a baseline for the engine at the rated standard design operating conditions. This baseline engine operating condition will also be repeated at the beginning of each test day to ensure the integrity and consistency of the experimental setup, instrumentation, and engine performance.

Task 2 established the benefit of hydrogen to reducing spark energy needed. At each hydrogen addition rate, spark energy was varied from the standard ignition value to $27 \%$ of the standard ignition energy in logical steps. IMEP was kept fixed at the maximum level for the test by varying the discharge pressure of the supercharger, and fixed combustion phasing was used to normalize the test data. The maximum oxygen concentration was chosen for experimental convenience and to have a point of reference.

\subsection{HALO/Spark Energy Reduction Results and Conclusions}

Throughout the HALO testing with spark energy reduction, brake fuel conversion efficiency was an average of 33\% (including the hydrogen as fuel), and brake specific fuel consumption was $226 \mathrm{~g} / \mathrm{kW}$-hr (this includes hydrogen as fuel as well).

The HALO testing with the reduction of ignition energy showed promising results for the improvement of spark life. It was shown that ignition energy can be reduced with additional hydrogen supplementation, which will in turn lead to an increase in plug life. The highlights of the testing are shown below:

Table 15. Hydrogen Supplementation and Ignition Energy Reduction

\begin{tabular}{|c|c|}
\hline $\begin{array}{c}\text { Ignition Energy } \\
\text { Reduction }\end{array}$ & $\begin{array}{c}\text { Hydrogen } \\
\text { Supplementation } \\
\text { (LHV H2/LHV CH4) }\end{array}$ \\
\hline$-27 \%$ & $17 \%$ \\
$-22 \%$ & $13 \%$ \\
$-16 \%$ & $10 \%$ \\
$-7 \%$ & $10 \%$ \\
$0 \%$ & $8 \%$ \\
\hline
\end{tabular}

Table 15 highlights the trade-off between ignition energy and the ingestion of additional hydrogen. All of the points shown above in the table have acceptable combustion stability limits by IMEP COV being less than $8 \%$. This table highlights the spark plug life-increasing potential of the hydrogen supplementation, as even a 13\% hydrogen supplementation rate will allow for a 22\% reduction in ignition energy. This table is shown graphically in Figure 24. 


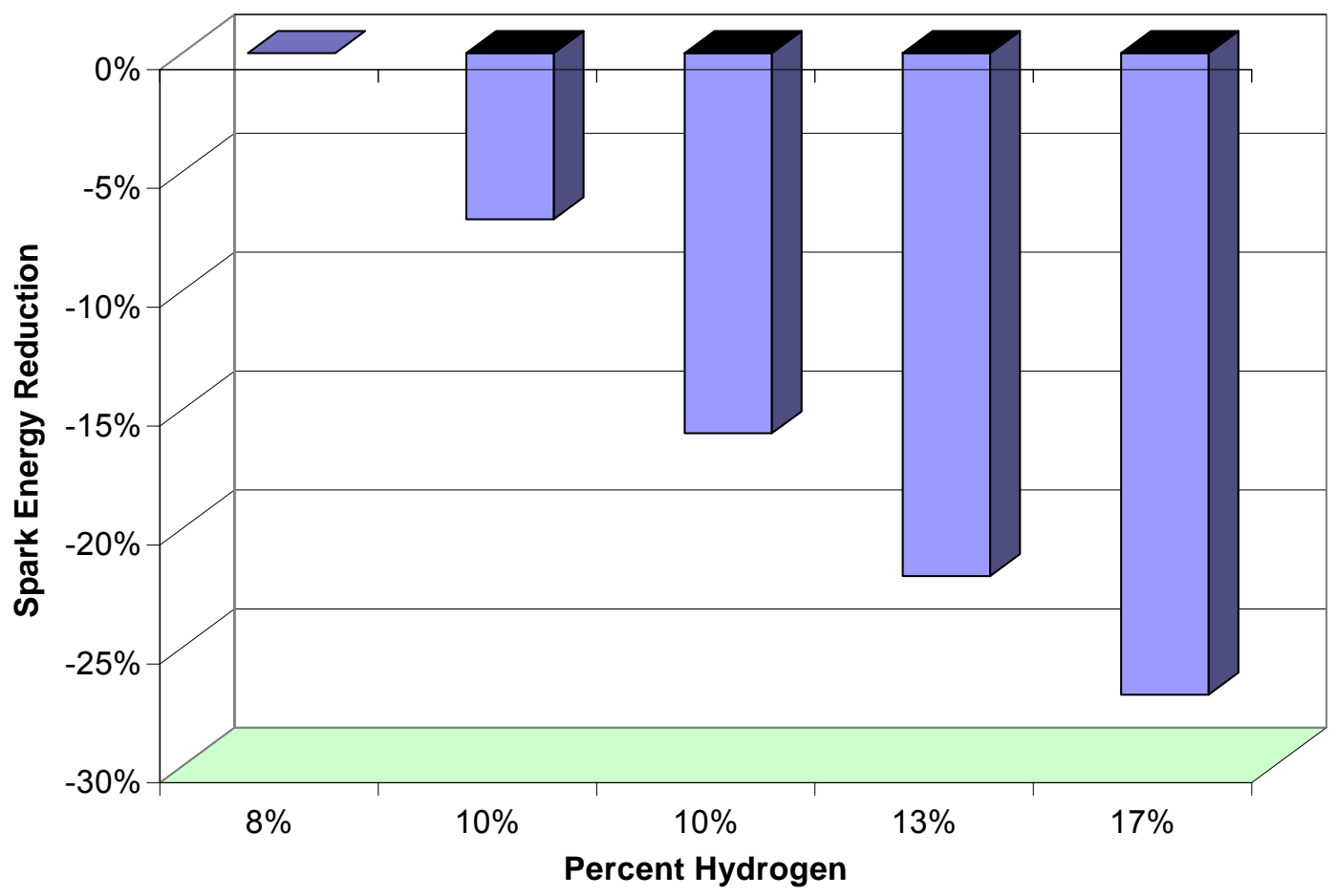

Figure 24. Spark Energy Reduction Potential as a Function of Hydrogen Supplementation

An important consideration in the test program was whether the spark energy reduction would adversely affect the $\mathrm{NO}_{\mathrm{x}}$ emissions from the engine. Comparing representative conditions, the effects are negligible. Table 16 summarizes the data used to reach this conclusion. Please note the reduced spark energy data shown here includes only stable combustion points (i.e., the 33\% reduction is not included because it was not stable)

Table 16. Comparison of Standard and Reduced Spark Energies

\begin{tabular}{|c|c|c|c|c|c|}
\hline Operating Condition & $\begin{array}{c}\text { Exhaust } \mathbf{0}_{\mathbf{2}} \\
\text { Conc. } \\
\text { Average } \\
\text { (\%) }\end{array}$ & NOx Average & $\begin{array}{c}\text { Average } \\
\text { IMEP (Bar) }\end{array}$ & $\begin{array}{c}\text { Average } \\
\text { LPP (deg } \\
\text { ATDC) }\end{array}$ & $\begin{array}{c}\text { Dwell Time } \\
\text { (ms) }\end{array}$ \\
\hline Standard Spark Energy & $9.2 \pm 0.2$ & $\begin{array}{c}22 \mathrm{ppm}(0.11 \\
\mathrm{g} / \mathrm{bhp}-\mathrm{hr}) \\
28 \mathrm{ppm}(0.13 \\
\mathrm{g} / \mathrm{bhp}-\mathrm{hr})\end{array}$ & $7.1 \pm 0.6$ & $18.0 \pm 1.5$ & 2.5 \\
Reduced Spark Energy & $9.1 \pm 0.2$ & 0.5 & $18.2 \pm 0.9$ & 2.5 \\
\hline
\end{tabular}

The table shown above highlights that considering the average of the points in conjunction with one standard deviation error, the reduced spark plug energy has a null effect on the $\mathrm{NO}_{\mathrm{x}}$ production.

The second part of the scoping plan was to examine how combustion responded to reduced spark energy. The result of this is summarized in Figure 25. 


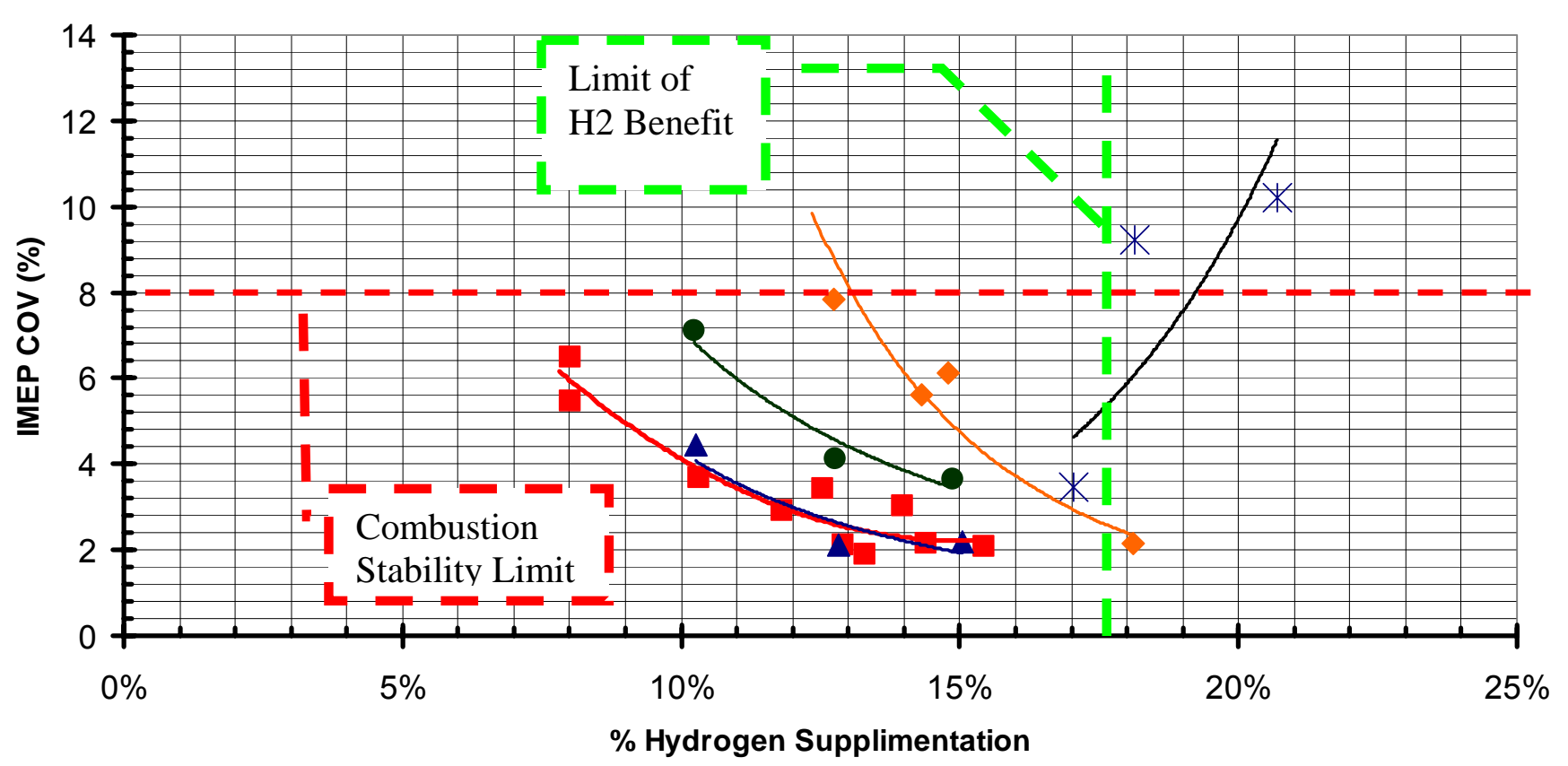

Figure 25. HALO Engine Operation with Reduced Ignition Energy

Figure 25 shows the IMEP COV as a function of hydrogen supplementation. Here again, 8\% IMEP COV is used as the limit of stable combustion. The standard ignition energy case is shown as red squares, the blue triangles represent a 7\% reduction in energy, the green circles represent a $16 \%$ reduction, the orange diamonds represent a $22 \%$ reduction in ignition energy, and the black stars represent a 33\% reduction in spark energy. A small reduction in delivered ignition energy does not require the addition of hydrogen to maintain combustion as shown by the fact that the $7 \%$ curve falls right on top of the baseline case. However, each stepwise energy reduction beyond $7 \%$ requires the addition of more hydrogen to maintain equivalent combustion stability. Finally, as shown by the 33\% reduction, the addition of hydrogen does not offset the reduced spark plug energy. However, a 27\% reduction in spark plug energy is achievable with $17 \%$ hydrogen supplementation. These are the results for this experimental setup-using surface gap plugs instead of the J-type plugs would have likely extended the operating range slightly. 


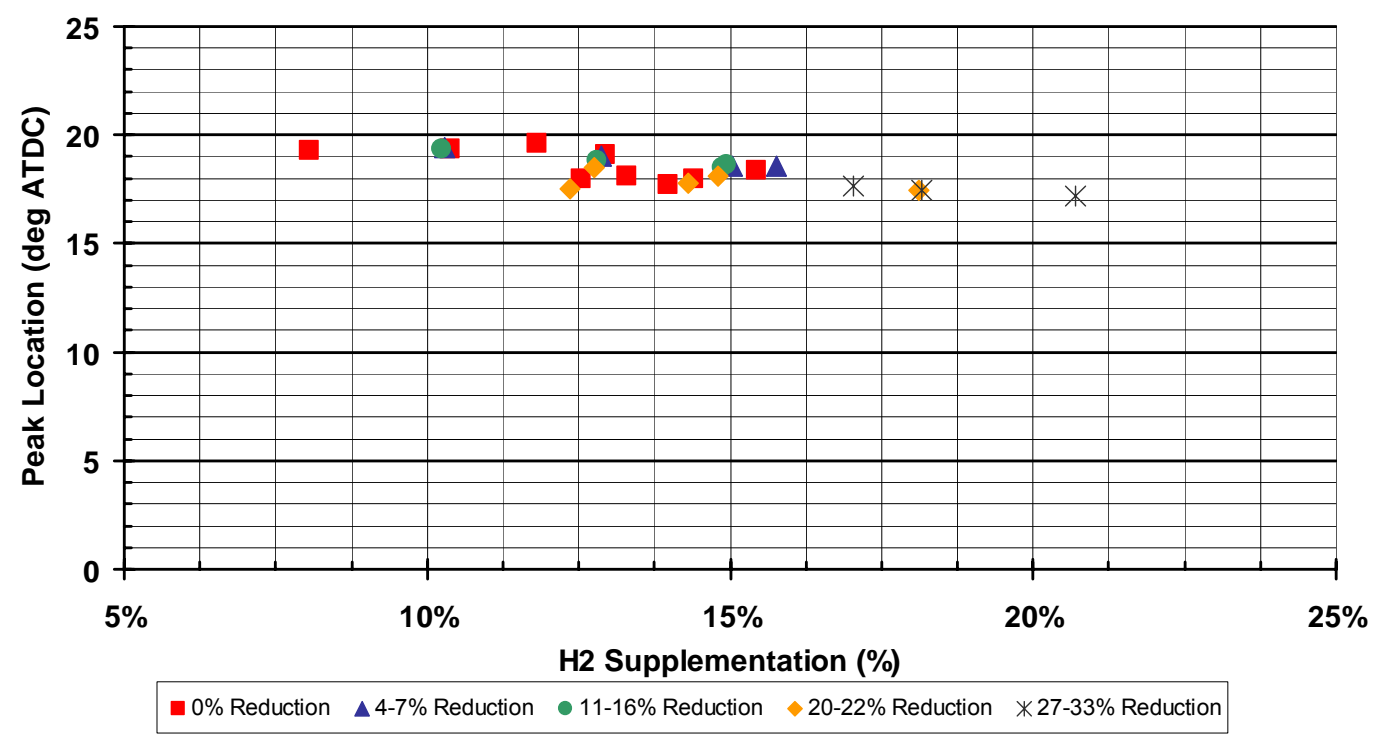

Figure 26. Peak Pressure Location throughout Testing Program

Figure 26 shows the excellent control exhibited throughout the testing program (engine power output was also held fixed). As was discussed earlier, the combustion phasing affects the $\mathrm{NO}_{\mathrm{x}}$ production. So to provide a fair comparison, it is essential to keep the phasing as constant as possible. The variation across all of the ranges tested is 2 degrees, which leads to being able to say that the LPP was essentially fixed through all of the test points.

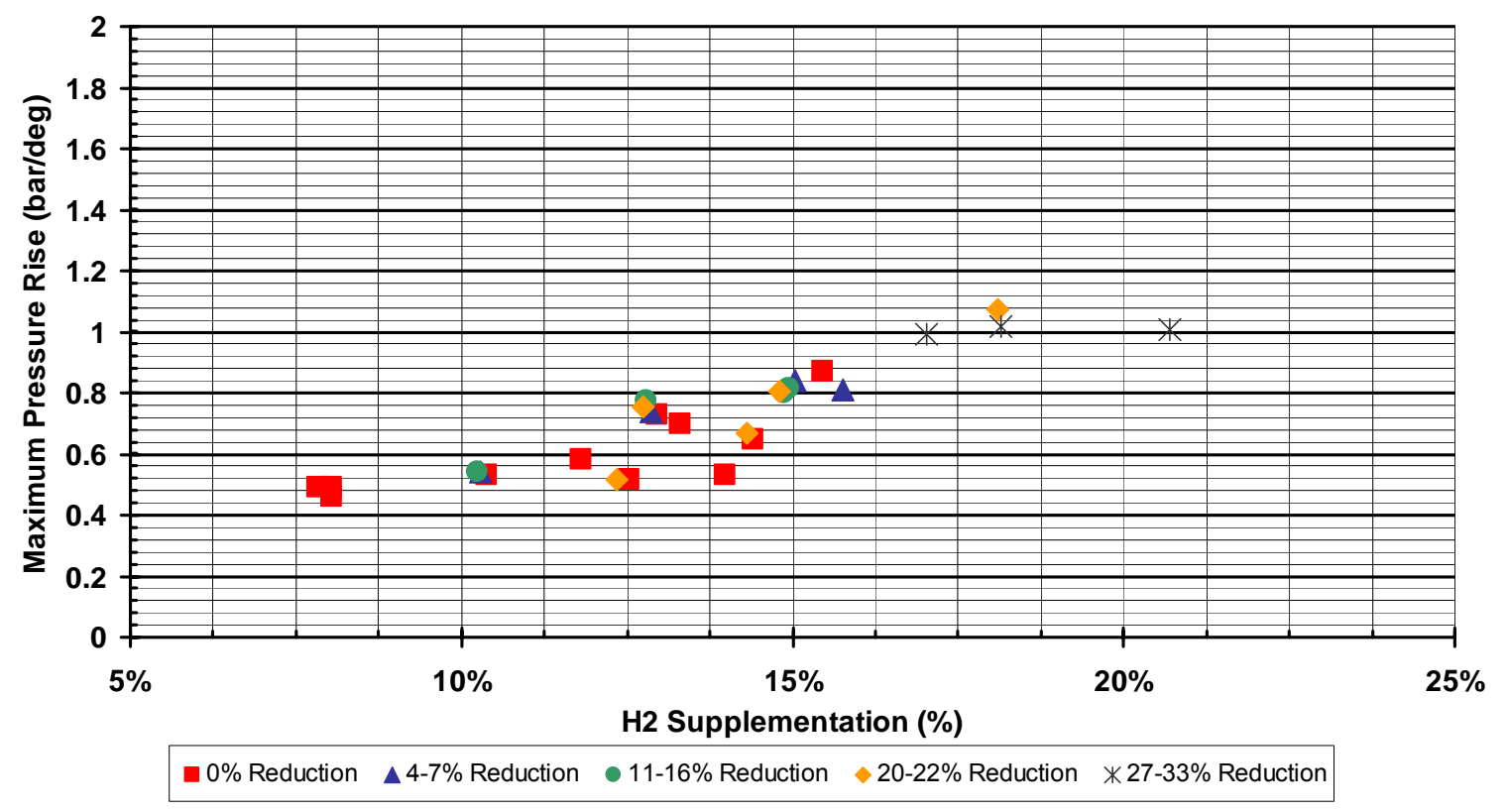

Figure 27. Maximum Pressure Rise Rate as a Function of Hydrogen Supplementation 
The maximum pressure rise is shown Figure 27. As more hydrogen is added to the engine, the burn rate increases. The greater the fraction of hydrogen, the faster the pressure will rise, which will be reflected in the burn rate. This trend is highlighted in Figure 27.

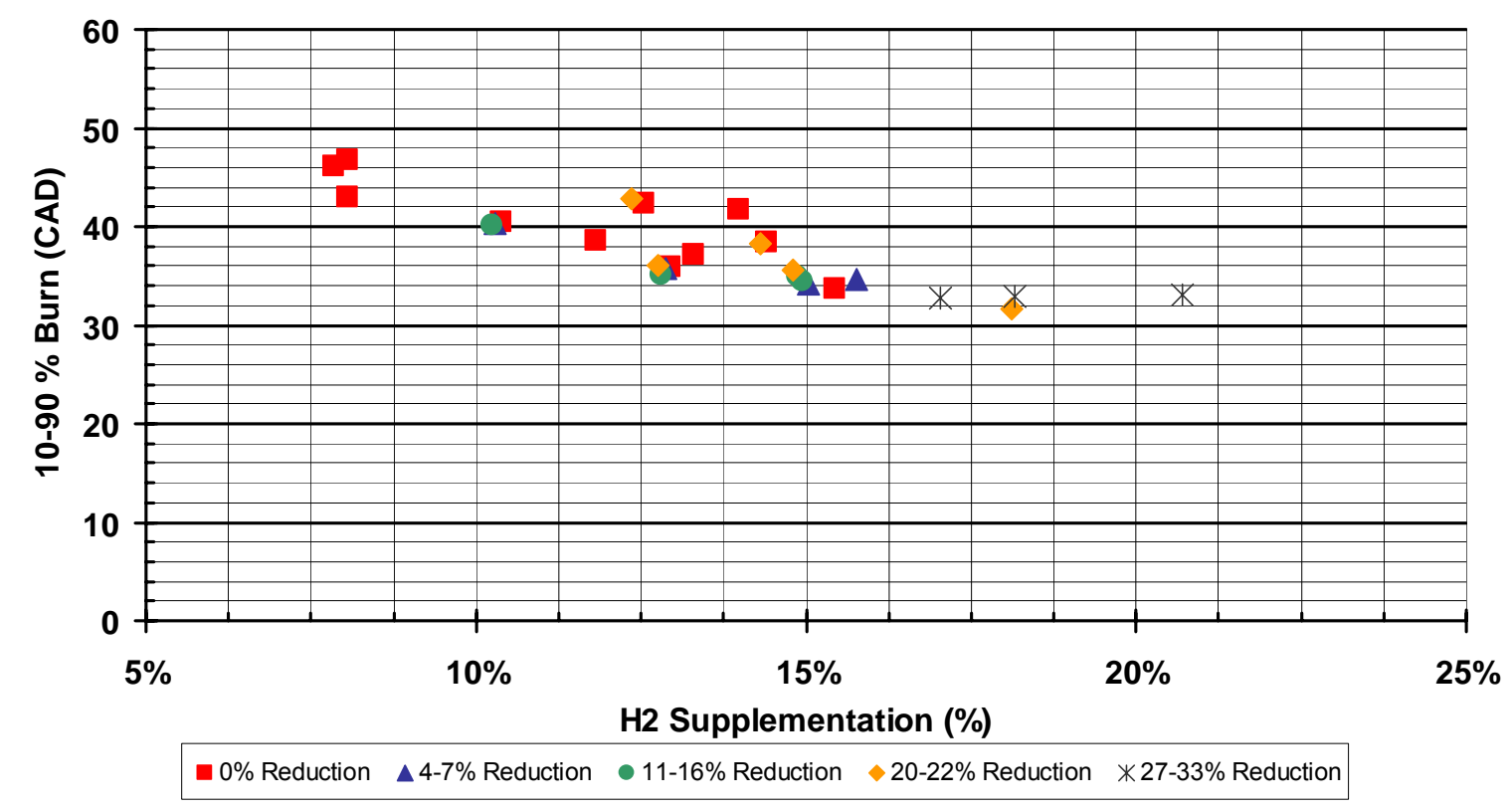

Figure 28. $10-90$ Burn Time as Function of Hydrogen Supplementation

The combustion duration, shown in Figure 28 as the $10 \%$ to $90 \%$ burn time, shows a trend of decreasing as the hydrogen supplementation is increased. This is as expected because the faster combustion of the hydrogen will lead to a decrease in the burn duration. This increase is what allows the stable operation at this operating condition. Interestingly, there is no apparent effect from the reduction in spark plug energy as the lower energy points fall close to the higher energy points. This points to the fact that the hydrogen supplementation is performing well in offsetting any difference that the spark energy reduction may make. 


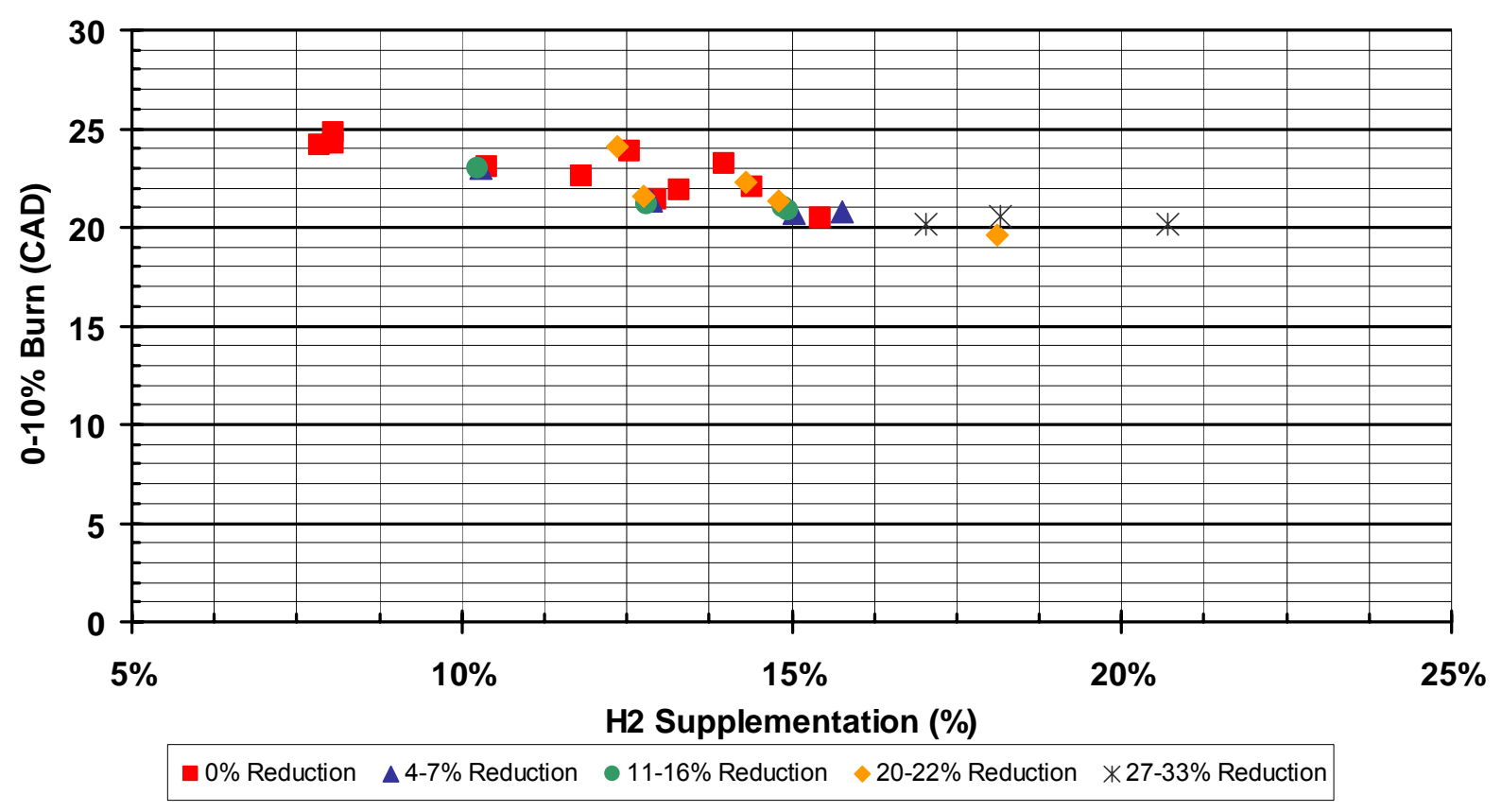

Figure 29. Start of Combustion Times as a Function of Hydrogen Supplementation

The $0 \%$ to $10 \%$ burn time shown in Figure 29 is slightly decreased with the higher values of $\mathrm{H}_{2}$ supplementation, but is not affected by the reduced ignition energy. Again, this may be attributed to the easy ignitability of the hydrogen mixture allowing for the quicker ignition of the lean mixture. Once the mixture is ignited, it burns, as the $00-10 \%$ burn time not changing for different ignition energies. The $00-10 \%$ burn time is shown to be a function of the hydrogen supplementation, not the ignition energy. This is an encouraging result, as this shows that within the ignitability limits, the reduced spark energy does not adversely affect combustion.

Selected Smartfire traces are shown below in Figure 30 to highlight the effect of spark energy reduction on the engine. From the figure, it may be seen that the ion current does behave differently for the case of spark energy reduction than that of the case shown with equivalent hydrogen supplementation but with standard spark energy. Interestingly, even though this difference is clear from the ion current traces, it does not change the combustion output as discussed earlier. 


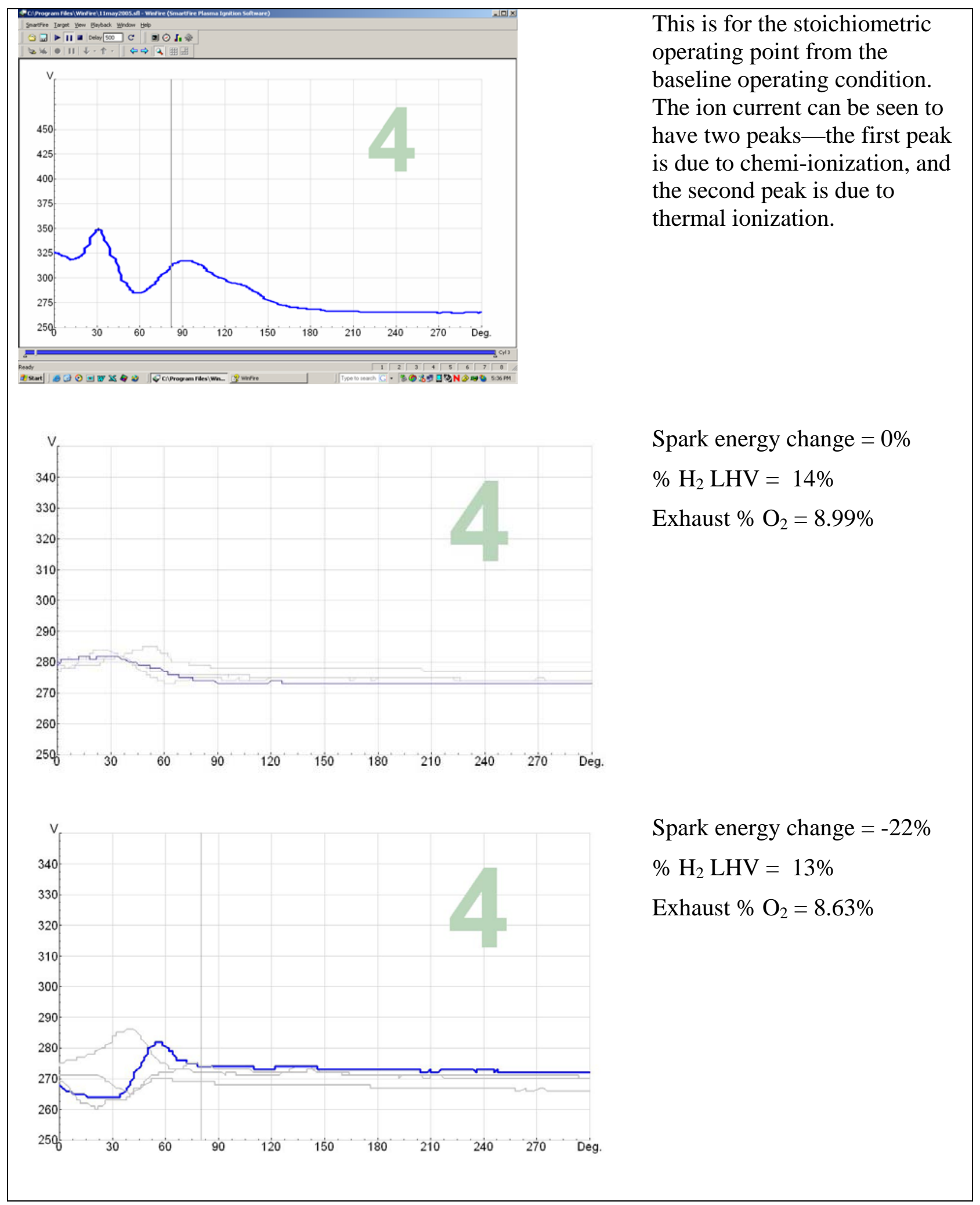

Figure 30. Ion-current Results Comparison for HALO Tests With Spark Energy Reduction 


\section{Conclusion and Recommendations}

This body of work has shown that with the supplementation of hydrogen, it is possible to reduce the spark ignition energy for natural gas engine applications while simultaneously reducing NOx to ultra-low levels. These results are very encouraging, as this reduction in spark plug energy is key to decreasing the frequency of maintenance intervals. This reduction has tremendous potential to translate to cost savings and emissions benefits for natural gas engines.

A further extension of the work performed here could include the testing of different levels of ethane, propane, and butane in the natural gas mixture, as all of these components increase ignitability when compared to methane. This would most likely make it possible to add less hydrogen, although the concentrations of these constituents would have to be noticeably increased to match the performance of hydrogen, some presence would improve the results.

There was cylinder to cylinder variation in the engine due to fueling non-uniformities. Inclusion of the hydrogen into the engine fuel could offset some of the bias against cylinders 6 and 8 , as the hydrogen would be moved from single-point injection to multipoint injection. Another option that may further improve the results would be to use Smartfire-recommended surface gap plugs instead of the J-gap plugs used throughout the experiments (J-gap plugs were used in the program to be consistent with standard engine configuration).

Even though the above explorations could be performed, this body of work has conclusively shown that a reduction in ignition energy is possible while still maintaining stable combustion. The next logical question is how much of an effect this energy reduction will have on the life of spark plugs. Answering this question would be beneficial and informative, as well as have a large commercial and environmental impact. A durability study would allow the translation of the spark energy reduction into increasing spark plug life and maintenance savings. 


\section{Appendix A: Equations used}

Since NOx formation is affected by humidity at the test site, a correction will be made using the following expression [1]:

$$
\text { NOcorr }=\frac{N O}{K}
$$

NO has units of ppm, and $\mathrm{K}$ (a dimensionless correction factor) is defined as follows:

$$
K=1+7 * A(H-10.714)+1.8 B(T-29.44))
$$

A in the above equation is:

$$
A=0.044\left(\frac{\text { Fuel }}{\text { Air }}\right)-0.0038
$$

The fuel-air-ratio is on a dry mass basis for both equations A3 and A4:

The variable $B$ from equation $A 2$ is:

$$
B=-0.116\left(\frac{\text { Fuel }}{\text { Air }}\right)+0.0053
$$

$\mathrm{T}$ is the intake temperature in $\operatorname{deg} \mathrm{C}$, and $\mathrm{H}$ is defined as:

$$
H=\frac{621.98 P v}{P b-P v}
$$

$\mathrm{Pv}$ is the partial pressure of the water vapor in in $\mathrm{Hg}$, and $\mathrm{Pb}$ is the barometric pressure in in $\mathrm{Hg}$. Since during the test dry bulb temperature and Relative Humidity were recorded, $\mathrm{Pv}$ may be calculated from equation A8:

$$
P v=R H(P d)
$$

Pd is calculated from the following equation:

$$
\begin{aligned}
& P d=-4.14438 \times 10^{-3}+5.76645 \times 10^{-3} T-6.32788 \times 10^{-5} T^{2} \\
& +2.12294 \times 10^{-6} T^{3}-7.85415 \times 10^{-9} T^{4}+6.55263 \times 10^{-11} T^{5}
\end{aligned}
$$

Where $\mathrm{T}$ is Temperature in deg $\mathrm{F}$, and the equation is valid from 20 to 110 deg $\mathrm{F}$.

The Relative Air/Fuel Ratio is calculated using the well-accepted Spindt method from the engine exhaust constituents as measured by the emissions bench. The Spindt equation is shown below [2]: 


$$
F b *(11.492 * F C *((1+0.5 * R+Q) /(1+R)))+((120 *(1-F C)) /(3.5+R)))
$$

$\mathrm{Fb}$ is defined below:

$$
\left(\mathrm{CO}_{2}+\mathrm{CO}\right) /\left(\mathrm{CO}_{2}+\mathrm{CO}+(0.001 * T H C)\right)
$$

Where $\mathrm{CO}_{2}$ and $\mathrm{CO}$ are in volume percent, and THC is in ppm.

Fc is defined as:

$$
12.01 /(12.01+1.008 * Y)
$$

Where $\mathrm{Y}$ is the $\mathrm{H} / \mathrm{C}$ mass ratio of the fuel being used during the test. $\mathrm{R}$ is the ratio of $\mathrm{CO}$ to $\mathrm{CO}_{2}$, and $\mathrm{Q}$ is the ratio of $\mathrm{O}_{2}$ to $\mathrm{CO}_{2}$, all expressed in volume percent.

Indicated Power in $\mathrm{kW}$ was calculated from the IMEP $(\mathrm{kPa})$ by the following expression:

$$
P=\frac{\operatorname{IMEP}\left(V_{d}\right)(N)}{1000 n_{r}}
$$

Where $\mathrm{Vd}$ is the engine displaced volume in $\mathrm{dm}^{3}, \mathrm{~N}$ is the number of revolution per second, and $\mathrm{n}_{\mathrm{r}}$ is 2 for a four-stroke engine.

The fuel conversion efficiency is calculated as:

$$
\eta_{f i}=\frac{P}{\dot{m}_{f} Q_{L H V}}
$$

Where $\mathrm{P}$ is the power as calculated above in Watts, $\mathrm{m}_{\mathrm{f}}$ is the fuel flow rate in $\mathrm{kg} / \mathrm{s}$, and $\mathrm{Q}_{\mathrm{LHV}}$ is the Lower Heating Value of the fuel in $\mathrm{J} / \mathrm{kg}$. For the fuel conversion efficiencies shown here, hydrogen was included as a fuel, with a LHV $=120 \mathrm{MJ} / \mathrm{kg}$, and Natural Gas with a LHV $=45$ $\mathrm{MJ} / \mathrm{kg}$.

The specific emissions were calculated using the following formula:

$$
\left[\frac{g}{k W-h r}\right]=\frac{0.062(\text { exh })(N O x)}{P}
$$

Where exh is the exhaust mass flow rate in $\mathrm{kg} / \mathrm{min}, \mathrm{NO}_{\mathrm{x}}$ has units of ppm, and Power is in $\mathrm{kW}$, and due to the conservation of mass, includes the air, fuel, $\mathrm{CO}_{2}, \mathrm{~N}_{2}$, and reformate ingested into the engine ${ }^{\mathrm{A} 1}$.

\section{References:}

A1. SAE J177 Jun95: "Measurement of Carbon Dioxide, Carbon Monoxide, and Oxides of Nitrogen in Diesel Exhaust."

A2. Spindt, R.S., 1965, “Air-Fuel Ratios From Exhaust Gas Analyzer,” SAE Paper No. 650507. 


\section{Appendix B: Smartfire Ion Current Traces}
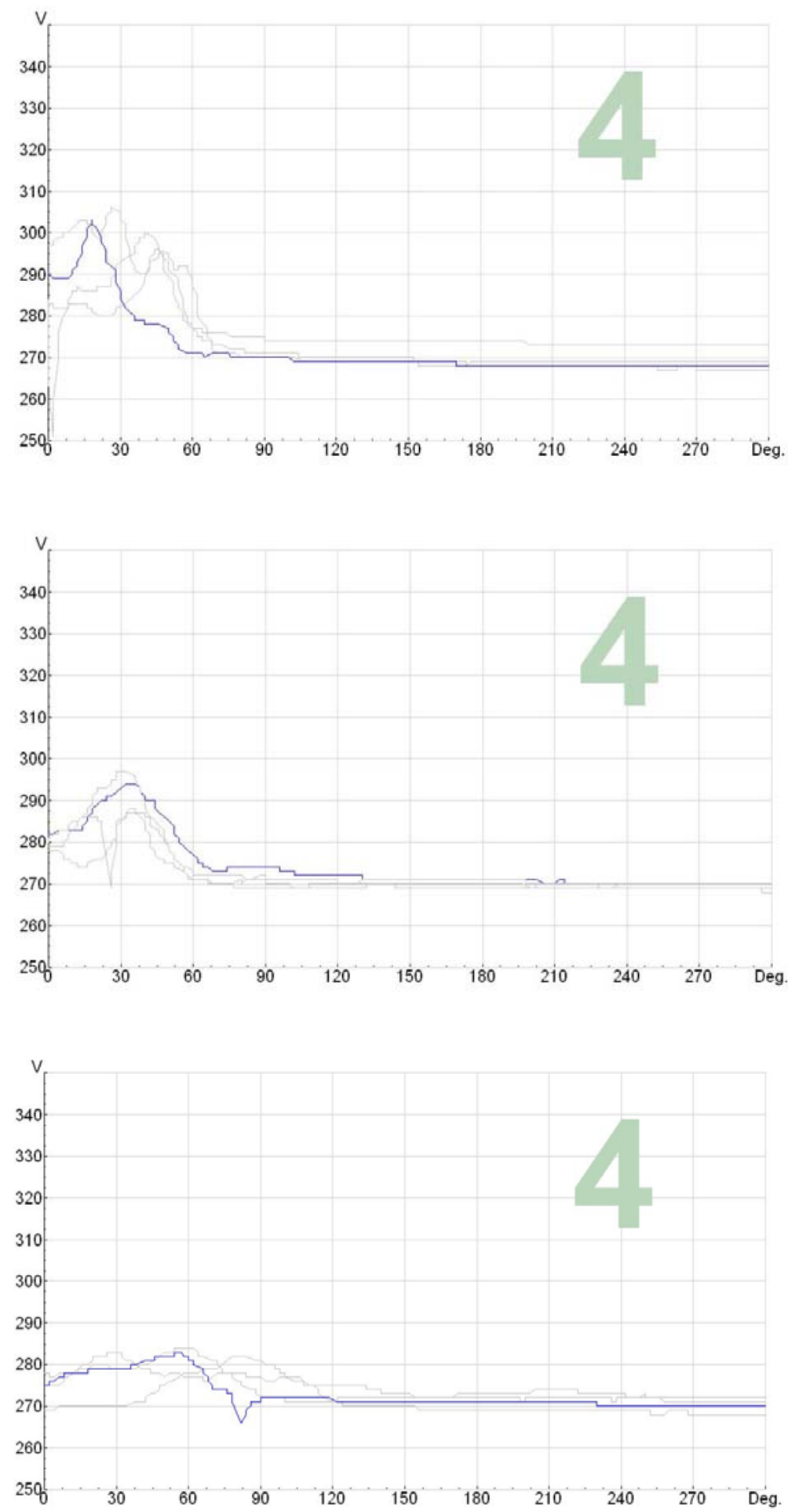

Spark energy change $=0 \%$

$\% \mathrm{H}_{2} \mathrm{LHV}=0 \%$

Exhaust $\% \mathrm{O}_{2}=5.01 \%$

$\% \mathrm{H}_{2} \mathrm{LHV}=0 \%$

Exhaust $\% \mathrm{O}_{2}=6.16 \%$

$\% \mathrm{H}_{2} \mathrm{LHV}=0 \%$

Exhaust $\% \mathrm{O}_{2}=6.81 \%$
Spark energy change $=0 \%$

Spark energy change $=0 \%$ 

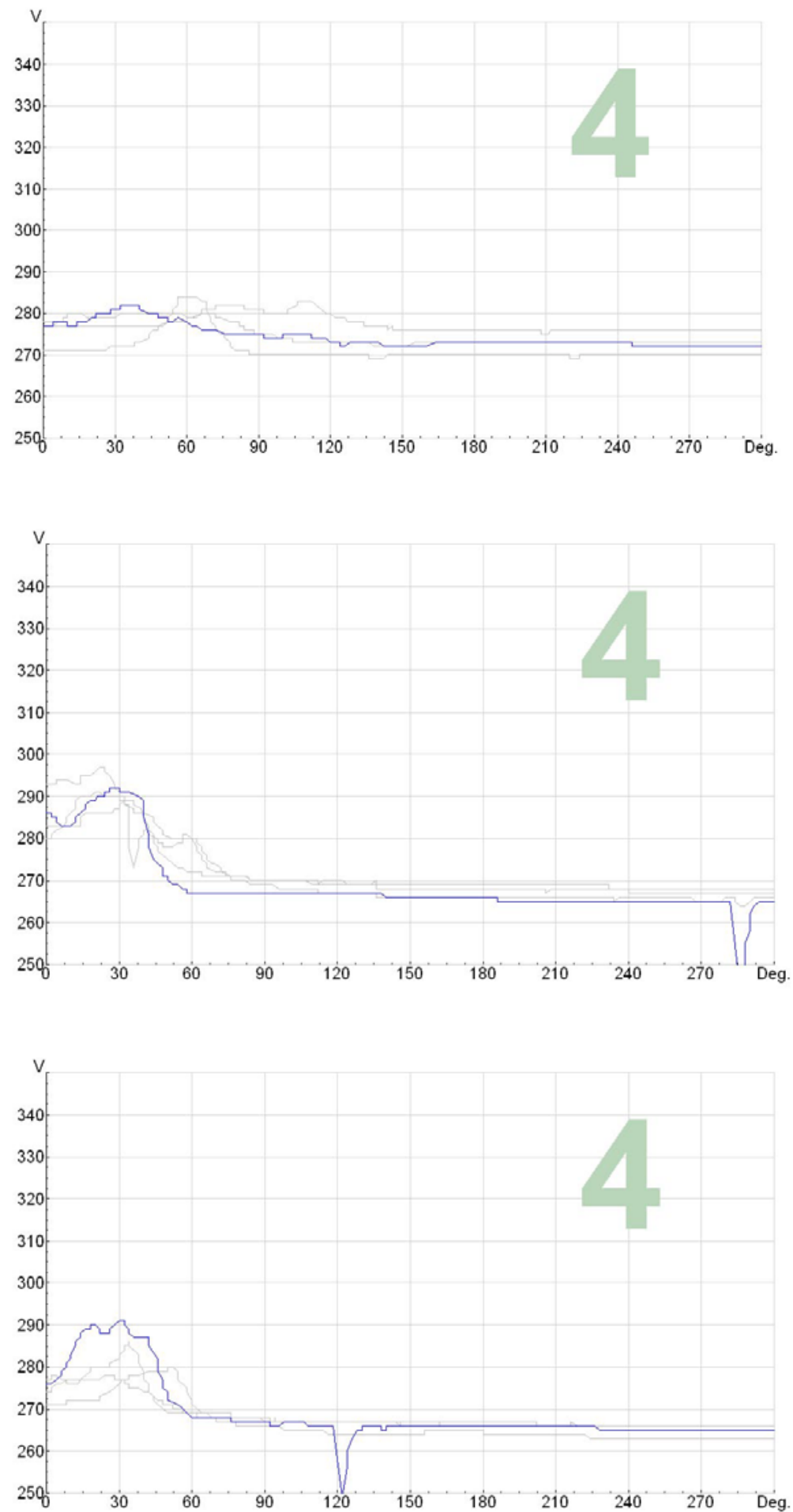

Spark energy change $=0 \%$

$\% \mathrm{H}_{2} \mathrm{LHV}=0 \%$

Exhaust $\% \mathrm{O}_{2}=7.45 \%$
Spark energy change $=0 \%$

$\% \mathrm{H}_{2} \mathrm{LHV}=0 \%$

Exhaust $\% \mathrm{O}_{2}=8.24 \%$
Spark energy change $=0 \%$

$\% \mathrm{H}_{2} \mathrm{LHV}=11 \%$

Exhaust $\% \mathrm{O}_{2}=6.82 \%$ 

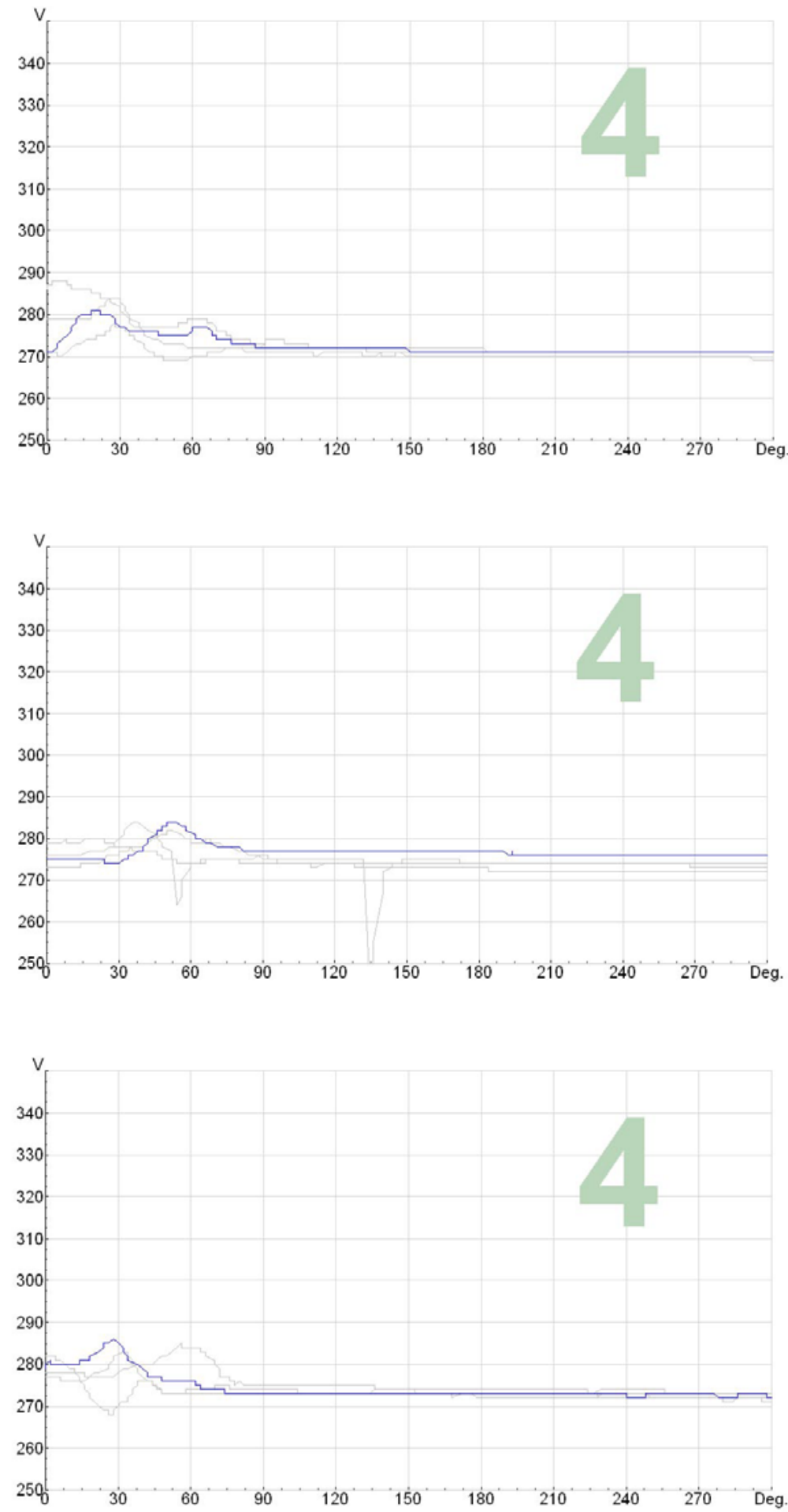

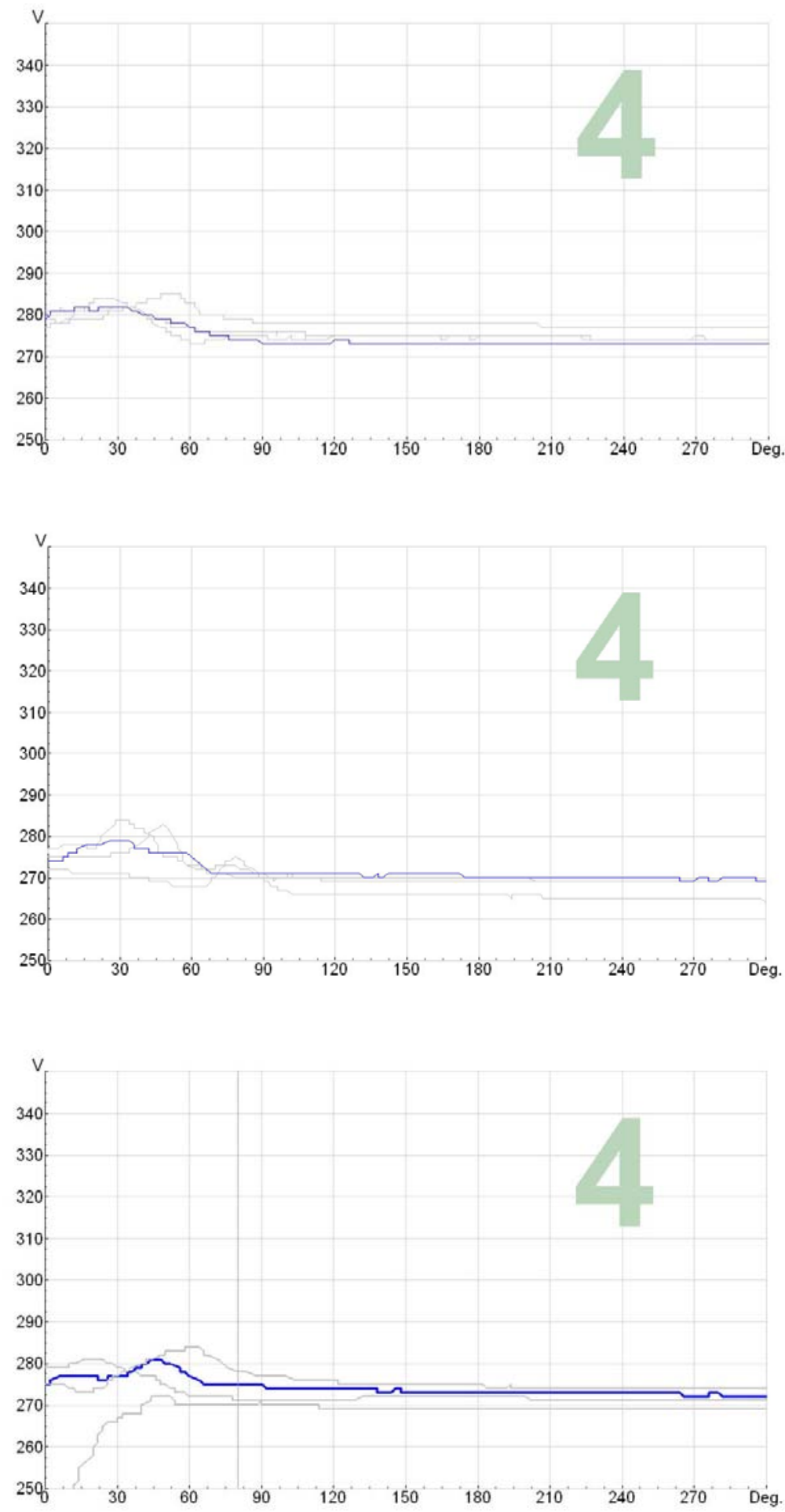


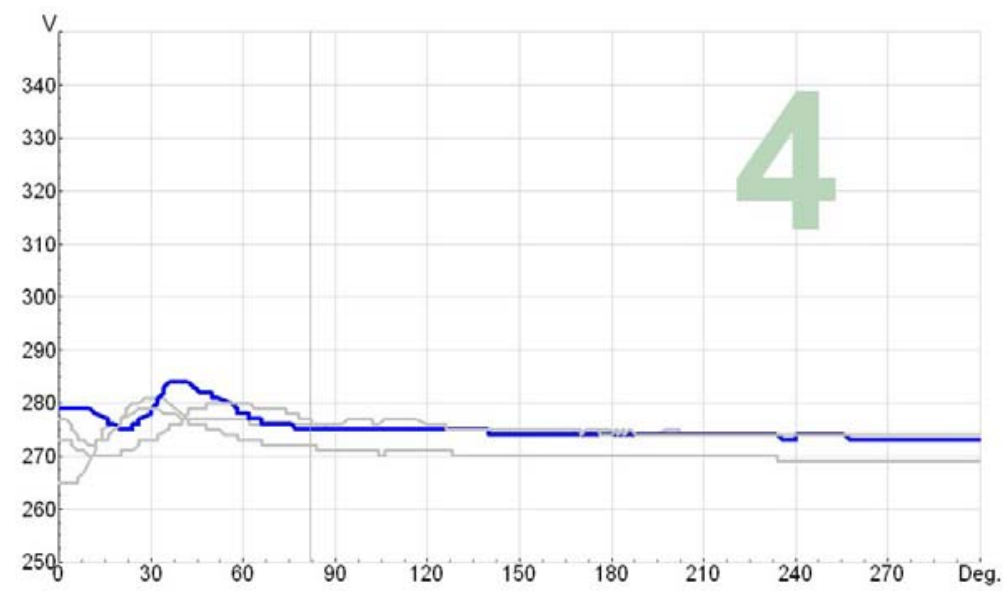

Spark energy change $=-7 \%$

$\% \mathrm{H}_{2} \mathrm{LHV}=15 \%$

Exhaust $\% \mathrm{O}_{2}=8.74 \%$

Spark energy change $=-11 \%$

$\% \mathrm{H}_{2} \mathrm{LHV}=15 \%$

Exhaust $\% \mathrm{O}_{2}=8.83 \%$

Spark energy change $=-22 \%$

$\% \mathrm{H}_{2} \mathrm{LHV}=15 \%$

Exhaust $\% \mathrm{O}_{2}=8.79 \%$ 


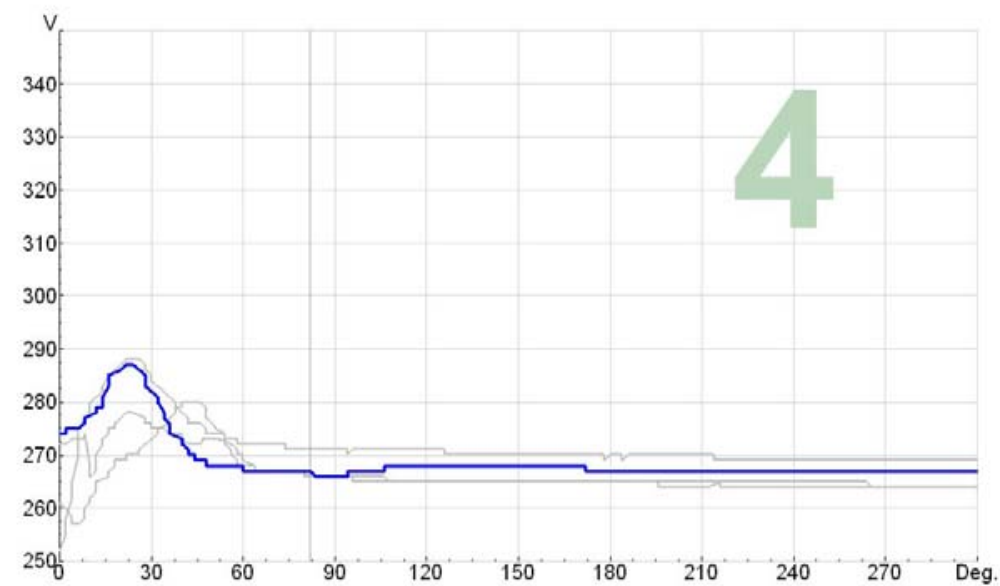

Spark energy change $=-22 \%$

$\% \mathrm{H}_{2} \mathrm{LHV}=18 \%$

Exhaust $\% \mathrm{O}_{2}=8.30 \%$

Spark energy change $=0 \%$

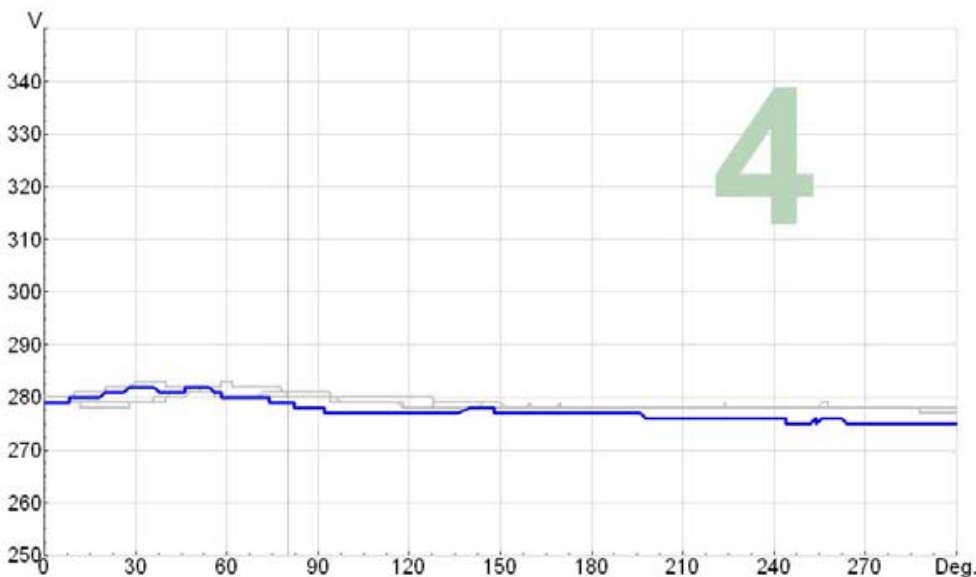

$\% \mathrm{H}_{2} \mathrm{LHV}=8 \%$

Exhaust $\% \mathrm{O}_{2}=9.46 \%$

Spark energy change $=0 \%$

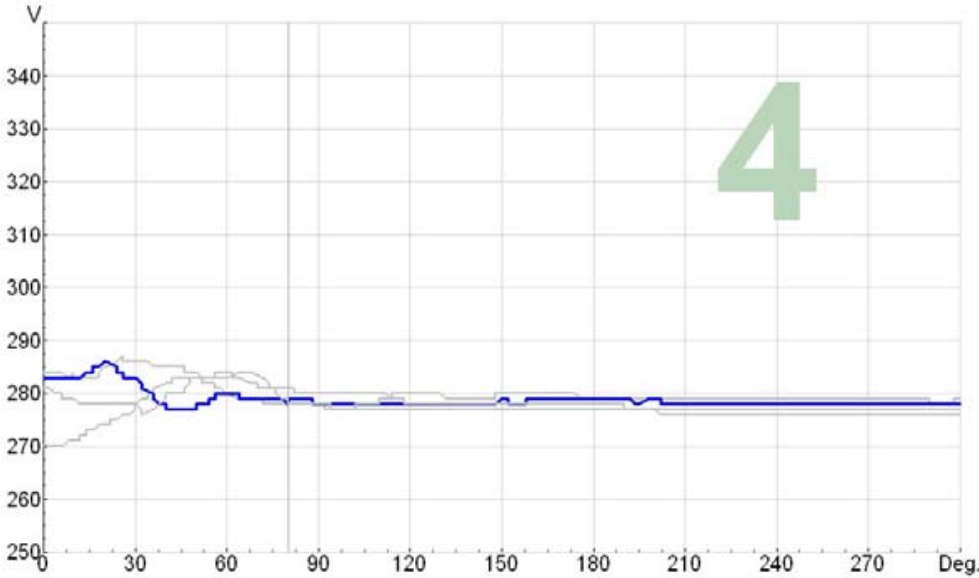

$\% \mathrm{H}_{2} \mathrm{LHV}=10 \%$

Exhaust $\% \mathrm{O}_{2}=9.11 \%$ 


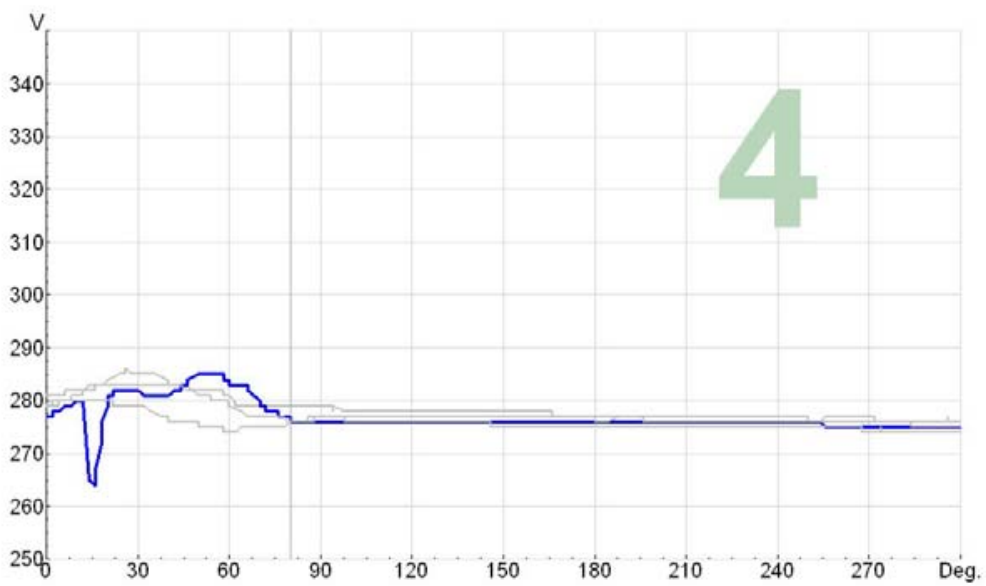

Spark energy change $=-7 \%$

$\% \mathrm{H}_{2} \mathrm{LHV}=10 \%$

Exhaust $\% \mathrm{O}_{2}=9.09 \%$

Spark energy change $=-16 \%$

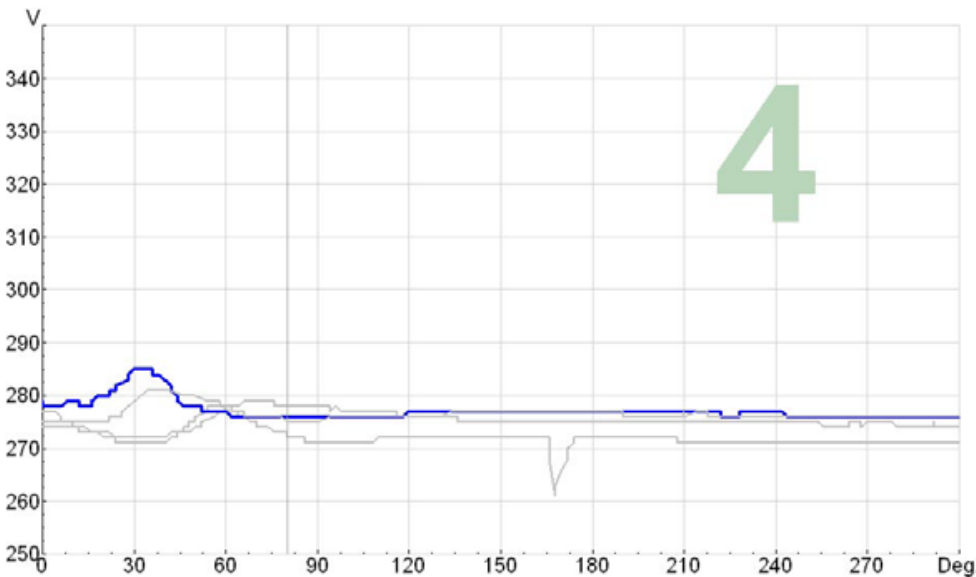

$\% \mathrm{H}_{2} \mathrm{LHV}=10 \%$

Exhaust $\% \mathrm{O}_{2}=9.13 \%$

Spark energy change $=0 \%$

$\% \mathrm{H}_{2} \mathrm{LHV}=13 \%$

Exhaust $\% \mathrm{O}_{2}=8.73 \%$ 


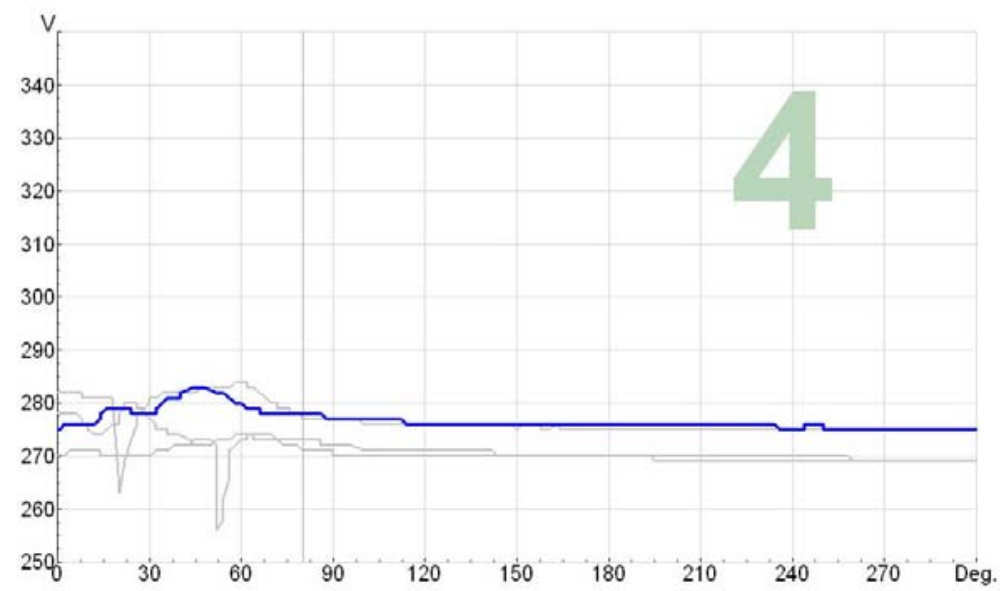

Spark energy change $=-7 \%$

$\% \mathrm{H}_{2} \mathrm{LHV}=13 \%$

Exhaust $\% \mathrm{O}_{2}=8.65 \%$

Spark energy change $=-16 \%$

$\% \mathrm{H}_{2} \mathrm{LHV}=13 \%$

Exhaust $\% \mathrm{O}_{2}=8.61 \%$

Spark energy change $=-22 \%$

$\% \mathrm{H}_{2} \mathrm{LHV}=13 \%$

Exhaust $\% \mathrm{O}_{2}=8.63 \%$ 
12 Appendix C: Comparison of Energy Fraction, Volume Fraction, and Mass Fraction of Hydrogen and Methane

Table 17. Comparison of LHV, Volume, and Mass Fractions

\begin{tabular}{|c|c|c|}
\hline $\begin{array}{c}\text { LHV } \\
(\mathrm{H} 2 / \mathrm{CH} 4) \\
\%\end{array}$ & $\begin{array}{c}\text { Volume Fraction } \\
(\text { Vol H2/Vol Fuel }) \\
\%\end{array}$ & $\begin{array}{c}\text { Mass Fraction (mass } \\
\text { H2/mass fuel })\end{array}$ \\
\hline $2 \%$ & $7 \%$ & $0.8 \%$ \\
\hline $3 \%$ & $10 \%$ & $1.2 \%$ \\
\hline $4 \%$ & $13 \%$ & $1.6 \%$ \\
\hline $5 \%$ & $16 \%$ & $2.0 \%$ \\
\hline $6 \%$ & $18 \%$ & $2.4 \%$ \\
\hline $7 \%$ & $21 \%$ & $2.8 \%$ \\
\hline $8 \%$ & $23 \%$ & $3.2 \%$ \\
\hline $9 \%$ & $25 \%$ & $3.6 \%$ \\
\hline $10 \%$ & $27 \%$ & $4.0 \%$ \\
\hline $11 \%$ & $29 \%$ & $4.4 \%$ \\
\hline $12 \%$ & $31 \%$ & $4.8 \%$ \\
\hline $13 \%$ & $32 \%$ & $5.1 \%$ \\
\hline $14 \%$ & $34 \%$ & $5.5 \%$ \\
\hline $15 \%$ & $36 \%$ & $5.9 \%$ \\
\hline $16 \%$ & $37 \%$ & $6.3 \%$ \\
\hline
\end{tabular}


13 Appendix D: Comparison of Inclusion of Cylinder 6 on the COV Average Versus Exclusion of Cylinder 6

Table 18. HALO Testing Averages

\begin{tabular}{|c|c|c|c|}
\hline $\begin{array}{c}\text { Spark } \\
\text { Energy } \\
\text { Percent } \\
\text { Reduction }\end{array}$ & $\begin{array}{c}\% \text { LHV } \\
\mathrm{H} 2 / \mathrm{CH} 4\end{array}$ & $\begin{array}{c}\text { Engine } \\
\text { Avg COV } \\
1,2,3,4,5,7\end{array}$ & $\begin{array}{c}\text { Engine Avg } \\
\text { COV } \\
1,2,3,4,5,6,7\end{array}$ \\
\hline $0 \%$ & $0 \%$ & 3.9 & 4.4 \\
\hline $0 \%$ & $0 \%$ & 2.2 & 2.4 \\
\hline $0 \%$ & $0 \%$ & 2.7 & 2.8 \\
\hline $0 \%$ & $0 \%$ & 1.3 & 1.4 \\
\hline $0 \%$ & $0 \%$ & 9.5 & 12.1 \\
\hline $0 \%$ & $8 \%$ & 5.5 & 5.9 \\
\hline $0 \%$ & $8 \%$ & 6.5 & 7.3 \\
\hline $0 \%$ & $10 \%$ & 3.7 & 3.8 \\
\hline $0 \%$ & $11 \%$ & 1.3 & 1.4 \\
\hline $0 \%$ & $12 \%$ & 2.9 & 3.3 \\
\hline $0 \%$ & $12 \%$ & 1.4 & 1.5 \\
\hline $0 \%$ & $13 \%$ & 3.4 & 4.4 \\
\hline $0 \%$ & $13 \%$ & 2.1 & 2.4 \\
\hline $0 \%$ & $13 \%$ & 1.9 & 1.9 \\
\hline $0 \%$ & $14 \%$ & 3.0 & 3.1 \\
\hline $0 \%$ & $14 \%$ & 2.2 & 2.2 \\
\hline $0 \%$ & $15 \%$ & 2.1 & 2.2 \\
\hline
\end{tabular}

Table 19. Spark Energy Reduction Testing Averages

\begin{tabular}{|c|c|c|c|}
\hline $\begin{array}{c}\text { Spark } \\
\text { Energy } \\
\begin{array}{c}\text { Percent } \\
\text { Reduction }\end{array}\end{array}$ & $\begin{array}{c}\% \text { LHV } \\
\mathrm{H} 2 / \mathrm{CH} 4\end{array}$ & $\begin{array}{c}\text { Engine } \\
\text { Avg COV } \\
1,2,3,4,5,7\end{array}$ & $\begin{array}{c}\text { Engine Avg } \\
\text { COV } \\
1,2,3,4,5,6,7\end{array}$ \\
\hline $0 \%$ & $8 \%$ & 5.5 & 5.9 \\
\hline $0 \%$ & $8 \%$ & 6.5 & 7.3 \\
\hline $0 \%$ & $10 \%$ & 3.7 & 3.8 \\
\hline $0 \%$ & $12 \%$ & 2.9 & 3.3 \\
\hline $0 \%$ & $13 \%$ & 3.4 & 4.4 \\
\hline $0 \%$ & $13 \%$ & 2.1 & 2.4 \\
\hline $0 \%$ & $13 \%$ & 1.9 & 1.9 \\
\hline $0 \%$ & $14 \%$ & 3.0 & 3.1 \\
\hline $0 \%$ & $14 \%$ & 2.2 & 2.2 \\
\hline $0 \%$ & $15 \%$ & 2.1 & 2.2 \\
\hline$-4 \%$ & $16 \%$ & 2.3 & 2.5 \\
\hline$-7 \%$ & $10 \%$ & 4.5 & 5.4 \\
\hline$-7 \%$ & $13 \%$ & 2.1 & 3.2 \\
\hline$-7 \%$ & $15 \%$ & 2.2 & 2.5 \\
\hline$-11 \%$ & $15 \%$ & 2.4 & 3.4 \\
\hline$-16 \%$ & $10 \%$ & 7.1 & 9.3 \\
\hline$-16 \%$ & $13 \%$ & 4.1 & 5.9 \\
\hline$-16 \%$ & $15 \%$ & 3.7 & 4.5 \\
\hline$-20 \%$ & $14 \%$ & 5.6 & 7.0 \\
\hline$-22 \%$ & $13 \%$ & 7.8 & 9.7 \\
\hline$-22 \%$ & $15 \%$ & 6.1 & 7.8 \\
\hline$-22 \%$ & $18 \%$ & 2.1 & 2.5 \\
\hline$-27 \%$ & $17 \%$ & 3.5 & 4.8 \\
\hline$-33 \%$ & $18 \%$ & 9.2 & 10.9 \\
\hline$-33 \%$ & $21 \%$ & 10.2 & 10.2 \\
\hline & & & \\
\hline 0 & & \\
\hline
\end{tabular}

